\title{
Hybrid Organic/Inorganic Flexible Structures: Low Temperature Deposition of Silver Conductive Tracks on Flexible Substrates
}

\author{
Phillip R. McElfresh \\ West Virginia University
}

Follow this and additional works at: https://researchrepository.wvu.edu/etd

\section{Recommended Citation}

McElfresh, Phillip R., "Hybrid Organic/Inorganic Flexible Structures: Low Temperature Deposition of Silver Conductive Tracks on Flexible Substrates" (2011). Graduate Theses, Dissertations, and Problem Reports. 241.

https://researchrepository.wvu.edu/etd/241

This Thesis is protected by copyright and/or related rights. It has been brought to you by the The Research Repository @ WVU with permission from the rights-holder(s). You are free to use this Thesis in any way that is permitted by the copyright and related rights legislation that applies to your use. For other uses you must obtain permission from the rights-holder(s) directly, unless additional rights are indicated by a Creative Commons license in the record and/ or on the work itself. This Thesis has been accepted for inclusion in WVU Graduate Theses, Dissertations, and Problem Reports collection by an authorized administrator of The Research Repository @ WVU. For more information, please contact researchrepository@mail.wvu.edu. 
Hybrid Organic/Inorganic Flexible Structures: Low Temperature Deposition of Silver Conductive Tracks on Flexible Substrates

\author{
Phillip R. McElfresh \\ Thesis submitted to the \\ College of Engineering and Mineral Resources \\ at West Virginia University \\ in partial fulfillment of the requirements \\ for the degree of
}

Master of Science

in

Mechanical Engineering

Konstantinos A. Sierros, Ph.D., Chair

Darran R. Cairns, Ph.D.

Edward M. Sabolsky, Ph.D.

Department of Mechanical and Aerospace Engineering

Morgantown, West Virginia

2011

Keywords: silver conductive tracks; low temperature deposition; metallo-organic ink; flexible polymer substrate; electromechanical

Copyright@2011 Phillip R. McElfresh 


\section{ABSTRACT \\ Hybrid Organic/Inorganic Flexible Structures: Low Temperature Deposition of Silver Conductive Tracks on Flexible Substrates}

Phillip R. McElfresh

The ability to atmospherically deposit conductive patterns on flexible polymeric substrates has recently gained considerable interest as an alternative to vacuum processes. This is because it can potentially lead to highly efficient and reliable transparent electrode components that can be used in lightweight and flexible optoelectronic devices such as sensors, solar panels, touch screens, displays and solid state lighting. Common approaches to fabricate transparent conductors include the physical deposition of transparent conductive oxide (TCO) films on polymer substrates. This is leading to mechanically brittle components which are fabricated using costly vacuum coating equipment. It is therefore important to research an alternate route for depositing mechanically reliable conductive structures on unheated flexible substrates.

Metallo-organic decomposition (MOD) inks formulate a metal-organic precipitate beginning with the reduction of metal salt precursor which is then combined with an organic solvent. The ink can then be deposited using various processes such as syringe writing, spray masking, screen printing and ink-jet printing. Low-temperature curing can be achieved without compromising the functionality of the polymer substrate leading to a ductile conductive pattern.

In this work, a MOD ink was formulated by the reduction of silver nitrate $\left(\mathrm{AgNO}_{3}\right)$ to yield silver octanoate $\left(\mathrm{AgC}_{8} \mathrm{H}_{15} \mathrm{O}_{2}\right)$ precipitate which is then combined with xylene $\left(\mathrm{C}_{8} \mathrm{H}_{10}\right)$ solvent. Deposition on polymer base substrates was performed using masking techniques and involving a small gauge needle tip luer-lock syringe or a spray gun. Relatively uniform Ag track surface geometries were obtained. Contact angle measurements $\left(<17^{\circ}\right)$ showed good adhesion of the Ag ink on the PEN substrate. Curing of the $\mathrm{Ag}$ patterns was performed via radiation-conduction-convection heating at temperatures as low as $150^{\circ} \mathrm{C}$ yielding electrical resistivities as low as $4.13 \times 10^{-6} \Omega \cdot \mathrm{m}$, with higher temperatures offering electrical resistivities as low as $3.01 \times 10^{-7} \Omega \cdot \mathrm{m}$. Monotonic tensile testing of the cured samples was performed at a cross-head speed of $1 \mathrm{~mm} / \mathrm{min}$ resulting in a marginal change in resistance up to $10 \%$ strain. Cyclic mandrel testing was conducted in order to assess the fatigue characteristics of the flexible components. Nanoindentation testing was performed to analyze mechanical properties of the cured ink in relation to curing temperature. Finally, nanoscratch testing showed good adhesion of the cured ink to the PEN substrate. Surface porosity was related to all mechanical and electromechanical testing.

Hybrid organic/inorganic flexible structures allow for the atmospheric deposition of ductile conductive components unlike current applications requiring vacuum deposition of films that need further patterning. 


\section{ACKNOWLEDGEMENTS}

I would firstly like to thank Dr. Kostantinos A. Sierros for his continual guidance, understanding, knowledge, and creativity throughout my research and the constant focus towards the goals of my future. Secondly, to Dr. Darran R. Cairns for his invaluable knowledge and research aptitude. To Dr. Edward M. Sabolsky for the use of his laboratory and research instrumentation, as well as his industry knowledge. To Dr. Aaron Kessman for his well-rounded knowledge in engineering and complementary fields, and his desire for creativity in research. To Theodros Bejitual for all his help and guidance. To Andrew Hoover for his enthusiasm and helpful assistance on this project, and his desire to further this research. To Derrick Banerjee and Sean Cronin for their well-rounded knowledge and training of laboratory instrumentation. To Emmie DeFusco and Nicholas Morris for their interest and helpful comments. To West Virginia University and all others unsaid who contributed immensely to my studies and research, and provided me with an immeasurable experience.

A special thanks to Joshua R. Mullenax, a great friend and colleague, for a continual interest in my research, the supplement of creativity towards its furthering, and the constant offer of a challenging viewpoint and inquisitive insight to the betterment of my project.

To all my friends and family who offered continual enthusiasm and interest in my studies and research. Your thoughts and encouragement can never be measured.

And finally, to my parents, William B. McElfresh and Lisa A. McElfresh, I cannot begin to thank you for your endless pride and belief in me, your encouragement and guidance, and ultimately a love immeasurable. 


\section{TABLE OF CONTENTS}

1.1 Motivation

1.2 BACKGROUND

1.2.1 COMMON SUBSTRATES 2

1.2.2 Conductive Materials on Polymer Substrates 1

$\begin{array}{ll}1.2 .3 & \text { INK DEPOSITION TECHNIQUES } \\ 1.2 .4 & 10\end{array}$

$\begin{array}{ll}\text { 1.2.4 THERMAL PROCESSING AND CURING OF INK } & 11\end{array}$

1.2.5 Mechanical and Electromechanical Testing 14

1.3 HYBRID ORGANIC/INORGANIC FLEXIBLE STRUCTURES

1.3.1 PRELIMINARY INVESTIGATION RESULTS 23

$\underline{2} \quad$ EXPERIMENTAL METHODS AND MATERIALS $\quad 26$

2.1 SILVER INK SYNTHESIS AND FORMULATION

2.1.1 PARTICLE SIZE ANALYSIS $\quad 29$

2.2 SUbStrate Cleaning $\quad 30$

2.3 INK DEPOSITION TECHNIQUES

2.3.1 FreE WRITING SYRINGE DePOSITION

2.3.2 MASKING SYRINGE DEPOSITION

2.3.3 SPRAY MASKING DEPOSITION

2.3.4 DIP PEN LITHOGRAPHY (DPL) 39

2.4 Thermal Processing AND Resistivity Testing 40

2.4.1 CURING OF SILVER INK $\quad 40$

2.4.2 RESISTIVITY TESTING OF CURED SILVER INK

2.5 Electromechanical Testing $\quad 47$

2.5.1 Tensile Testing $\quad 48$

2.5.2 Cyclic fatigue Testing $\quad 50$

2.6 Mechanical testing $\quad \mathbf{5 0}$

2.6.1 NANOINDENTATION TESTING 
2.6.2 NANOSCRATCH TESTING

2.7 CONTACT ANGLE ANALYSIS

2.7.1 WATER VS. INK

2.7.2 GLASS VS. PEN

2.8 SURFACE POROSITY

3 RESULTS AND DISCUSSION

3.1 Resistivity OF CURED Ag TRACKS

3.2 Electromechanical Testing

3.3 Mechanical Testing

3.4 DIP PEN LITHOGRAPHY (DPL) 


\section{LIST OF TABLES}

TABLE 1 - COMPARISON OF COMMON PROPERTIES OF POLYMER MATERIALS FOR FLEXIBLE SUBSTRATES (5). 3

TABLE 2 - PROPERTIES OF BASE FILM FOR POLYMER SUBSTRATES (5).

TABLE 3 - MINIMUM PROPERTY REQUIREMENTS OF POLYMER SUBSTRATES FOR FLEXIBLE DISPLAY APPLICATIONS (5).

TABLE 4 - TEMPERATURE AND TIME TRIAL PARAMETERS OF THE CURING REGIME USED FOR SILVER OCTANOATE INK ON GLASS SUBSTRATE.

TABLE 5 - HARDNESS AND ELASTIC MODULUS DATA FOR NANOINDENTATION TESTING PERFORMED ON SPRAY MASKED AG COATINGS CURED AT VARIOUS TEMPERATURES.

TABLE 6 - VOLUME FRACTION COMPOSITIONS OF LOW AND HIGH VISCOSITY SOLVENTS FOR RHEOLOGICAL TESTING TO BE USED IN DPL PATTERNING WITH SILVER INK. 


\section{LIST OF FIGURES}

FIGURE 1 - MAXIMUM UTILIZATION TEMPERATURE COMPARING COMMON FLEXIBLE POLYMERS (10).

FIGURE 2 - COMPARISON OF TENSILE STRENGTH OF COMMON POLYMERS FOR FLEXIBLE ELECTRONIC APPLICATIONS (10).

FIGURE 3 - TEM IMAGE OF SILVER NPS DISPERSED IN WATER DEPICTING AGGLOMERATION (31). 8

FIGURE 4 - SILVER INK CURED ON COPPER SUBSTRATE AT $100^{\circ} \mathrm{C}, 130^{\circ} \mathrm{C}$, AND $200^{\circ} \mathrm{C}$ (34). 12

FIGURE 5 - SEM IMAGE OF CONDUCTIVE FILM ON PET SUBSTRATE AT 10\% STRAIN. CRACKING FORMS PERPENDICULAR TO THE DIRECTION OF STRAIN (3).

FIGURE 6 - SEM IMAGES OF ITO FILM ON PET SUBSTRATE DEPICTING FATIGUE CRACKING PERPENDICULAR TO THE DIRECTION OF STRAIN AFTER 100K CYCLE FATIGUE TESTING. IN THE IMAGES, STRAINING IS APPLIED IN THE TOP-BOTTOM DIRECTION (13).

FIGURE 7 - TYPICAL SURFACE PROFILES OF DEPOSITED AND CURED TRACKS. INCONSISTENCY AND UNIFORMITY IS A CHALLENGE DUE TO THE MIGRATION OF SOLIDS IN THE INK DURING DRYING (21).

FIGURE 8 - A) 3-D PROFILE SCAN OF AN INK-JET PRINTED TRACK. B) TYPICAL PROFILE SCAN OF THE INK-JET PRINTED TRACK SHOWN ON LEFT USED TO DETERMINE CROSS-SECTIONAL AREA OF TRACK DIMENSIONS TO CALCULATE RESISTIVITY GIVEN THE LENGTH OF THE TRACK (20).

FIGURE 9 - CHANGE IN RESISTANCE OF SILVER CONDUCTIVE TRACKS ON PEN SUBSTRATE DURING TENSILE TESTING (3).

FIGURE 10 - RESISTANCE CHANGE OF SILVER CONDUCTIVE TRACKS ON PEN SUBSTRATE DURING CYCLIC LOADING

FIGURE 11 - RESISTIVITY RELATION TO CURING TEMPERATURE OF SILVER CONDUCTIVE TRACKS (30).

FIGURE 12 - SCHEMATIC REPRESENTATION OF SILVER NANOPARTICLE PRODUCTION VIA THE REDUCTION OF METALLO-ORGANIC PRECURSOR SUCH AS SILVER NITRATE (2).

23

FIGURE 13 - OPTICAL MICROSCOPY OF SILVER INK ON PEN SUBSTRATE CURED AT A) $150^{\circ} \mathrm{C}$ FOR $70 \mathrm{MIN}$. B) $160^{\circ} \mathrm{C}$ FOR 60 MIN. C) $180^{\circ} \mathrm{C}$ FOR 40 MIN. D) $200^{\circ} \mathrm{C}$ FOR 20 MIN.

FIGURE 14 - RESISTIVITY TRENDS GIVEN CURING AT TEMPERATURES OF 160, 170, AND $180^{\circ} \mathrm{C}$ FOR TIMES RANGING 40-80 MINUTES.

FIGURE 15 - SCHEMATIC OF METHOD 1 SYNTHESIS OF SILVER OCTANOATE PRECIPITATE ADAPTED FROM A SIMILAR PROCESS USED BY DEARDEN ET AL (20).

FIGURE 16 - DUPONT SURVALL RT6000B REFRIGERATED CENTRIFUGE USED TO CLEAN SILVER OCTANOATE PRECIPITATE.

FIGURE 17 - PARTICLE SIZE DISTRIBUTION OF SILVER OCTANOATE PRECIPITATE SOLUTION IN ETHANOL SHOWING AGGLOMERATION EXISTING AT VARIOUS SIZES.

FIGURE 18 - OPTICAL MICROSCOPY OF B) DIRTY PEN SUBSTRATE AFTER SUBMERSION IN SOLVENT SHOWING ADEQUATE COLLECTION OF SURFACE DEBRIS INTO LOCALIZED DROPLETS PRIOR TO RINSING WITH DEIONIZED WATER. A) SOLVENT DROPLET SHOWING COLLECTION OF SURFACE DEBRIS. CLEANING PROCESS INVOLVED USING MULTIPLE SUBMERSION STEPS WITH ISOPROPYL ALCOHOL AND ACETONE SOLVENTS, THEN RINSING WITH DEIONIZED WATER.

FIGURE 19 - PEN SAMPLE AFTER CLEANING PROCESS AND DRYING SHOWING REMOVAL OF SURFACE DEBRIS. 31

FIGURE 20 - FREE WRITING SYRINGE DEPOSITION LACKS CONTROLLABILITY WHEN ATTEMPTING TO DEPOSIT UNIFORM STRAIGHT LINES (RIGHT). ENHANCED IMAGE (LEFT) SHOWS ALSO INCONSISTENCIES IN INK DISPERSION. 
FIGURE 21 - CROSS-SECTIONAL PROFILE SCAN OF MASKED TRACK PATTERNS SHOWING MIGRATION OF SOME SOLIDS TOWARDS WALLS OF MASK DURING DRYING. SURFACE MORPHOLOGY IS CONSISTENT POSTTHERMAL PROCESSING.

FIGURE 22 - SPRAY MASKED SAMPLE SURFACE PROFILE DEPICTING A MORE UNIFORM MORPHOLOGY WITH THE LOCATION OF MORE SOLIDS IN THE CENTER OF THE TRACK AS DESIRED. EVIDENCE OF DECREASED MIGRATION OF SOLIDS DURING DRYING AS WAS PROBLEMATIC WITH MASKED SYRINGE DEPOSITION. $\quad 38$

FIGURE 23 - A HOTPLATE WAS USED FOR ALL THERMAL PROCESSING OF SAMPLES.

FIGURE 24 - SURFACE POROSITY TRENDS APPROACH A MAXIMUM REDUCTION IN SURFACE POROSITY EVEN WITH EXTENDED THERMAL EXPOSURE TIME AT CURING TEMPERATURE.

FIGURE 25 - VECCO DEKTAK 150 SURFACE PROFILER USED TO MEASURE CROSS-SECTIONAL AREA OF TRACK PROFILES. ENHANCED IMAGE OF PROFILE STYLUS TIP AND LEVELING STAGE (RIGHT).

FIGURE 26 - X-RAY DIFFRACTION ANALYSIS OF AG-OCTANOATE PRECIPITATE POWDER PRIOR TO INK FORMULATION, AND SCAN DATA OF THE AG INK CURED AT TEMPERATURES OF 150 AND 200 ${ }^{\circ} \mathrm{C}$ DEPICTING THE COMPLETE REMOVAL OF ORGANIC MATERIAL VIA THERMAL PROCESSING RESULTING IN THE EXISTENCE OF SOLELY AG.

FIGURE 27 - XRD SCAN DATA FOR AG INK COATINGS SHOWING THE ATTAINABILITY OF FULLY CURED SAMPLES AT TEMPERATURES AT/BETWEEN 150 AND $200^{\circ} \mathrm{C}$.

FIGURE 28 - TENSILE TESTING OF CURED SAMPLES ON PEN SUBSTRATE WERE PERFORMED USING INSTRON 4411 TENSILE TESTING MACHINE.

FIGURE 29 - ADHESION OF AG INK (BOTTOM) TO PEN SUBSTRATE HAVING CONTACT ANGLE OF $<17^{\circ}$ IS COMPARED VIA DROP ANALYSIS TO THAT OF DEIONIZED WATER (TOP) ON PEN SUBSTRATE HAVING CONTACT ANGLE OF $64^{\circ}$.

FIGURE 30- DROP ANALYSIS OF DEIONIZED WATER ON COMPARISON SUBSTRATES. PEN SUBSTRATE (BOTTOM IMAGE) IS COATED FOR ADHESION SHOWING LOWER CONTACT ANGLE AS COMPARED TO GLASS SUBSTRATE (TOP IMAGE).

FIGURE 31 - RESISTIVITY TRENDS SHOWN FOR CURING OF SPRAY MASKED SAMPLES AT TEMPERATURES OF 160, 170, AND $180^{\circ} \mathrm{C}$. IT IS NOTICED THAT OPTIMAL CURING FOR SHORTER EXPOSURE TIME OCCURS AT TEMPERATURES ABOVE $160^{\circ} \mathrm{C}$.

FIGURE 32 - AVERAGE RESISTIVITY VALUES FOR CURING TEMPERATURES OF 170 AND $180^{\circ} \mathrm{C}$ EXHIBITED DESIRABLE RESISTIVITIES AROUND 5\% THAT OF BULK SILVER.

FIGURE 33 - SEM MICROGRAPHS AT DIFFERENT MAGNIFICATION SHOWING SURFACE MICROSTRUCTURE WITH HIGH SURFACE POROSITY CURED AT $180^{\circ} \mathrm{C}$ FOR 40 MIN ON PEN. CONNECTED STRUCTURES SPANNING VOIDS LIKELY ACT AS PERCOLATION PATHWAYS FOR CARRYING CURRENT ACROSS SILVER TRACKS.

FIGURE 34 - OPTICAL MICROSCOPY IMAGES OF CURED SPRAY MASKED SILVER TRACKS ON PEN SHOWING A PROGRESSIVE DECREASE IN SURFACE DISSIMILARITIES AND GAINED UNIFORMITY WHEN APPROACHING HIGHER CURING TEMPERATURES.

FIGURE 35 - A RELATIVELY SMALL DECREASE (7.7\%) IN PERCENT SURFACE POROSITY IS OBSERVED FOR SAMPLES CURED AT VARIOUS TEMPERATURES SUGGESTING THAT SIMILAR SURFACE POROSITY IS OBTAINABLE IF EXPOSED FOR ADEQUATE TIME.

FIGURE 36 - RESISTIVITY, P, AND SURFACE POROSITY, \%P, OBSERVE SIMILAR DECREASING TRENDS WITH EXTENDED EXPOSURE TIME AT RESPECTIVE CURING TEMPERATURES OF 170 AND $180^{\circ} \mathrm{C}$.

FIGURE 37 - COMPARATIVELY, RESISTIVITY (P) DECREASES WITH DECREASING SURFACE POROSITY (\%P) AS IT DOES ALSO WITH INCREASING THERMAL EXPOSURE TIME.

FIGURE 38 - ELECTROMECHANICAL BEHAVIOR OF CURED SILVER INK TRACKS ON PEN SAMPLES SEEN AS A CHANGE IN RESISTANCE DURING MONOTONIC TENSILE TESTING. IT IS NOTICED THAT THERE EXISTS ELECTRICAL BEHAVIOR UP TO THE FAILURE STRAIN OF THE PEN SAMPLE. 
FIGURE 39 - OPTICAL MICROSCOPY OF SPRAY MASKED CURED AG TRACK ON PEN SUBSTRATE AFTER TENSILE TESTING AND FAILURE VIA MONOTONIC STRAINING IN THE DIRECTION OF THE ARROW. DEPICTS THE MIGRATION OF STRAINING FROM LOCATIONS BETWEEN 0-8 MM FROM THE FAILURE SITE SHOWING INCREASED SURFACE UNIFORMITY AS SEEN WITH CLOSER PROXIMITY TO THE FAILURE SITE, AS ILLUSTRATED ON THE REPRESENTATIVE CURED SAMPLE SCHEMATIC ON THE RIGHT (NOT DRAWN TO SCALE).

FIGURE 40 - SURFACE POROSITY OBSERVED AN INTERESTING TREND IN RELATION TO INCREASING PROXIMITY TO THE FAILURE SITE.

FIGURE 41 - SEM MICROGRAPHS SHOWING CURED TRACKS OF UNSTRAINED (LEFT) SAMPLES HAVING CONNECTED STRUCTURES, AND POST-TENSILE TESTING STRAINED (RIGHT) SAMPLES HAVING LOSS OF CONNECTED STRUCTURES DUE TO BREAKAGE AND ELONGATION OF VOIDS FROM PRE-EXISTENT POROSITY. THE DIRECTION OF STRAIN IS FROM LEFT TO RIGHT.

FIGURE 42 - MANDREL FATIGUE TESTING WAS PERFORMED ON CURED AG TRACK ON PEN SAMPLE AT 0.6\% STRAIN FOR 640K CYCLES. THREE DISTINCT REGIMES EXIST. THE INSET GRAPH SHOWS REGIME 1 AT EARLY CYCLES UP TO 22K.

FIGURE 43 - AG COATING HARDNESS EXHIBITS A LINEAR INCREASE WITH AN INCREASE IN CURING TEMPERATURE BETWEEN 170 AND $200^{\circ} \mathrm{C}$, AS WELL AS A WITH SIMILAR DECREASE IN SURFACE POROSITY. 70

FIGURE 44 - ELASTIC MODULUS OBSERVES A DECREASE AT HIGHER CURING TEMPERATURE ABOVE $190^{\circ} \mathrm{C} . \quad 71$

FIGURE 45 - FAILURE CRITICAL LOAD (FCL) OBSERVES A SHARP DECREASE AT $190^{\circ} \mathrm{C}$ SUGGESTING AN INCREASED EASE IN COATING FAILURE AT THAT CURING TEMPERATURE.

FIGURE 46 - THE MAGNITUDE OF DELAMINATION OF THE AG COATING CURED AT $190^{\circ} \mathrm{C}$ WAS GREATER THAN OTHER CURING TEMPERATURES. THE SCRATCH DIRECTION IS FROM LEFT TO RIGHT.

FIGURE 47 - THE MAGNITUDE OF COATING DELAMINATION OBSERVED WAS SIMILAR WITH SCRATCHING PERFORMED ON 150, 160, 170, 180, AND $200^{\circ} \mathrm{C}$ SAMPLES. THIS SUGGESTS POSSIBLE INCREASED BRITTLENESS AT CURING TEMPERATURE OF $190^{\circ} \mathrm{C}$. SCRATCH DIRECTION IS FROM LEFT TO RIGHT.

FIGURE 48 - DOT PATTERNING USING DPL WITH AG INK ON PEN DEPICTING VARIABILITY IN DOT SIZE AND SPACING. 


\section{INTRODUCTION}

\subsection{Motivation}

Current advancements in technology are demanding more efficient and cost-effective devices to satisfy energy production worldwide. Incorporating multiple applications within competitive and comparable fields offers a way to satisfy the demand. Devices are being pushed towards the smaller scale everyday while requiring better operation and efficiency than previously possible. It is desirable to create devices that not only provide equal or better operation outputs, but also satisfy a lightweight, flexible, and transparent existence. This desire is especially applicable in areas incorporating precise componentry and versatility such as optoelectronics, automotives, sustainable energy systems, sensors, among others. Many of the current production techniques required to fabricate these components are expensive and timely, and may require special environments to do so.

The motivation of this work is to create and devise a means of combining a flexible media and a conductive carrier material. Further motivation was to achieve the fabrication of a flexible, transparent structure in a simple, low cost, environmentally friendly process. Also, application and deposition processes of the conductive carrier material needed to offer more versatility and controllability than seen in current methods in relation to transparent conductive oxide (TCO) films on polymer substrates, or the creation of complex patterns obtained via etching processes such as in sensors. Additionally, the fabrication must incorporate a low-waste process offering a highly functional structure in betterment of the aforementioned processes. 


\subsection{Background}

Hybrid organic/inorganic flexible structures incorporating the deposition of silver conductive tracks on flexible substrates offer benefits within mechanical engineering. In conjunction with flexible substrates such as polyethylene naphthalate, these hybrid organic/inorganic structures allow for the ability to achieve conductivity by deposition of the conductive material on the surface while still demonstrating conformability.

\subsubsection{Common Substrates}

Various substrates are applicable such as glass, copper or aluminum foil, and polymers (1) (2) (3) (4). Glass exhibits high tolerance to heat but is limited in flexibility. Copper or aluminum foils also offer high tolerance of heat. However, they are subject to crumpling, and do not offer good adhesion of the deposited components to their surface (5). Furthermore, substrates such as aluminum and copper do not offer the desirable optical transparency. Polymers such as polyethylene terephthalate (PET) and polyethylene naphthalate (PEN) offer a much larger range of flexibility as compared to glass while showing structural integrity and lack of deformation as compared to copper and aluminum foils. Also, polymers like PET or PEN demonstrate a good resistance to thermal shrinkage noticed during thermal processing (3) (5).

The flexible nature of polymers allows for vast array of applications. A large part of their contribution to industry comes in respect to flexible electronics (6). These can include liquid crystal displays (LCDs), flexible optics, thin film solar panels, sensors, and flexible printable circuitry (7) (8). The latter is gathering much attention in recent times due to its direct relation to the possibility of making 
thinner, more lightweight components and more efficient production. All of the aforementioned devices require the incorporation of flexible printable circuitry (FPC) to operate functionally.

The benefit with using relatively thin polymer substrates such as PEN or PET comes from their desirable mechanical properties of each such as strain toleration up to $70 \%$ in some cases and corrosion resistance to salts and acids. Additional attractive properties for PEN include high stiffness and mechanical strength, low thermal shrinkage $<1 \%$ after exposure to $180^{\circ} \mathrm{C}$ for $5 \mathrm{~min}$, excellent dielectric strength, low moisture absorption, excellent solvent resistance, and high optical transmittance (5) (9). Comparisons of common polymers such as PET, PEN, and polyimide (PI) used in flexible applications and their minimal requirements needed to be used in flexible display applications can be seen in Table 1, Table 2, and Table 3 . Although PI exhibits better performance in terms of thermal stability and upper operating temperature, PEN was selected due to PI having a yellowish hue limiting its optical clarity and light transmittance. PEN was also selected above PET because of its higher maximum utilization temperature up to $200^{\circ} \mathrm{C}$ as shown in Figure 1.

\begin{tabular}{|c|c|c|c|c|c|c|}
\hline & PET & PEN & PC & PAR & PES & PI \\
\hline Optical charity & 0 & 0 & ( & 0 & 0 & $x$ \\
\hline Upper operating temp. & $\Delta$ & 0 & $\triangle$ & (B) & o & (2) \\
\hline Dimensional stability & o & o & $\Delta$ & $\Delta$ & $\Delta$ & o \\
\hline Surface roughness & $x$ & $x$ & o & $\circ$ & 0 & o \\
\hline Solvent resistance & o & o & $x$ & $x$ & $x$ & o \\
\hline Moisture absorption & o & o & $\Delta$ & $\Delta$ & $x$ & $\times$ \\
\hline Young's modulus & 0 & o & $\Delta$ & $\Delta$ & $\Delta$ & $\Delta$ \\
\hline
\end{tabular}

ఐ: Excellent, $\mathrm{O}$ : good, $\Delta$ : fair, $\times$ : poor.

Table 1 - Comparison of common properties of polymer materials for flexible substrates (5). 


\begin{tabular}{lllllll}
\hline & PET & PEN & PC & COC & PES & PI \\
\hline Thickness $(m m)$ & 0.1 & 0.1 & 0.1 & 0.1 & 0.1 & 0.1 \\
Total light transmittance $(\%)$ & 90.4 & 87.0 & 92.0 & 94.5 & 89.0 & $30-60$ \\
Retardation $(\mathrm{nm})$ & Large & Large & 20 & 7 & $<10$ & Large \\
Reflactive index & 1.66 & 1.75 & 1.56 & 1.51 & 1.6 & - \\
Gass transition temperature $\left({ }^{\circ} \mathrm{C}\right)$ & 80 & 150 & 145 & 164 & 223 & $300<$ \\
Coefficient of thermal expansion $(\mathrm{ppm} / \mathrm{C})$ & 33 & 20 & 75 & 70 & 54 & $8-20$ \\
Water absorption ratio $(\%)$ & 0.5 & 0.4 & 0.2 & $<0.2$ & 1.4 & $2.0-3.0$ \\
$\mathrm{H}_{2} \mathrm{O}$ barrier $\left(\mathrm{g} / \mathrm{m}^{2} /\right.$ day) & 9 & 2 & 50 & - & 80 & - \\
\hline
\end{tabular}

Table 2 - Properties of base film for polymer substrates (5).

\begin{tabular}{|c|c|c|c|}
\hline & Property & & Requirement \\
\hline \multirow[t]{6}{*}{ Polymer substrates } & \multicolumn{2}{|l|}{ Total light transmittance over $400-800 \mathrm{~nm}(\%)$} & $>85$ \\
\hline & \multicolumn{2}{|l|}{$\operatorname{Hax}(\%)$} & $<0.7$ \\
\hline & \multicolumn{2}{|l|}{ Upper operating temperature (C) } & $>150$ \\
\hline & \multicolumn{2}{|l|}{ Coefficient of thermal expansion $\left(\mathrm{ppm} /{ }^{\circ} \mathrm{C}\right.$ ) } & $<20$ \\
\hline & \multicolumn{2}{|l|}{ Average surface roughness $(\mathrm{nm})$} & $<5$ \\
\hline & \multicolumn{2}{|l|}{ Chemical resistance } & Resistance to acid, alkali, and solvent \\
\hline \multirow[t]{4}{*}{ Barrier coated substrates } & \multirow{4}{*}{$\begin{array}{l}\text { Water vapor transmission rate }\left(\mathrm{g} / \mathrm{m}^{2} / \text { day } /\right. \\
\text { atm) }\end{array}$} & OLED & $<10^{-6}$ \\
\hline & & LCD & $<10^{-3}$ \\
\hline & & EPD & $<10^{-2}$ \\
\hline & & TFT & $<10^{-3}$ \\
\hline \multirow{3}{*}{$\begin{array}{l}\text { Transparent anode coated } \\
\text { substrates }\end{array}$} & \multicolumn{2}{|l|}{ Resistance $(\Omega / s q)$} & $<20$ \\
\hline & \multicolumn{2}{|l|}{ Total light transmittance (\%) } & $>80$ \\
\hline & \multicolumn{2}{|l|}{ Flexiblility } & A bility to bend over a 1 in diameter 1000 times \\
\hline
\end{tabular}

Table 3 - Minimum property requirements of polymer substrates for flexible display applications (5).

In relation to this study involving the exploration of the deposition of conductive silver inks on thin polymers, PEN will be the polymer substrate of interest due to its higher toleration to heat as compared to PET. PEN exhibits a glass transition temperature $T_{\mathrm{g}}$ of $\sim 128^{\circ} \mathrm{C}$ which is higher than that of PET at $\sim 80^{\circ} \mathrm{C}(5)$. Considering the need for curing or metallization of the deposited silver ink, it is beneficial to have a high $\mathrm{T}_{\mathrm{g}}$ in order to achieve curing of the ink while not compromising the mechanical properties, surface integrity, and surface morphology of the PEN substrate. Especially with polymers, the effect of heating or cooling in relation to the $T_{\mathrm{g}}$ is very important. After curing at a higher temperature, the polymer sample experiences cooling - the rate of which affects the final crystalline 
nature. Because polymers lack a well-defined crystalline state, thermal processing of the samples results in the transformation from polymer to glass. However, using heat-stabilized polymer substrates negates the effect of the $T_{g}$ and allows for much higher maximum utilization temperatures as shown in Figure 1.

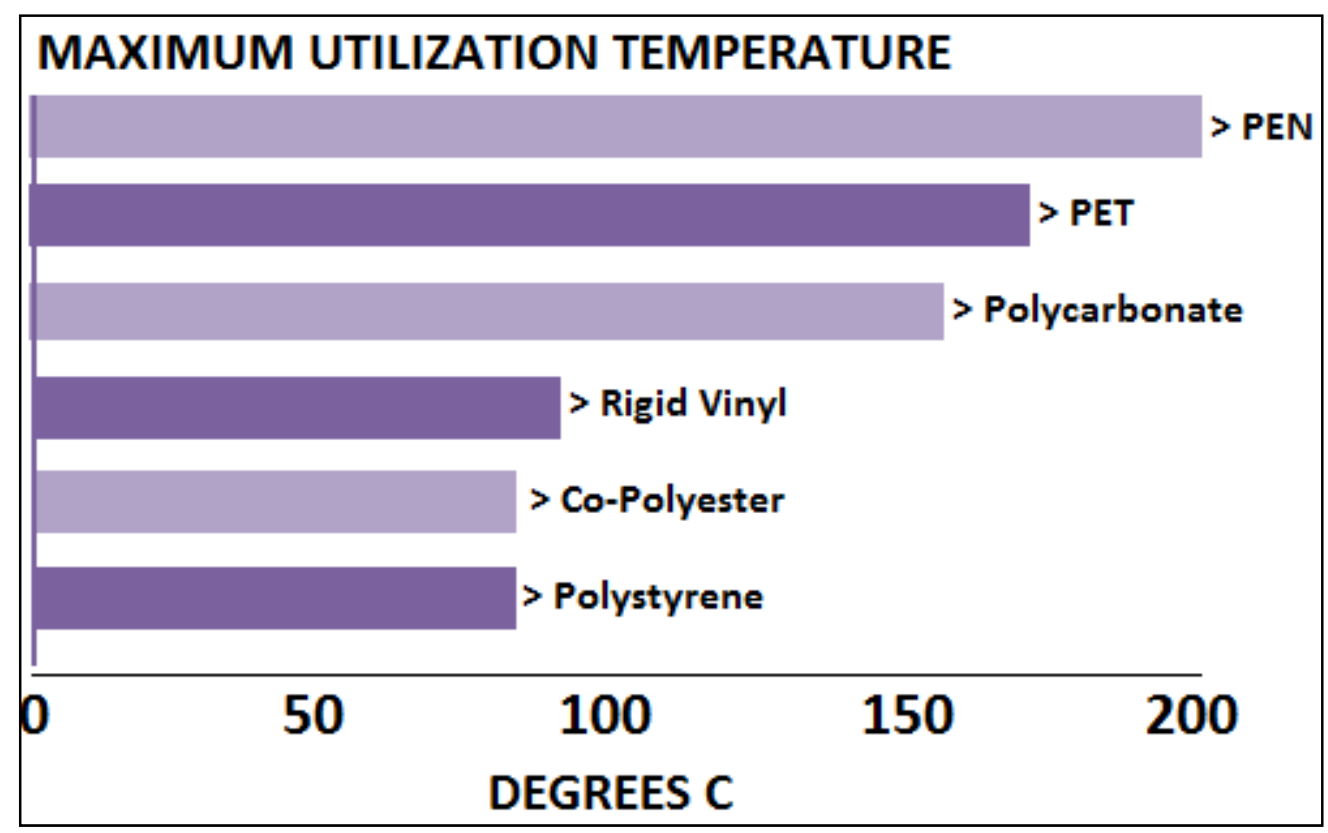

Figure 1 - Maximum utilization temperature comparing common flexible polymers (10).

PEN exhibits a maximum utilization temperature up to $200^{\circ} \mathrm{C}$ which is almost $20 \%$ higher than that of PET (10). This allows for the incorporation of PEN into a wider range of applications requiring use in higher temperatures.

Additionally, it is necessary not only to incorporate the use of polymer substrate with a high maximum utilization temperature but also one that exhibits a high tensile strength as shown in Figure 2. It is desirable to use a polymer substrate such as PEN that performs well in high strength applications. Performance in harsh environments is crucial to the overall efficiency of flexible devices and their versatility. 


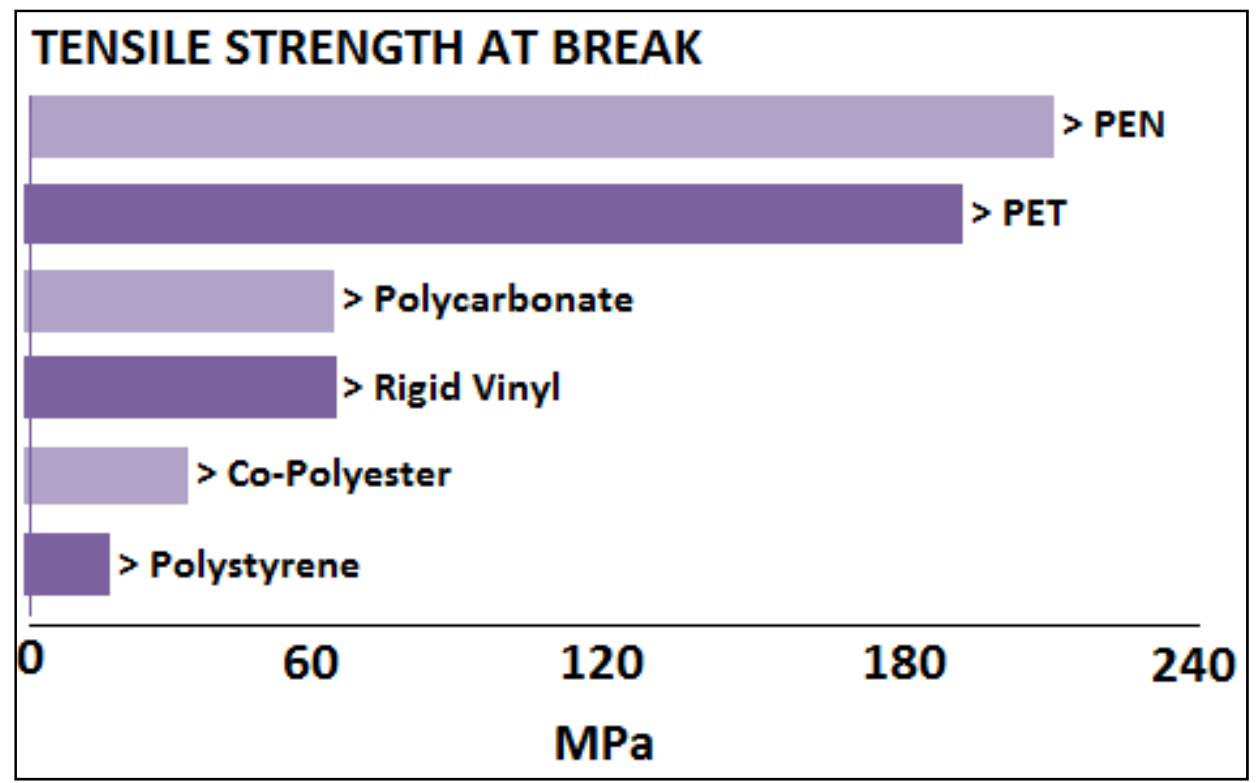

Figure 2 - Comparison of tensile strength of common polymers for flexible electronic applications (10).

\subsubsection{Conductive Materials on Polymer Substrates}

Polymers have incorporated means of achieving conductivity while maintaining flexibility using TCO films, conductive polymers, carbon nanotubes, and metal structures (5). TCOs are thin metal/ceramic oxide films of a few hundred nanometers thickness deposited on the surface of polymers (11) (12). They are usually zinc oxide (ZnO) or indium tin oxide (ITO) (5). TCOs are beneficial in areas such as displays, but their level of flexibility is limited by their brittle nature (5) (13) (14). Although their level of optical transparency is similar to that of TCOs, conductive polymers offer a higher level of mechanical flexibility which makes it more suitable for touch screen applications (5). However, conductive polymers exhibit lower conductivity than TCOs and are subject to scratching (5) (15). Metal structures applied to the substrate surface offer a means of achieving high conductivity and flexibility (16) (17). Carbon nanotube applications demonstrate attractive mechanical properties and electrical conductivity (5) (18). However, CNT performance is limited in its application to large areas because of its difficulty in deposition due to dispersion uniformity caused by the tendency of CNTs to curl and 
agglomerate (18) (19). Silver is a promising alternative because it exhibits the highest conductivity of all metals (20). Silver can be deposited as an ink and cured at relatively low temperatures $100-200^{\circ} \mathrm{C}$ on some polymer substrates (1) (20). Also, silver exhibits adequate adhesion to substrates and exhibits a desirable mechanical flexibility which makes it advantageous in applications such as flexible printable circuitry (FPC) (21) (22) (23). This can be used in sensors, solar panels, touch screens, and liquid crystalline displays (LCDs) among many others.

However, many of the aforementioned conductive materials are expensive, require special processing environments, or are not yet applicable to large scale areas (18) (24). In light of maximizing reduction in production costs, it is desirable to attain inks using a low cost method of creation via the use of inexpensive materials and chemicals. Avoidance of additional patterning and lithographical steps is also of paramount importance.

For deposition of conductive silver tracks, two main methods are implemented. They involve either the combining of silver nanoparticles (NPs) of the range 20-50nm diameter with a solvent such as xylene of toluene, or the creation of a metallo-organic precursor solution where the molecular nature of the compound allows low-temperature conversion to the metal (20) (25) (26) (27) (28) (29). In order to achieve the highest possible conductivity of the tracks, silver-based inks are normally utilized because silver exhibits the lowest resistivity of the known metals equal to $1.6 \times 10^{-8} \Omega \cdot m(20)$. However, both methods pose significant challenges and limitations.

In the first method, involving Ag NPs, several factors must be considered. Although it is possible to control the particle size when using Ag NP inks, the nature of the method makes it less controllable in terms of uniformity throughout the applicable ink solution. Additionally, nanopowders have a strong tendency to agglomerate, which causes inter- and intra-agglomerate pores during sintering. The agglomeration of Ag NPs is seen in Figure 3 from nanopowders within the solution results 
in inconsistencies during the application of the ink to the substrate (25) (30). Ag NP inks require colloidal stabilizers and because of the existence of high particle loading, nozzle clogging during printing is observed. Further challenges to the use of NP-based inks come via expense due to production and cost (2). Low-temperature sintering may also hinder the development of full densification in sintered materials and the existence of weakened mechanical properties of the metal (30).

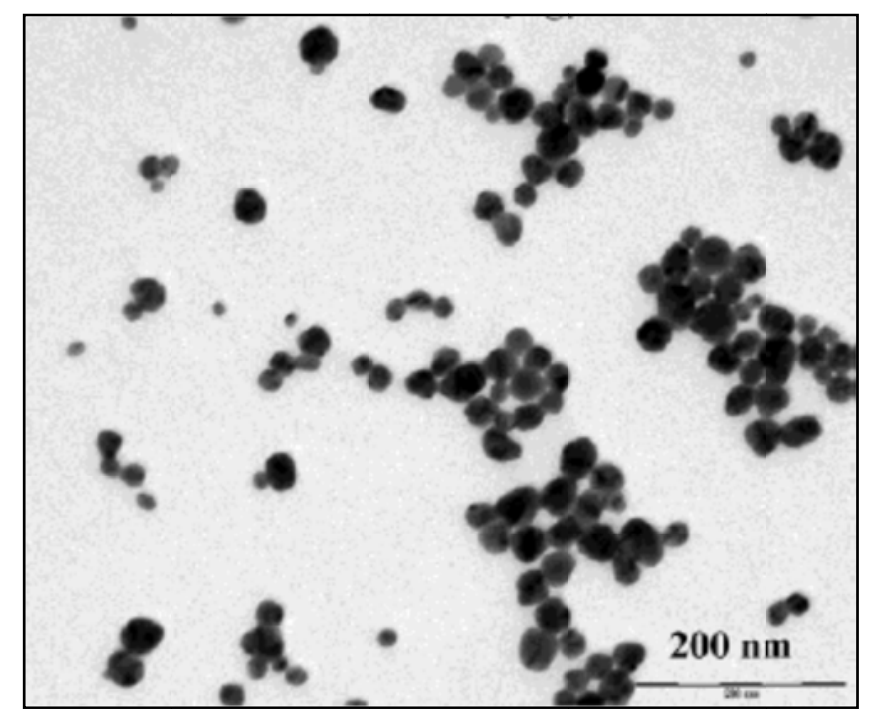

Figure 3 - TEM image of silver NPs dispersed in water depicting agglomeration (31).

In the second method, involving metallo-organic decomposition (MOD) inks, it is necessary to adequately investigate the chemistry involved in terms of the chemicals used and how each of them is properly incorporated in the formulation process of the ink. Most processes require the chemical reduction of silver salts such as silver nitrate $\left(\mathrm{AgNO}_{3}\right)(2)(20)$. The final product being a silver organic precipitate such as silver neodecanoate $\left(\mathrm{AgC}_{10} \mathrm{H}_{19} \mathrm{O}_{2}\right)$ which is combined with a solvent, usually xylene (3) (20) (32). One disadvantage with using MOD inks is the required time to attain the precipitate offering silver NPs. The time involved with MOD inks is related to the need for aggregation and precipitation in aqueous solutions (2). Also, it is difficult to ensure a small size variance within the range of silver NPs precipitated from the salt precursors. For the majority of different experimental trials, a 
particle size less than $50 \mathrm{~nm}$ has been observed (33). On the other hand, MOD inks offer a lack of agglomeration and subsequent clogging because of their compound structure and minimal solids within the deposited solution (2) (3). This allows for the deposition of precipitated NPs from the metalloorganic ink to sinter adequately (34).

For this investigation, the second method involving MOD inks is utilized. An Ag-based ink was formulated from a modified process similar to Dearden et al, involving silver octanoate dissolved into xylene (20). It is desirable to attain small particle sizes, on the nanoscale, to allow for increased conductivity and printability. Smaller particle size also offers the possibility of sintering at lower temperatures below the $T_{g}$ of the PEN substrate $\left(\sim 128^{\circ} \mathrm{C}\right)(30)(35)$.

Prior to ink deposition and to ensure adequate ink adhesion, PEN substrate surfaces need to be cleaned thoroughly using solvents such as acetone and isopropyl alcohol (1) (5). It is desirable to remove surface oils and debris before performing ink deposition and post-deposition treatment. This crucial step can provide a uniform and debris-free surface along the length of the conductive track area. Removing unnecessary surface protrusions due to debris allows the track to adhere better to the substrate surface. Most cleaning processes include the use of typical solvents such as acetone, ethanol, and isopropyl alcohol. Due to the soft nature of PEN, it is prone to scratching (5) (15). It is beneficial to acquire cleaned polymer substrates without scrubbing or wiping by either immersing in isopropyl alcohol or acetone (3). One possible process involves immersing the PEN substrate samples into a bath of acetone. The sample is then rinsed with deionized water and dried with compressed clean air, typically nitrogen (3). The process is repeated using isopropyl alcohol making sure to rinse the final step thoroughly with deionized water before drying with compressed air or in a vacuum hood. Furthermore, this ensures the removal of pre-cleaning debris that could potentially act as flaw generators during mechanical testing. 


\subsubsection{Ink Deposition Techniques}

Ink-jet printing, spray coatings, and dip pen lithography (DPL) are being investigated more routinely in recent years (36) (37). They offer the possibility of efficient production and precise deposition of aforementioned inks on substrates. The following study is a partial investigation of their possibilities using the formulated ink and alternate deposition techniques thereof. It is necessary when utilizing deposition methods and metal-based inks to consider viscosity, contact angle, and other flow related properties of the inks. The ink used must be able to flow easily through the nozzle without causing clogging or lack of uniformity when printing. Contact angle relates to how well the ink adheres to the PEN substrate surface. A lower contact angle relates to higher adhesion of the ink to the substrate surface. Ink-jet printing experimental trials similar to the MOD ink used in this investigation showed a viscosity range of varying wt\%(33-70\%) inks from 2.5 to $5.6 \mathrm{mPa} \cdot \mathrm{s}$ at a shear rate of $50 \mathrm{~s}^{-1}$, as measured by a cone and plate viscometer (2) (4) (20). The surface tension of the inks varies from 39 to $40 \mathrm{mN} / \mathrm{m}$, and the static contact angle of the inks on polyimide substrate is about $29^{\circ}-34^{\circ}$, as measured by conventional goniometry at room temperature (4) (25).

In this work, a simpler means of silver MOD ink deposition is used. It is necessary, though, to consider the aforementioned parameters such as viscosity, surface tension, and contact angle for consistency and validation reasons. During preliminary testing, the silver ink was applied to samples of the PEN Q65F1 polymer substrate (DuPont Teijin Films) using a simplistic syringe apparatus. This apparatus allowed for preliminary investigation of substrate wetting and ink adhesion. Applying even pressure to the syringe while moving across the PEN sample smoothly, applied uniform tracks along the length of the substrate. To accomplish small preliminary patterns in suggestion of possible inkjet printability, luer-lock syringe needle tips of gauge range $27-30 \mathrm{G}$ were used. The needle tips reflect an inner diameter ranging from 0.159-0.210 mm and were purchased from Small Parts (U.S.). 


\subsubsection{Thermal Processing and Curing of Ink}

Inks must undergo post-deposition curing to achieve metallization of the silver NPs within the solution resulting in adequate and uniform conductivity throughout the track. In any case, the means of acquiring the densification of the silver through sintering must conducted so as to not compromise the mechanical integrity of the PEN substrate. Heat treatment through radiation-conduction-convection is the most common means of attaining the annealing state and can be accomplished using a hotplate or an oven (33) (38). Laser sintering and microwave sintering have also been reported with and without the use of additional simultaneous heating of the substrate (25) (33) (39). The PEN substrate used has been heat stabilized so the glass transition temperature $T_{g}$ is cancelled allowing for operating temperatures up to $200^{\circ} \mathrm{C}$ with thermal shrinkage $<1 \%$ (10). For the purposes of this work, curing of the deposited silver MOD ink will be investigated. Curing temperature will be most important in consideration because it offers conductivity but results at a lower temperature not affecting the substrate.

It has been reported in the past that that complete thermal annealing and sintering of silver MOD inks can be achieved at temperatures in the range of $200-300^{\circ} \mathrm{C}$ whereas adequate curing has been observed at temperatures below $150^{\circ} \mathrm{C}$ with exposure times varying between 5 and 10 minutes (3)

(25) (33) (34) (38). More precisely, curing temperatures of 140,125 , and $100^{\circ} \mathrm{C}$ were shown to exhibit desirable conductivity (3). The latter temperature range is appealing considering that PEN starts exhibiting a thermal shrinkage around $150^{\circ} \mathrm{C}$. The following images show thermal curing at similar temperatures, 100,130 , and $200^{\circ} \mathrm{C}$, Figure 4. 

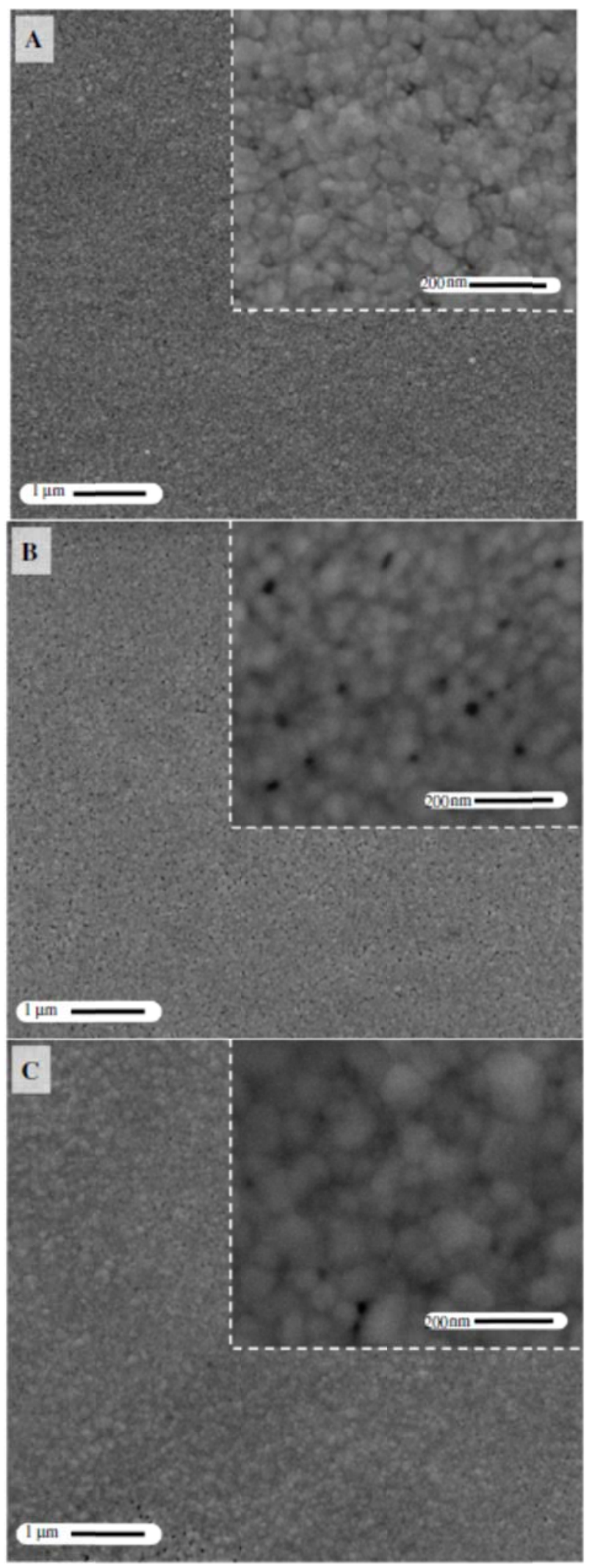

Figure 4 - Silver ink cured on copper substrate at $100^{\circ} \mathrm{C}, 130^{\circ} \mathrm{C}$, and $200^{\circ} \mathrm{C}(34)$. 
A relatively low curing temperature in conjunction with a proposed silver MOD ink is important in polymer electronic applications where polymers are used because low deposition temperatures are reguired (1) (5) (36).

Commercially available inks include particle sizes lower than $50 \mathrm{~nm}$. Two particle-based inks exhibit particle sizes ranging from 5-10 $\mathrm{nm}$ and $20-30 \mathrm{~nm}$ (21) (33). Decreased particle size shows an increased ease of curing in terms of temperature. Furthermore, the existence of smaller particle size offers faster curing because of the migration of MOD ink particles towards the surface of the applied ink. In relation to this, lower curing temperatures can be achieved by precipitating particles within the MOD inks (30) (34).

On the other hand, lower range curing temperatures $<200^{\circ} \mathrm{C}$ are limited by the intrinsic nature of metals regardless of the final particle size. This can be observed when a high enough curing temperature is not used during thermal annealing which results in the formation of pores within the cured silver conductive track. Additionally, the latter creates inconsistencies in conductivity because of the lack of densification which should have occurred during the radiation-convection-conduction process. This must be avoided in order to ensure percolation along the length of the silver track (30) (38). This can be avoided by heating the samples for extended periods of time so as to remove as much of the organic material as possible. Complications are evident from the lack of densification and existence of porosity when investigating the conductive structures electrically, mechanically, and structurally. Brittleness within the cured silver track is observed with high porosity (30). 


\subsubsection{Mechanical and Electromechanical Testing}

Mechanical testing aids in assessing the cohesive and adhesive failure mechanisms of the cured track when mechanically flexed or strained. It is desirable to perform mechanical testing such as tensile testing and bending of the coated substrate to relate at which critical strain the substrate fails, as well as to analyze the change in resistivity of the conductive tracks with applied strain. Scratch testing is also necessary to assess the adhesion of the cured track on the PEN substrate and the related failure mechanisms of the coating. Nanoindentation testing is useful to investigate the mechanical properties of the cured Ag coatings such as hardness, elastic modulus, and stiffness.

Analysis of the cured silver conductive tracks is necessary to gather desired data in relation to conductivity/resistivity, profile geometry, surface roughness, densification, stress and strain behavior. Mechanical properties are tested to explore response of samples and printed tracks in relation to stress and strain. For investigating the mechanical reliability of cured silver tracks on polymers, such as PEN, it is important to test maximum strain and cyclic loading.

Tensile testing offers data which relates the response to straining of the substrate and coating composite. It is interesting to determine the onset strain of the PEN substrate before loss of conductivity or fracture of the conductive track. Strain is applied with a cross-head speed of $1 \mathrm{~mm} / \mathrm{min}$ (3). An example of a fractured conductive film on PET substrate is depicted in Figure 5 with the formation of cracking perpendicular to the direction of strain. 


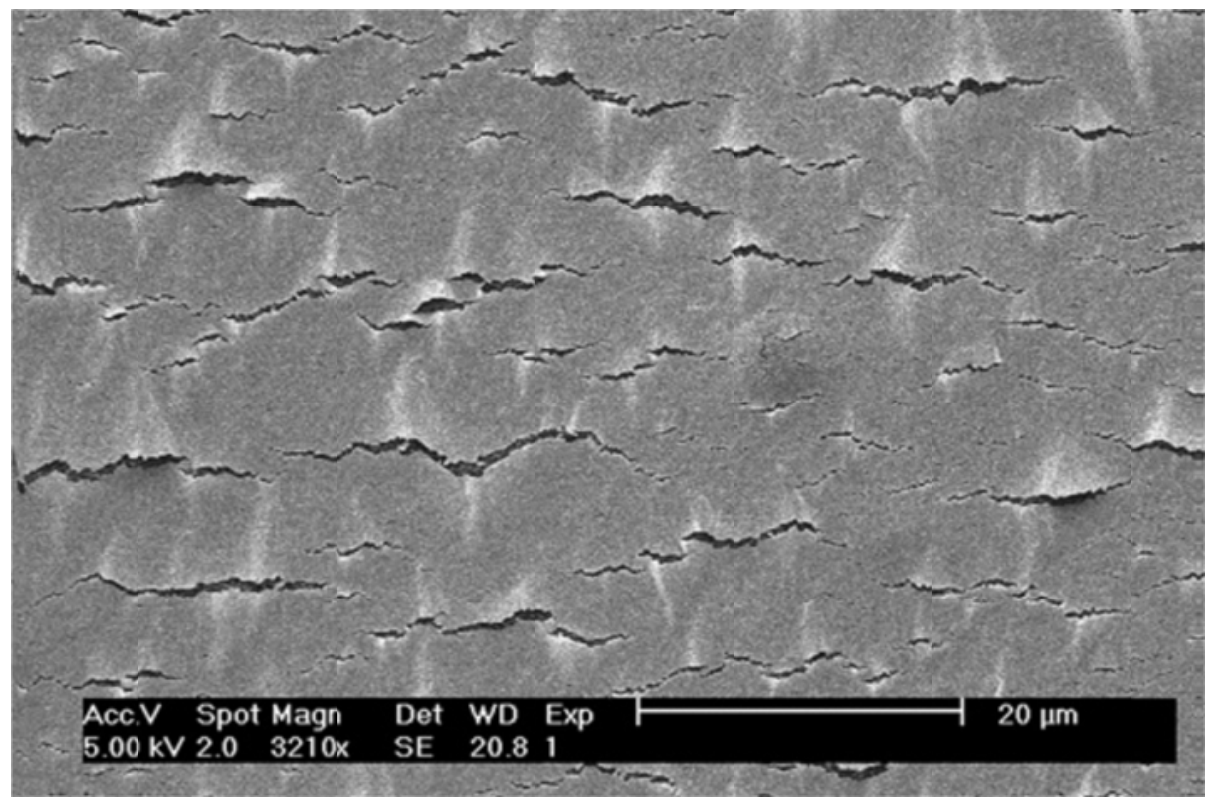

Figure 5 - SEM image of conductive film on PET substrate at $10 \%$ strain. Cracking forms perpendicular to the direction of strain (3).

Another method of testing contributes to evaluating the durability of a sample to repeated straining. Cyclic strain loading involves the straining of the sample many times, typically in the range of a multiple of a thousand loading cycle (3) (14). The idea is to measure how many cycles a sample can endure before the onset of degradation of conductivity. Cyclic bending typically results in fracturing of the conductive track perpendicular to the direction of the applied strain similarly as seen with monotonic tensile testing (3). Fatigue testing on coatings can be used to analyze coating adhesion and cohesion, and the fatigue behavior involved with adhesive and cohesive failure mechanisms of the coating, Figure 6 (13). 

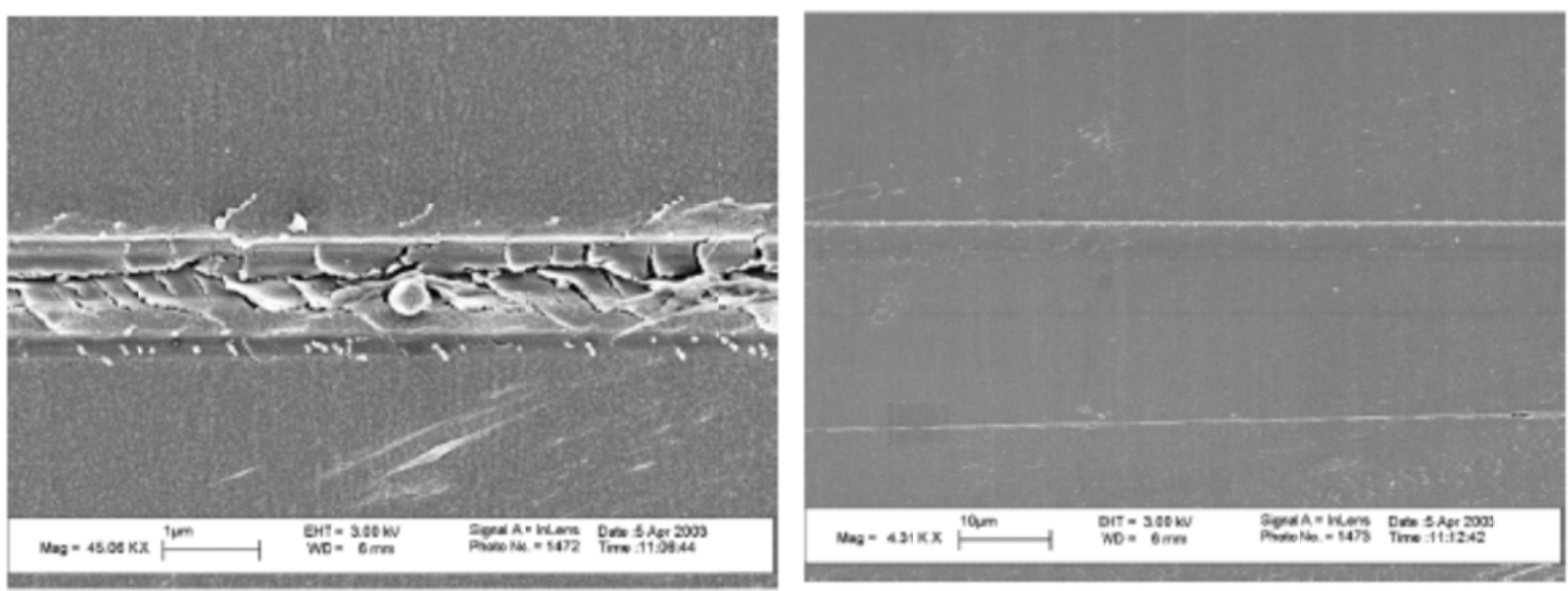

Figure 6 - SEM images of ITO film on PET substrate depicting fatigue cracking perpendicular to the direction of strain after $100 \mathrm{~K}$ cycle fatigue testing. In the images, straining is applied in the top-bottom direction (13).

Resistivity is another important electrical property of printed silver tracks. Taking into account the dimensions of the track, resistivity provides a measure of how efficiently the current movement of the track is. This can also give information as to the existence of porosity within the cured track. A higher porosity will usually lead to a high resistivity. Also, porosity can act as a flaw generator promoting potential fracture regions in the track. This is related to the dimensions of the printed track in terms of the calculated cross-sectional area and length of the sample as seen in Figure 7 and Figure 8 (20) (21). 

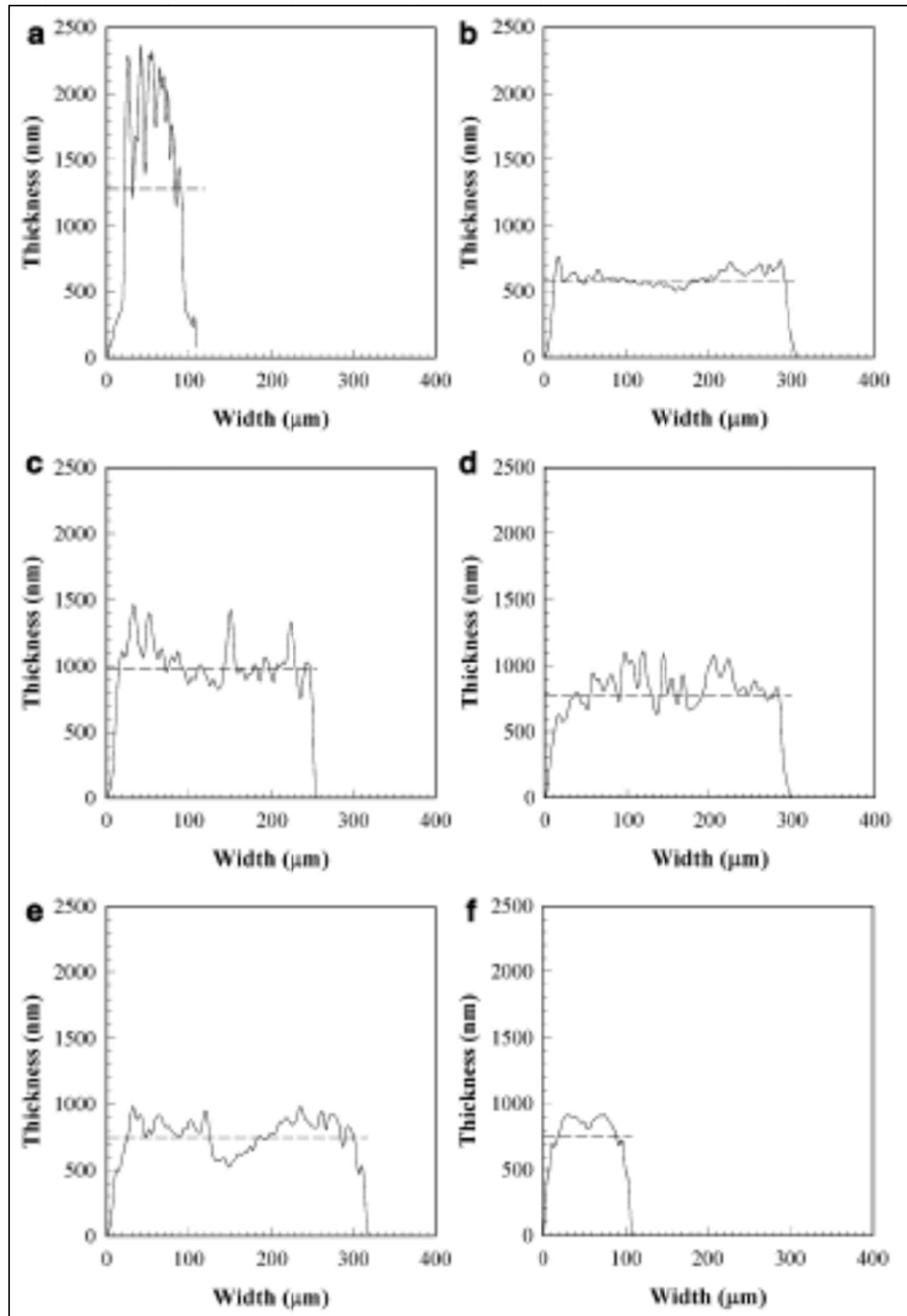

Figure 7 - Typical surface profiles of deposited and cured tracks. Inconsistency and uniformity is a challenge due to the migration of solids in the ink during drying (21). 

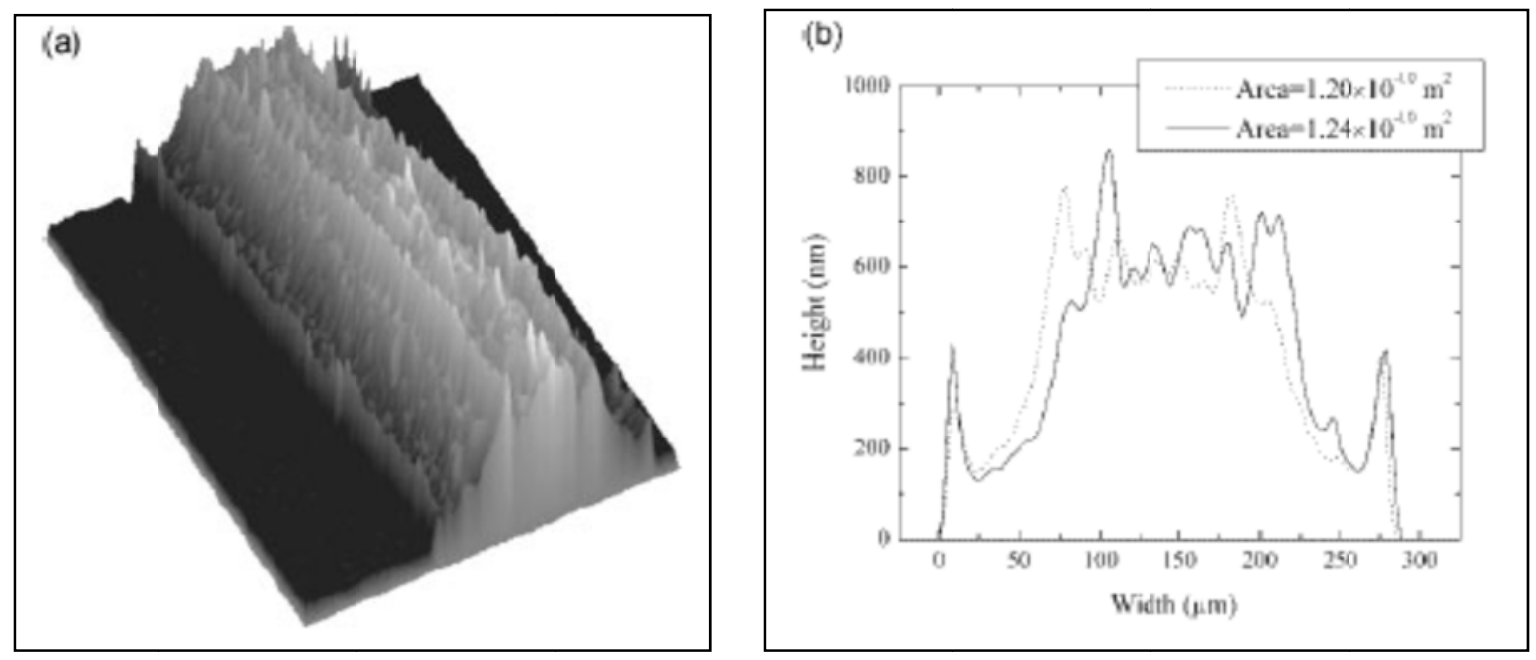

Figure 8-a) 3-D profile scan of an ink-jet printed track. b) Typical profile scan of the ink-jet printed track shown on left used to determine cross-sectional area of track dimensions to calculate resistivity given the length of the track (20).

The area is measured using a surface profile analysis of the area under the cross-sectional scan in the range of $30-130 \mathrm{~mm}^{2}(21)$. By combining the measured resistance through the silver track, the resistivity is found using Equation 1.

$$
\rho=\frac{R A}{l}
$$

Where $\rho$ is the resistivity in $\Omega \cdot m, R$ is the resistance in $\Omega, A$ is the cross-sectional area $\mathrm{m}^{2}$, and $I$ is the length of the track in $\mathrm{m}$. It is desirable to attain resistivity values close to that of bulk silver at $1.59 \times 10^{-8} \Omega \cdot m(34)$. Typical measured values are 2 or 3 times that of bulk Ag resistivity (20). It is important to compare the following parameters shown in the subsequent figures: Figure 9, Figure 10, and Figure 11. As in Figure 9, it is important to relate the electrical and mechanical properties of the conductive track and substrate. This can determine the onset strain for failure of the system. Figure 10 provides information about the mechanical reliability of the conductive track when exposed to cyclic 
loading. Determining a relation of resistivity and temperature is advantageous when later implementing curing regimes for specific substrates, as in Figure 11.

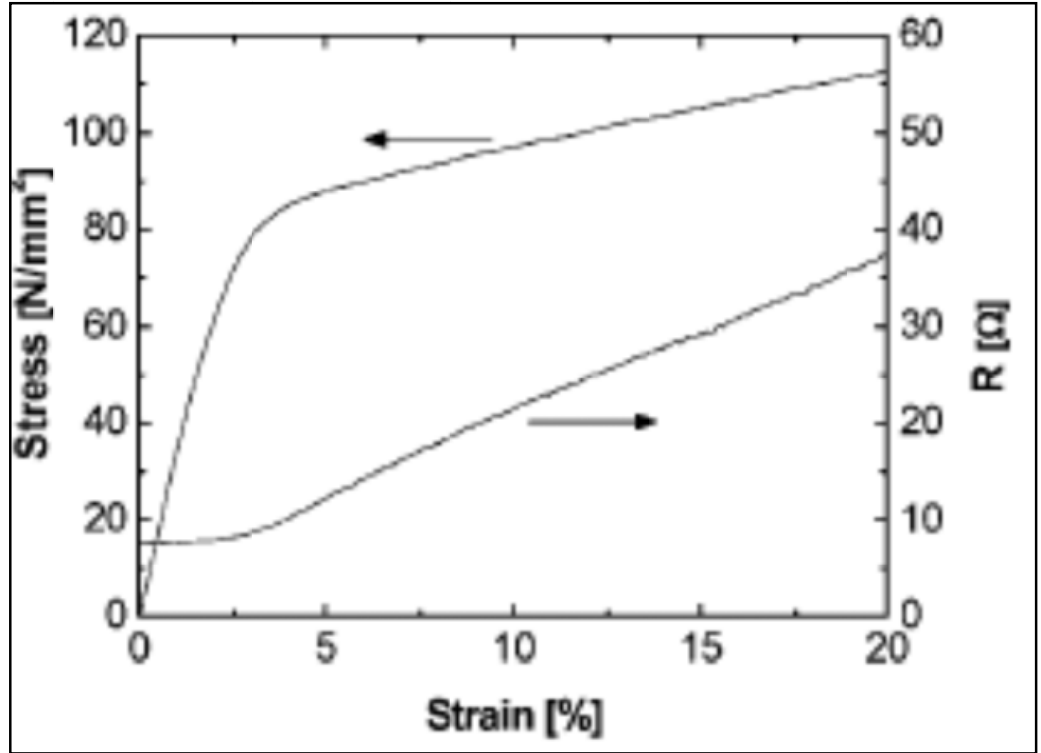

Figure 9 - Change in resistance of silver conductive tracks on PEN substrate during tensile testing (3).

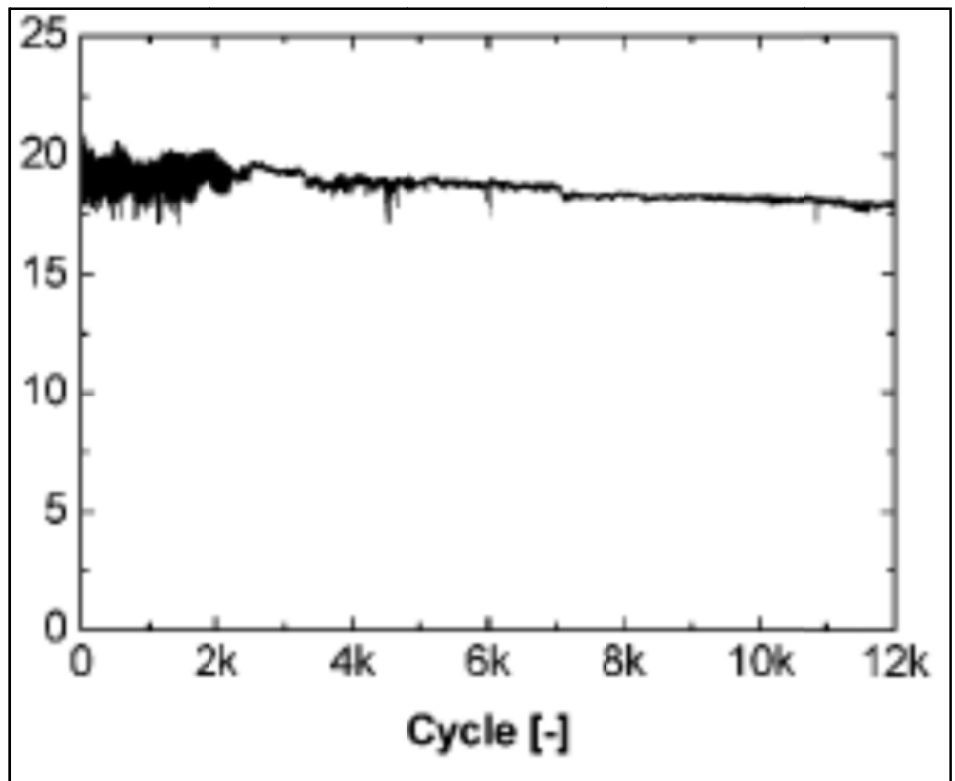

Figure 10 - Resistance change of silver conductive tracks on PEN substrate during cyclic loading (3). 


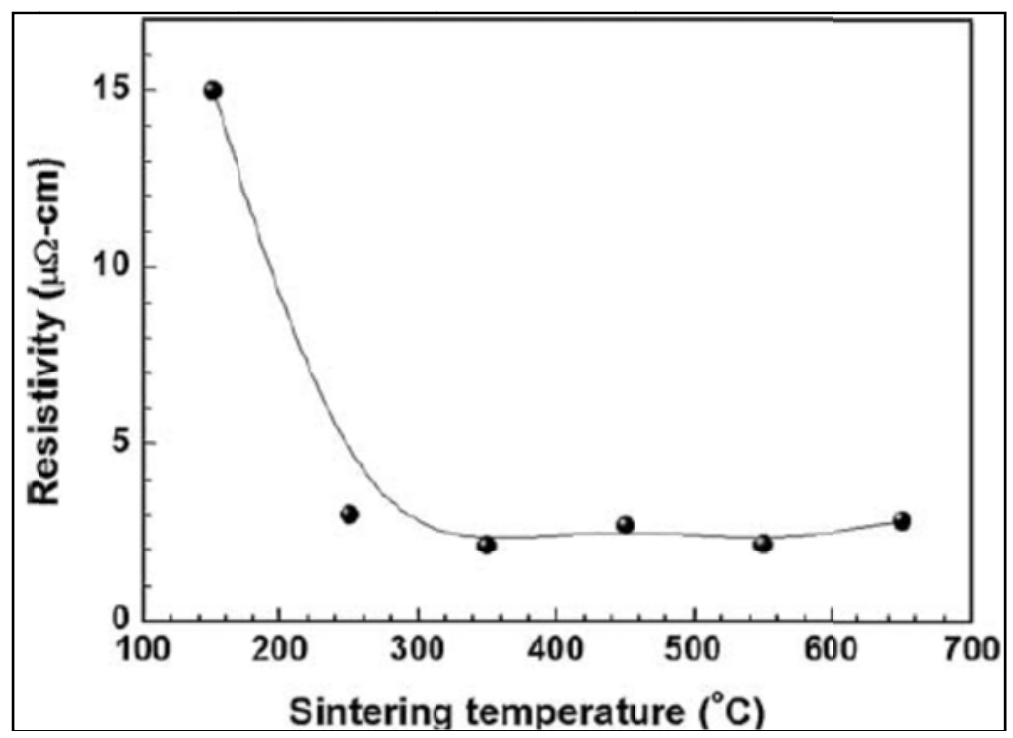

Figure 11 - Resistivity relation to curing temperature of silver conductive tracks (30).

It is interesting to analyze the surface attributes in terms of the surface morphology to relate porosity to the measured resistivity. Surface roughness of the deposited silver tracks can be analyzed using surface profilometry. This operates as a means of gauging the efficiency of particle packing within the MOD inks after being cured. Non-uniform curing may cause for particles on the exterior of the track to experience annealing more quickly than those particles located towards the center of the deposited ink (11). Furthermore, this could create regions of porosity and lack of conductivity as aforementioned due to the lack of percolation between particles.

Measurement of contact angle gives a quantitative means for assessing adhesion between the Ag ink and the PEN substrate surface. The contact angle of water on this surface can be used to characterize the substrate in terms of its composition. PEN exhibits a contact angle around 80 degrees due to the lower proportion of oxygen in its chemical structure (11). It is interesting to analyze the contact angle of the deposited ink and compare it to that of water. The PEN substrate used has been designed with an adhesion-promoting acrylate layer which will result in a lower contact angle. 
In all findings, it will be advantageous to perform multiple means of imaging including optical microscopy and scanning electron microscopy (SEM). These instruments provide information on surface microstructure and surface topography of the cured tracks. These imaging processes can be used to analyze tensile testing and response of the conductive tracks to such straining, agglomeration of silver NPs within the MOD ink, curing of the MOD ink, densification of the silver ink, porosity within the cured ink, and effects of thermal processing on the polymer substrate.

\subsection{Hybrid Organic/Inorganic Flexible Structures}

The combination of synthesized conductive components with light-weight flexible substrates offers immense benefit to previously unattainable applications such as flexible devices. Their benefit to industry is invaluable considering its direct relation to the roll-to-roll production capability on thin polymers of desirable mechanical properties such as strain, thermal tolerance, and corrosion resistance (12) (14) (17) (21) (27) (29) (30) (36) (40) (41). Synthesis of the conductive ink using low cost chemicals and simplistic formation processes offers attractive decreases in cost and production. Furthermore, this research leaves room for creativity and additional development. Possible additives/coatings suggest the possibility for better performance of devices in harsh environments (5) (8) (35).

Current industry competitors are making use of high cost NP powders in conjunction with organic solvents to formulate conductive inks. Due to the increasing demand for smaller particles in the nanoscale, agglomeration of the particles due the forces existent between the particles leads to clogging of dispensing methods such as ink-jet printing. By using an organic formulation, this provides a means of producing small silver particles resulting in conductivity with an organic structure attached to eliminate much of the agglomeration due to the small size. This enhances the printing abilities when 
combined with an organic solvent such as xylene. Furthermore, the existence of the organic material within the matrix of the silver octanoate ink composition allows for relatively easy low temperature metallization of the ink by means of thermal processing.

This project shows promising possibilities for the implementation of the silver organic conductive ink onto thermally tolerant flexible substrates such as PEN. Currently other coated conductive substrates such as indium tin oxide or carbon nanotubes are used (13) (18) (19) (24). This allows for the creation of relatively transparent substrates because of the ability to deposit the conductive material in a meshed structure where it is needed without excess. Due to the higher maximum utilization temperature of the PEN substrate, direct thermal processing using a hotplate can remove the organic material from the deposited ink and result in the metallization of the silver particles at relatively low temperatures up to $200^{\circ} \mathrm{C}$ (5) (10) (20) (35) (42).

This research addresses a couple of the critical areas within production of optical and electronic components on the large scale such as material reduction and electromechanical functionality. Currently, the majority of electronic components are comprised of thick, rigid materials offering sturdy foundations for working components. The heavy nature and lack of flexibility of these materials limits the variety of possible applications. Furthermore, the cost of production and processing is compiled due to the high cost of raw materials and extreme processing environments required.

Metal structures applied to the substrate surface offer a means of achieving good conductivity and flexibility. Silver is a promising candidate for this application because it exhibits the highest conductivity of all metals. Silver can be deposited as an ink and cured at relatively low temperatures on a polymer substrate. Also, it offers good adhesion and adequate resistance to corrosion while demonstrating tolerance of bending which makes it advantageous in applications such as flexible printable circuitry (FPC). It can also be used in sensors, solar panels, and liquid crystalline displays 
among others. Furthermore, the silver-based ink could be infused with palladium nanoparticles to boost corrosion resistance. Therefore, the low temperature deposition of conductive silver tracks on thin polymer substrates is an advantageous incorporation for the area of flexible electronics, flexible optics, printable circuit boards and sensors. The aim of this project is to fabricate truly flexible platforms that can be used in numerous optoelectronic applications.

\subsubsection{Preliminary Investigation Results}

In order to achieve the aforementioned outcome, the silver ink must be properly synthesized. The ink was made using a precipitated silver octanoate dissolved into a xylene solvent. Formulation of the silver octanoate was performed using a process similar to the one outlined by Dearden et al and Lee et al, implementing a silver precursor, as shown in Figure 12 (2) (20).

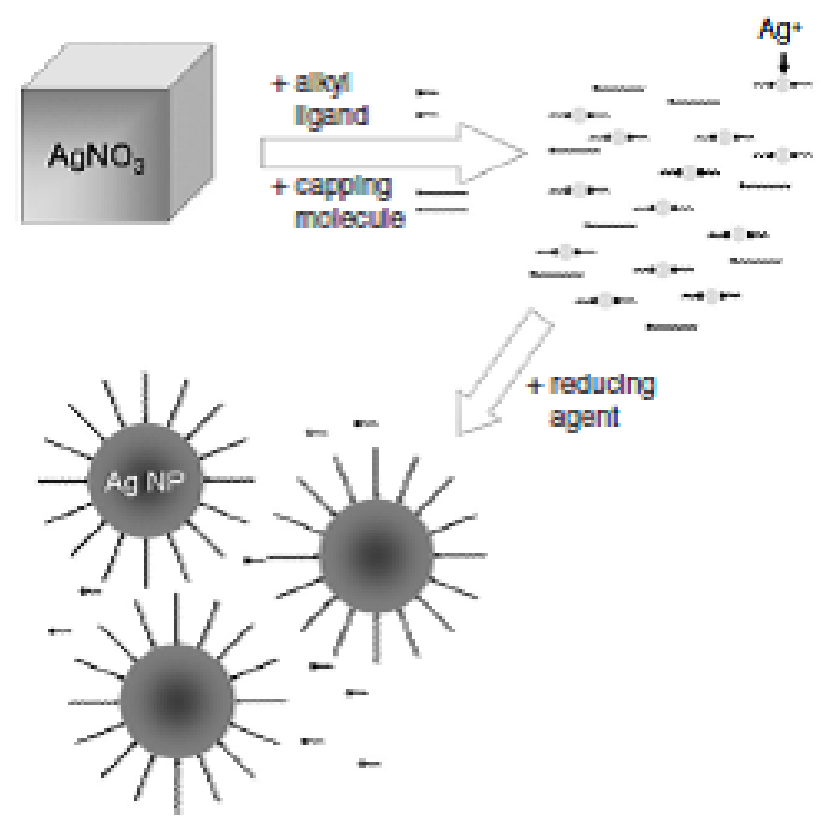

Figure 12 - Schematic representation of silver nanoparticle production via the reduction of metallo-organic precursor such as silver nitrate (2). 
The conductive characteristics of silver conductive tracks by means of the reduction of silver salt precursors and subsequent synthesis of metallo-organic precursors has been demonstrated to be advantageous and reproducible (2) (4) (20). When deposited on polyethylene naphthalate (PEN) substrates, curing of the tracks at relatively low temperatures $\left(100-200^{\circ} \mathrm{C}\right)$ has been accomplished without detrimental effects to the mechanical behavior of the substrate as shown in Figure 13 with the existence of no noticeable cracking of the cured surface. Furthermore, cured tracks demonstrated adequate adhesion to the PEN substrate as assessed by preliminary bend testing when handling samples. Resistance was monitored during mechanical testing of the tracks. Given track uniformity, surface analysis using surface profilometry demonstrated resistivities (2) (4) (25) (30), Figure 14.
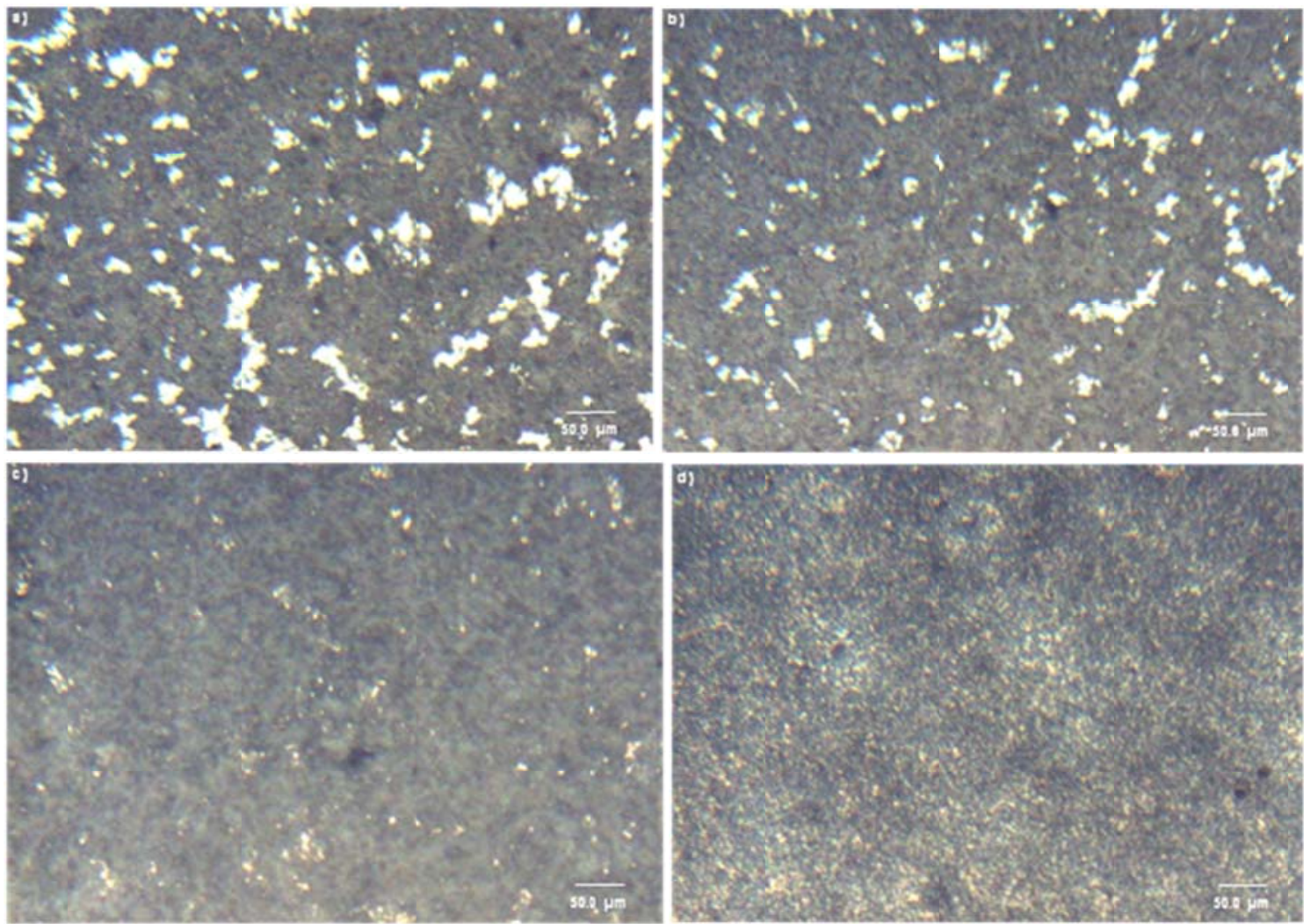

Figure 13 - Optical microscopy of silver ink on PEN substrate cured at a) $150^{\circ} \mathrm{C}$ for $70 \mathrm{~min}$. b) $160^{\circ} \mathrm{C}$ for $60 \mathrm{~min}$. c) $180^{\circ} \mathrm{C}$ for $40 \mathrm{~min}$. d) $200^{\circ} \mathrm{C}$ for $20 \mathrm{~min}$. 


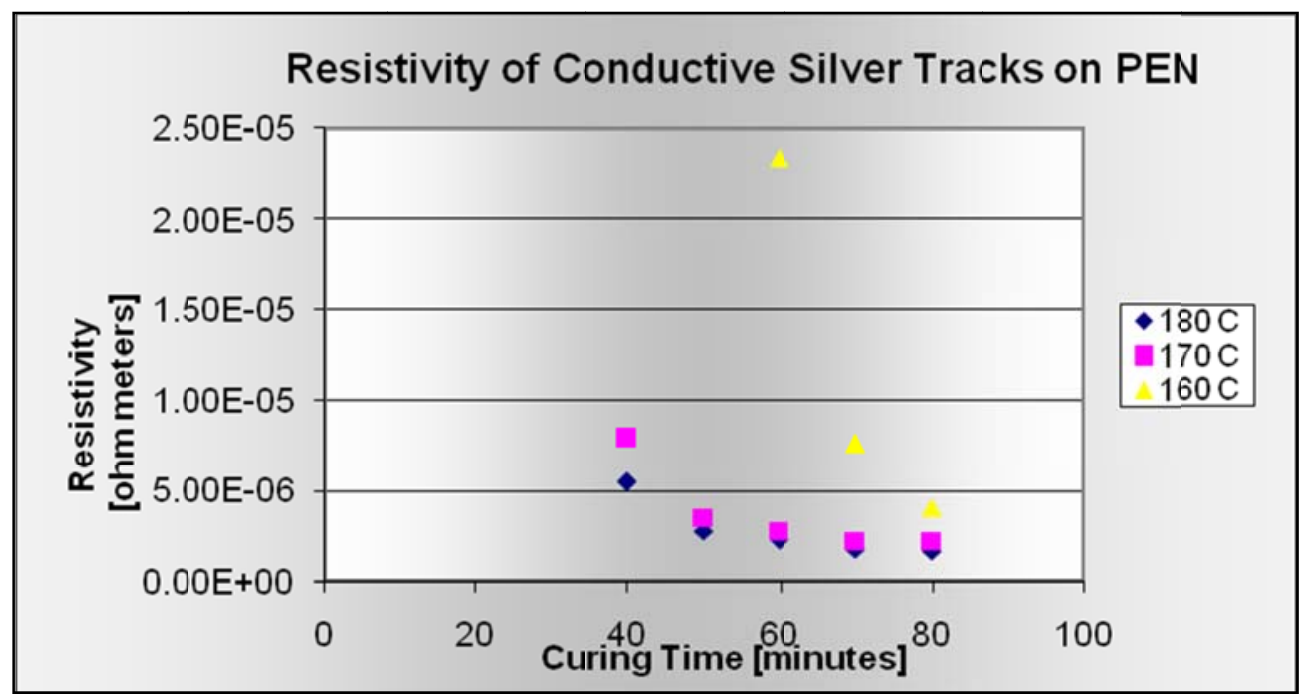

Figure 14 - Resistivity trends given curing at temperatures of 160,170 , and $180^{\circ} \mathrm{C}$ for times ranging $40-80$ minutes.

The silver-organic conductive ink showed similarities to more commonly used metal nanoparticle inks seen in other studies using silver nanoparticle suspensions (2) (4) (20) (28) (29). TEM analysis of the cured tracks shows a beneficial particle size distribution $20-50 \mathrm{~nm}$. Smaller particle size suggests lower temperature curing of the ink. At smaller size regimes $<5 \mathrm{~nm}$, particles tend to agglomerate during dispersal (29) (30) (36). Especially with the use of silver nanoparticle inks, agglomeration of increasingly small particles is of high occurrence. This is observed when using relatively precise techniques such as ink-jet printing. Within ink-jet printing techniques, nozzle sizes of smaller diameters are becoming more common. High-rate dispersal of inks in this technique increase the effect of particle agglomeration due to the quick ejection of the nanoparticle suspension inks usually by means of the heat created in the nozzle tip. This heating occurrence can be manually implemented to ensure track uniformity by means of the quicker evaporation of the dispersant, or by consequence of ohmic heating due to friction of the quick passing particle dispersion against the relatively rough inner walls of the nozzle head (36). 


\section{EXPERIMENTAL METHODS AND MATERIALS}

\subsection{Silver Ink Synthesis and Formulation}

Synthesis of Silver Octanoate Precipitate

Commercially available reagent grade chemicals were purchased for the synthesis of the silver octanoate precipitate from Sigma-Aldrich (U.S.). The synthesis process involves the combination of aqueous solutions of silver nitrate in deionized water, sodium hydroxide in deionized water, and octanoic acid in methanol. All solutions should be magnetically stirred to ensure complete dissolution prior to introduction into the chemical synthesis process. The ink was prepared beginning with sodium hydroxide $(\mathrm{NaOH})$ dissolved in distilled water. This was then added to octanoic acid $\left(\mathrm{C}_{8} \mathrm{H}_{16} \mathrm{O}_{2}\right)$ which had been dissolved in methanol $\left(\mathrm{CH}_{3} \mathrm{OH}\right)$. Both solutions were then added to a solution of silver nitrate $\left(\mathrm{AgNO}_{3}\right)$ which had been dissolved in distilled water. This process formed the desired precipitate silver octanoate $\left(\mathrm{AgC}_{8} \mathrm{H}_{15} \mathrm{O}_{2}\right)$. The silver octanoate was collected and washed using water filtration to separate it from the additional reaction products sodium nitrate and water. Furthermore, the silver octanoate was cleaned using distilled water and methanol. The final separated precipitate was combined with the solvent xylene $\left(\mathrm{C}_{8} \mathrm{H}_{10}\right)$ in adequate amounts to attain complete dissolution [ (20)]. 


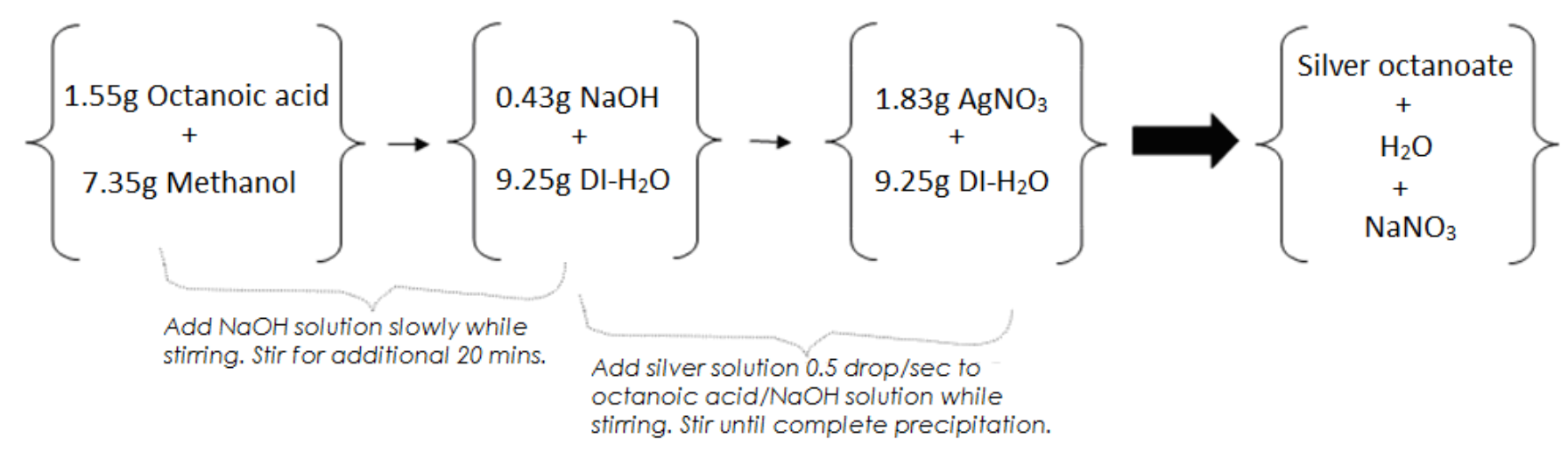

Figure 15 - Schematic of Method 1 synthesis of silver octanoate precipitate adapted from a similar process used by Dearden et al (20).

Method 1 follows the schematic in Figure 15 with the addition of the silver nitrate solution last in the process to initiate the precipitation of the silver octanoate. Method 2 interchanges the order of introduction of the silver nitrate and sodium hydroxide solutions with the sodium hydroxide solution being introduced last to initiate the precipitation of the silver octanoate.

Separation and Cleaning of Silver Octanoate Precipitate Powder

The silver octanoate precipitate is washed and separated using excess solution chemicals and centrifuging. Unwanted products are removed using DuPont Survall RT6000B centrifuge ( at $2000 \mathrm{rpm}$ for 15 minutes. Silver octanoate precipitate is cleaned using deionized water and methanol following the below cleaning regime:

Step 1 - Methanol is added twice the volume of the separated precipitate and stirred on magnetic stirrer for 3 minutes.

Step 2 - The stirred precipitate solution is centrifuged at 2000 rpm for 15 minutes.

Step 3 - The separated "dirty" methanol solution is removed. 
Steps 1-3 of the process are repeated using deionized water. The process should be repeated 3 times each alternating between methanol and deionized water, being sure that the last cleaning process is done using deionized water. The clean precipitate is allowed to dry in vacuum.
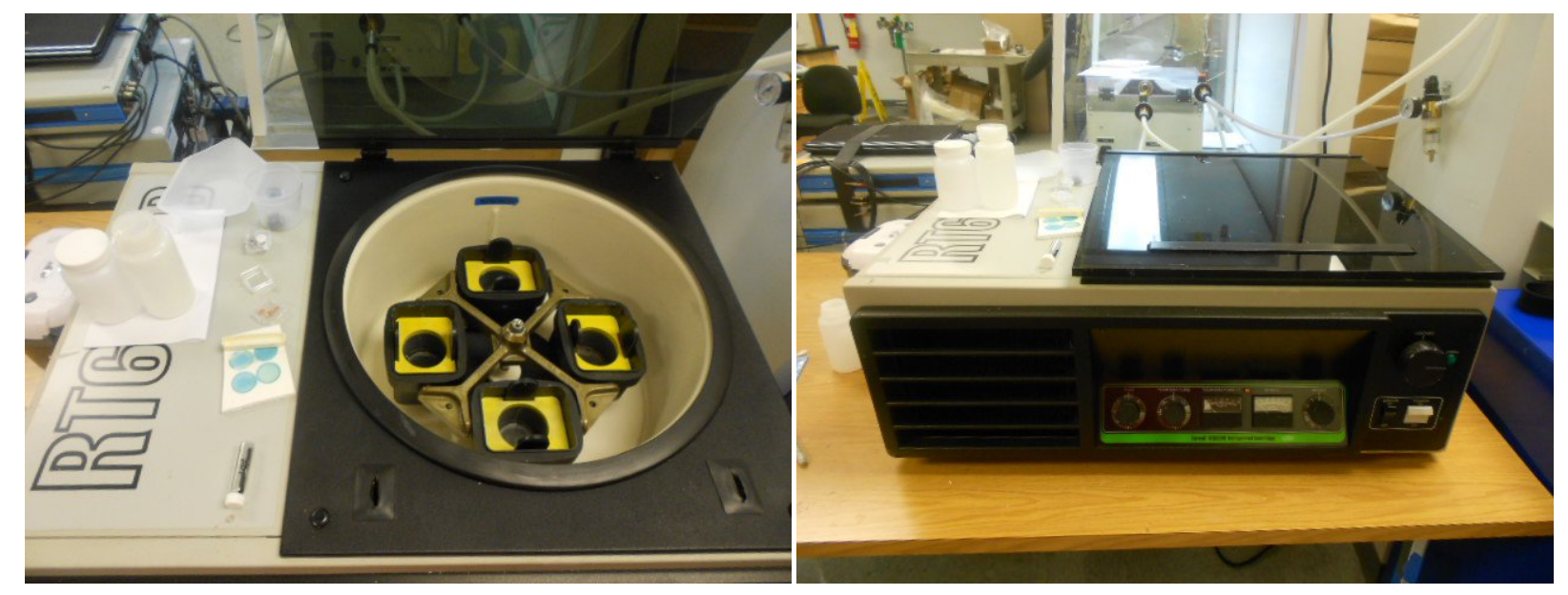

Figure 16 - DuPont Survall RT6000B refrigerated centrifuge used to clean silver octanoate precipitate.

\section{Ink Formulation with Xylene Solvent}

After complete evaporation/drying, the silver octanoate powder is combined with organic solvent xylene to make silver octanoate ink. To determine the best ink composition, it is necessary to combine the silver octanoate powder with xylene solvent to achieve dissolution while still affording easy dispensing using a 30 gauge needle tip without clogging. Silver octanoate powder will be combined in 2 $w t \%$ increments of powder to solvent in the range of $4-16 \mathrm{wt} \%$. The silver ink is placed in a $10 \mathrm{~mL}$ vial with re-sealable septum and sonicated for 30-60 minutes at room temperature to achieve complete dissolution. A necessary post-sonication step to test the dispensing ability of the various weight percent inks for applications is performed in two depositions techniques. The first uses a luer-lock syringe with $30 \mathrm{G}$ needle tip to test clogging tendencies involved with possible precise deposition apparatus. The second uses a spray masking technique which makes use of a spray gun and masked track patterns. It is desirable to determine for either deposition technique what weight percent silver octanoate ink offers 
the best results in terms of adhesion, track uniformity, deposition control, and resistivity. The ink solutions that are dispensed without clogging are then deposited on microscope slides and cured using a hot plate to observe which solution weight percent offers the lowest preliminary resistance.

\subsubsection{Particle Size Analysis}

Analysis of the particle size of the silver-organic compound within the solution is performed using a Hydro 200S Mastersizer 2000 (Malvern Instruments) particle size analyzer. The silver octanoate precipitate is dispersed in ethanol and sonicated in a sonication reservoir until complete dissolution. The particle analysis instrument operates with an ethanol dispersant.

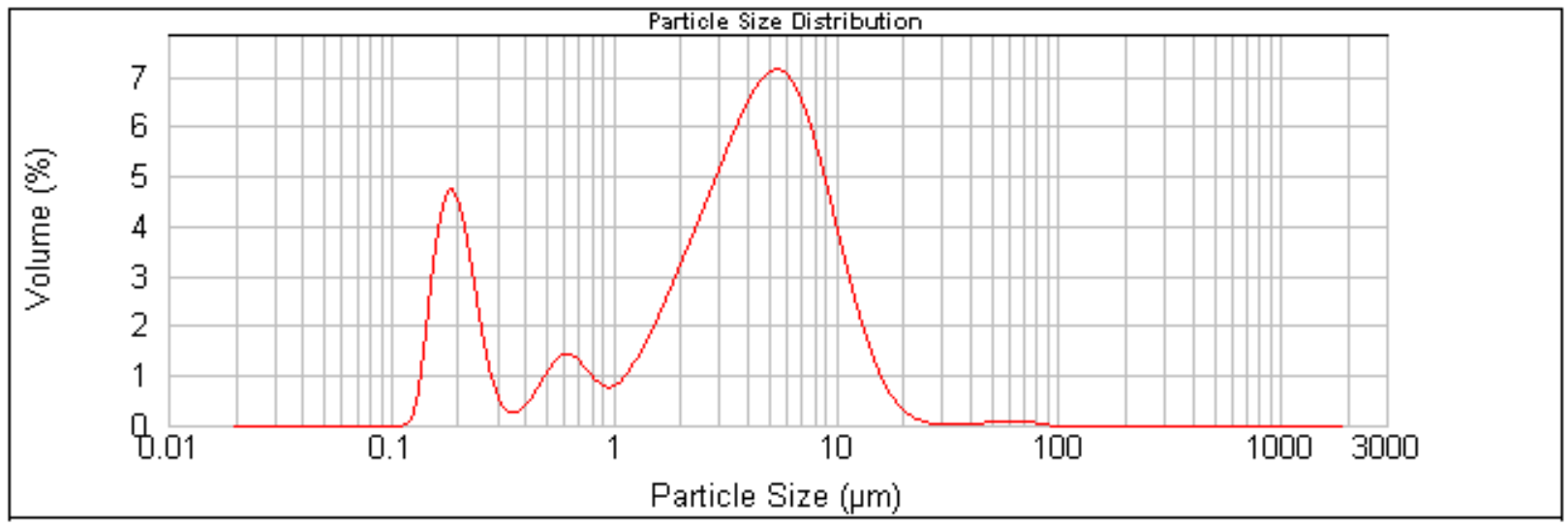

Figure 17 - Particle size distribution of silver octanoate precipitate solution in ethanol showing agglomeration existing at various sizes.

The sonicated silver octanoate/ethanol solution is dropped using a small pipette into the input chamber. Results showed a particle agglomeration size distribution of highest volume around $5.5 \mu \mathrm{m}$, as seen in Figure 17. 


\subsection{Substrate Cleaning}

The PEN substrate was cleaned to remove surface particulates and eliminate any grease or oils on the surface due to handling of the substrate. The PEN was cleaned with the solvents acetone and isopropyl alcohol as follows:

Step 1 - Submerge PEN sample in acetone bath with a dunking/swishing motion for approximately 5 seconds. Rinse the substrate with deionized water.

Step 2 - Submerge PEN in isopropyl alcohol bath with a dunking/swishing motion for approximately 5 seconds. Rinse with deionized water.

Step 3 - Dry the PEN sample with clean compressed air in a downward motion so that the liquid is blow off from the top to the bottom of the sample along the length of the sample with wash liquid exiting at the bottom of the sample.

Step 4 - Allow the PEN sample to dry completely on a microfiber cloth in a vacuum hood.

Optical microscopy was used to determine the effectiveness of the cleaning process in removing debris from the substrate surface by analyzing substrate samples before and after cleaning, as seen in Error! Reference source not found. and Error! Reference source not found.. Adequate collection of surface debris after submersion in the solvent bath can be seen in the localized droplets shown in Error! Reference source not found.. After submersion in the solvents acetone and isopropyl alcohol, rinsing with deionized water, and drying with clean compressed air, a clean substrate is prepared for ink deposition as shown in Error! Reference source not found. having little to no existent surface debris. 


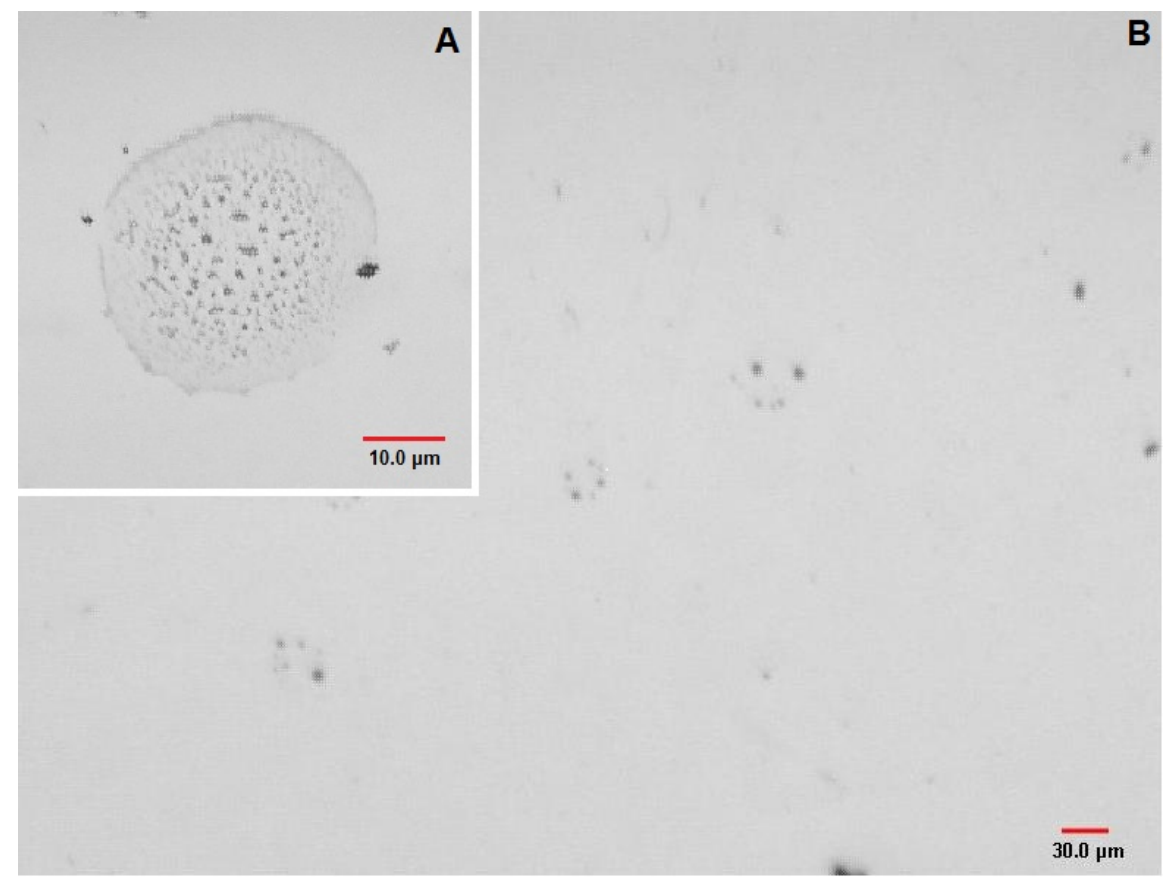

Figure 18 - Optical microscopy of B) dirty PEN substrate after submersion in solvent showing adequate collection of surface debris into localized droplets prior to rinsing with deionized water. A) Solvent droplet showing collection of surface debris. Cleaning process involved using multiple submersion steps with isopropyl alcohol and acetone solvents, then rinsing with deionized water.

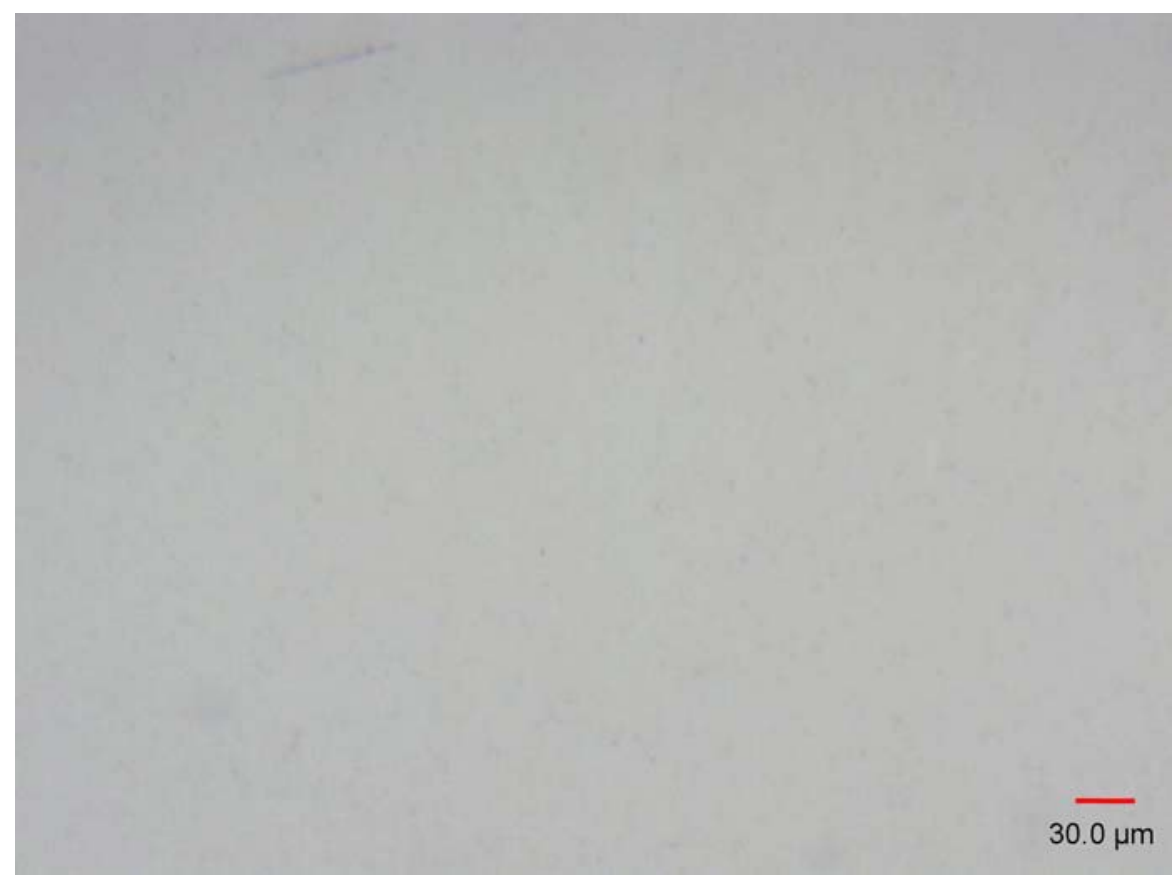

Figure 19 - PEN sample after cleaning process and drying showing removal of surface debris. 


\subsection{Ink Deposition Techniques}

The Ag ink was deposited on the PEN substrate using various deposition techniques making sure to deposit the ink on the side of the PEN that is primed for adhesion. The first method used a luer-lock syringe with $30 \mathrm{G}$ needle tip to simulate ink dispersal implementing a successive drop technique like that of ink-jet printing. The second method used a spray masking technique which makes use of a spray gun and masked track patterns. The same masking technique and dimensions were used. For all samples, the deposited tracks on the PEN substrate were subjected to the same curing regime as above.

Additionally, it was necessary to determine which curing regime point offers the best outcome in terms of sustaining the mechanical characteristics of the PEN substrate. As above, surface profilometry was used to calculate cross-sectional area and subsequent resistivity.

\subsubsection{Free Writing Syringe Deposition}

Preliminary trials using the luer-lock syringe and $30 \mathrm{G}$ needle tip were conducted manually. This was done in order to investigate the adhesion and writability of the preliminary ink. It was desirable to see the ink's behavior when deposited on both glass and PEN substrates. Free writing lacked controllability and resulted in inconsistencies when trying to deposit uniform tracks on either substrate as shown in Figure 20. 

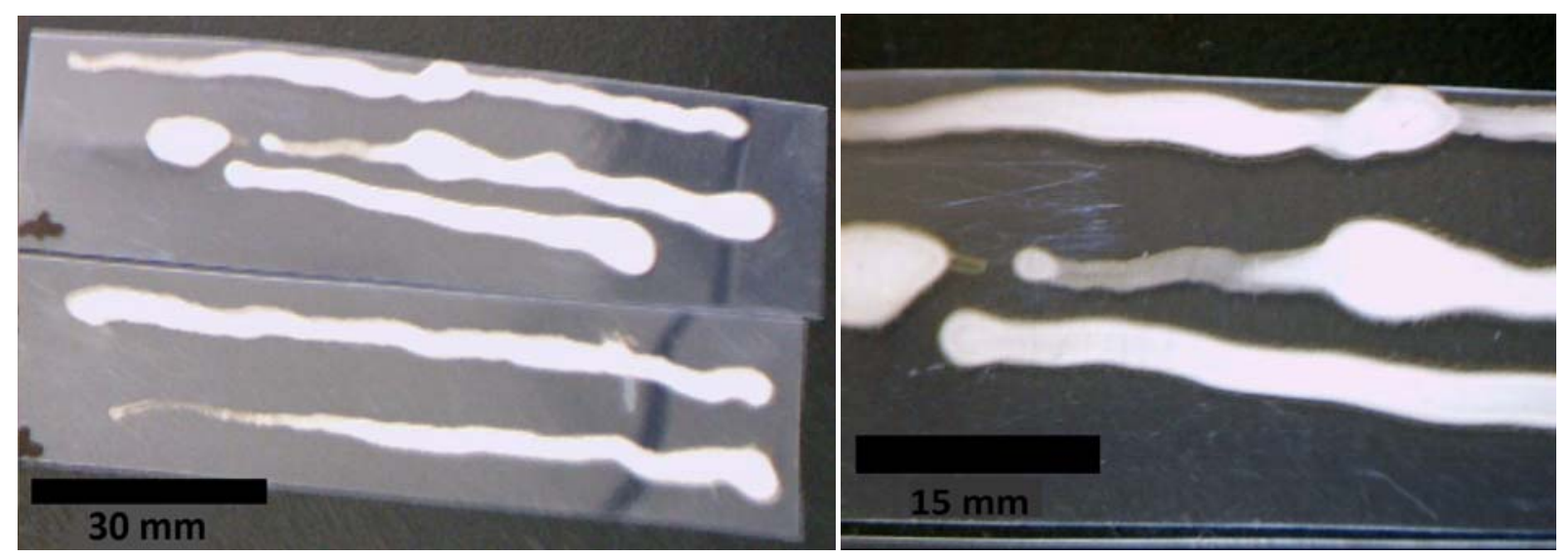

Figure 20 - Free writing syringe deposition lacks controllability when attempting to deposit uniform straight lines (right). Enhanced image (left) shows also inconsistencies in ink dispersion.

There was a lack of uniformity noticed in track width, height, and along the length. Also, there was much difficulty in applying consistent dispersal along the length of the track. The beginning and ending points of the track showed the most inconsistent behavior. This was attributed to the definite need for a uniform speed of ink deposition both from the needle tip and by the movement of the needle tip along the substrate.

\subsubsection{Masking Syringe Deposition}

Due to the aforementioned difficulties noticed when experimenting with the free writing deposition technique, a masking technique was implemented. Using this technique allowed for the definition of uniform tracks and patterns. Also, it acted to contain some of the behavior of the ink to spread when deposited on the substrate. By defining the dimensions of the track pattern, it was then possible to attain a more uniform track thickness. Incorporating a masking technique did pose some challenges. Because of the mask being in place, the solids within the ink tended to migrate towards the 
walls of the mask when drying. This caused undesirable track geometries and cross-sectional profiles such as the one in Figure 21.

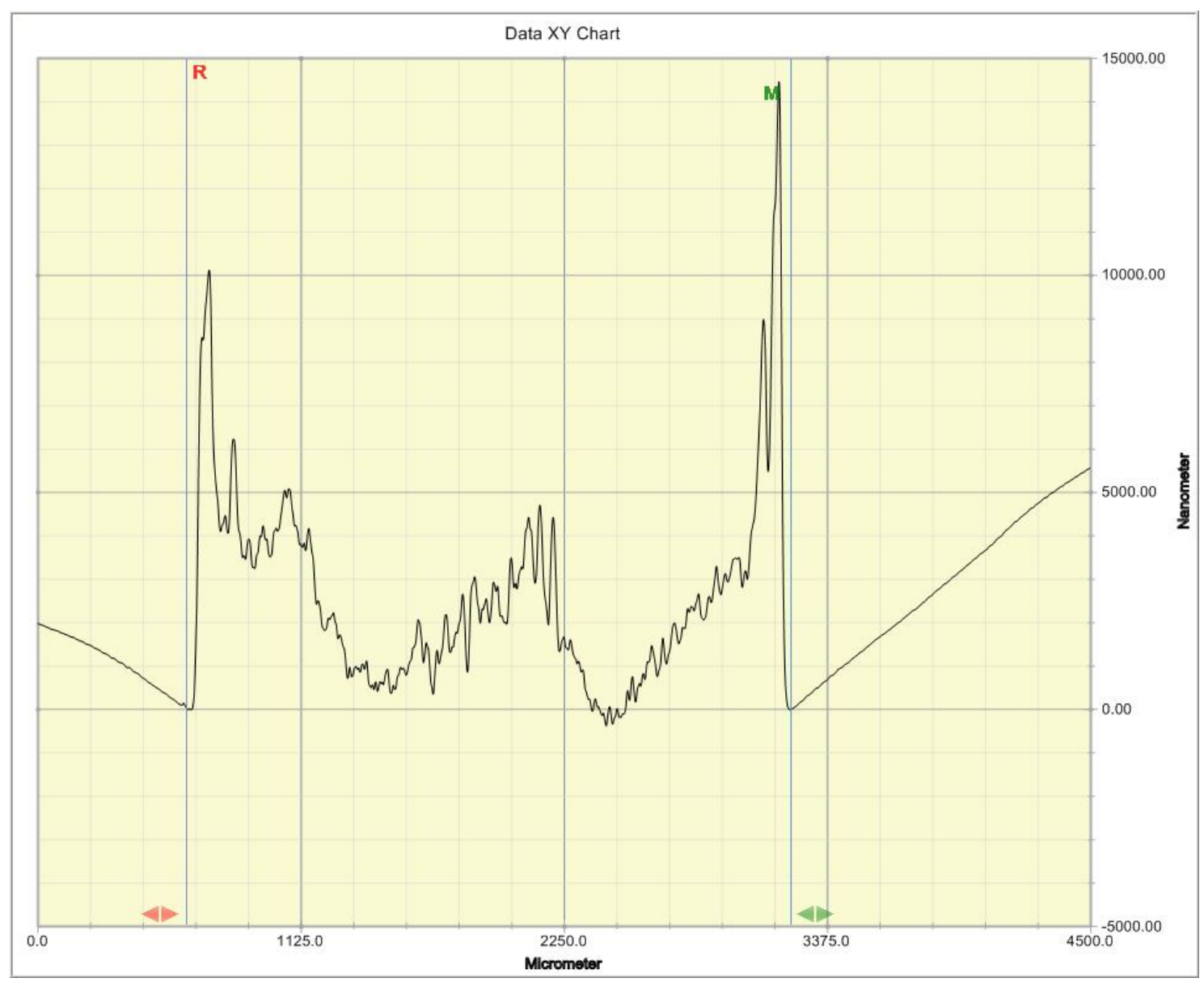

Figure 21 - Cross-sectional profile scan of masked track patterns showing migration of some solids towards walls of mask during drying. Surface morphology is consistent post-thermal processing.

There was also some difficulty noticed using this technique when depositing the ink. Initially, the ink was deposited in a manner so as to fill the mask pattern with a constant speed along the length of the track. This resulted in inconsistent uniformity of deposited solids throughout the track length for the majority of the time. Again, this was likely contributed to the migration of the solids towards the walls of the mask and operator error. This resulted in inconsistent profiles and poor resistivity measurements. This problem was solved by implementing a successive drop technique. This was 
performed by filling the masked track pattern starting from one end of the track and placing successive drops one at a time while moving along the length of the track. Each droplet was placed with approximately a quarter of the subsequent drop overlapping the previously deposited drop's radius. This filled track was allowed to dry before curing. This was also tried using multiple passes after drying between applications. This technique exhibited a more uniform track and reproducible outcome closer to automated printing methods.

\section{Syringe Deposition Challenges and Benefits}

Challenges within the free writing technique come by way of a lack of control when dispersing the ink onto substrate. Much of the inconsistency is noticed at the beginning or end of the track where it exhibits either a lack of material or overabundance of material. Free writing lacks the control necessary to make this deposition technique useful in large scale, reproducible applications.

Challenges within masking come via the migration of solids to the outer extents of the track pattern when drying. This results in a non-uniform track profile. Using the successive drop technique seems to offer somewhat better results in terms of solid dispersion along the length of the track and somewhat combats the inconsistent drying occurrence. The masking technique however is beneficial in providing a defined track pattern to the deposited tracks. This is necessary to make this form of study applicable in large scale applications requiring precisely reproducible components. 


\subsubsection{Spray Masking Deposition}

Spray masking was performed to exercise the possibilities of accomplishing more uniformly deposited tracks. Within the previously discussed masking technique using syringe deposition, a lack of uniformity was noticed. By utilizing spray masking, the ink can be deposited using air and a spray gun with directed nozzle. Air pressure can be varied to offer the best deposition of the ink. The air pressure is critical to allow for reliable deposition along the length of the track. Also, it is desirable to use an air pressure that offers controllability of the ink flow onto the masked substrate. The same air pressure should provide a means of delivering adequate solids from the ink to the substrate while offering more readily evaporation of the xylene solvent used. This acts to eliminate the migration of the solids to the walls of the masked tracks during drying observed within the masking technique using syringe deposition.

\section{Spray Masking Apparatus}

The spray gun used is a commercially available Badger Crescendo 175 Air-brush (Badger AirBrush Company). It comes with various sized nozzles of which the smallest, most direct and precise opening was used in the spraying of the masked tracks. This offered the most precision and controllability when spraying the ink. Also, it served as means to conserve the loss of excess ink deposited on the exterior of the masked patterns which is ultimately lost after removal of the mask.

The Ag ink was prepared for spraying in commercially available $10 \mathrm{~mL}$ glass vials with resealable PTFE/silicon septum tops (Microliter Analytical Supplies Inc.). The vials were capped with a septum to allow for a tight seal when combined with the spray gun base. Flexible tubing was attached to the stock plastic tubing of the spray gun to allow for the use of the vial and promote upright spraying. 


\section{Spray Masking Parameters and Environment}

After performing preliminary spray trials at air pressures in the range $10-40 \mathrm{psi}$, it was found that an air pressure of 20 psi resulted in consistent and reproducible sprayed coatings. Additionally, a spray height was investigated in the range of $5-20 \mathrm{~cm}$ with a spray height of approximately $12 \mathrm{~cm}$ producing the most desirable results. For all sprayed samples, the spray gun was operated at air pressure of 20 psi and a spray height of $12 \mathrm{~cm}$. The spray gun was sprayed in an almost upright manner with the nozzle and direction of the exiting ink being normal to the masked samples. Each sample was sprayed in a similar manner. All spraying was performed in a vacuum hood. Each sample was sprayed in a back-and-forth motion making sure to fill the masked pattern. This was done involving two total passes along the length of the masked sample length. The sprayed sample was allowed to dry in a vacuum hood until the masked pattern was white in color. The spraying process was performed 4-5 times. After the final spraying, the masked pattern was allowed to dry 3-5 minutes before removing the mask.

\section{Spray Masking Surface Morphology}

Spray masking resulted in a more uniform track profile as seen in Figure 22. In comparison to track profiles resultant of syringe deposition seen in Figure 21, there is a significant lack of migration of solids noticed at the extremities of the profile scan. Also, there is more well-defined track profile exhibiting the existence of the majority of solids in the center of the track as desired. This not only offers more consistent results during electromechanical testing, but also allows for the production more reproducible samples resulting in the elimination of the need for large quantities of sample to be made in order to harvest good results. 


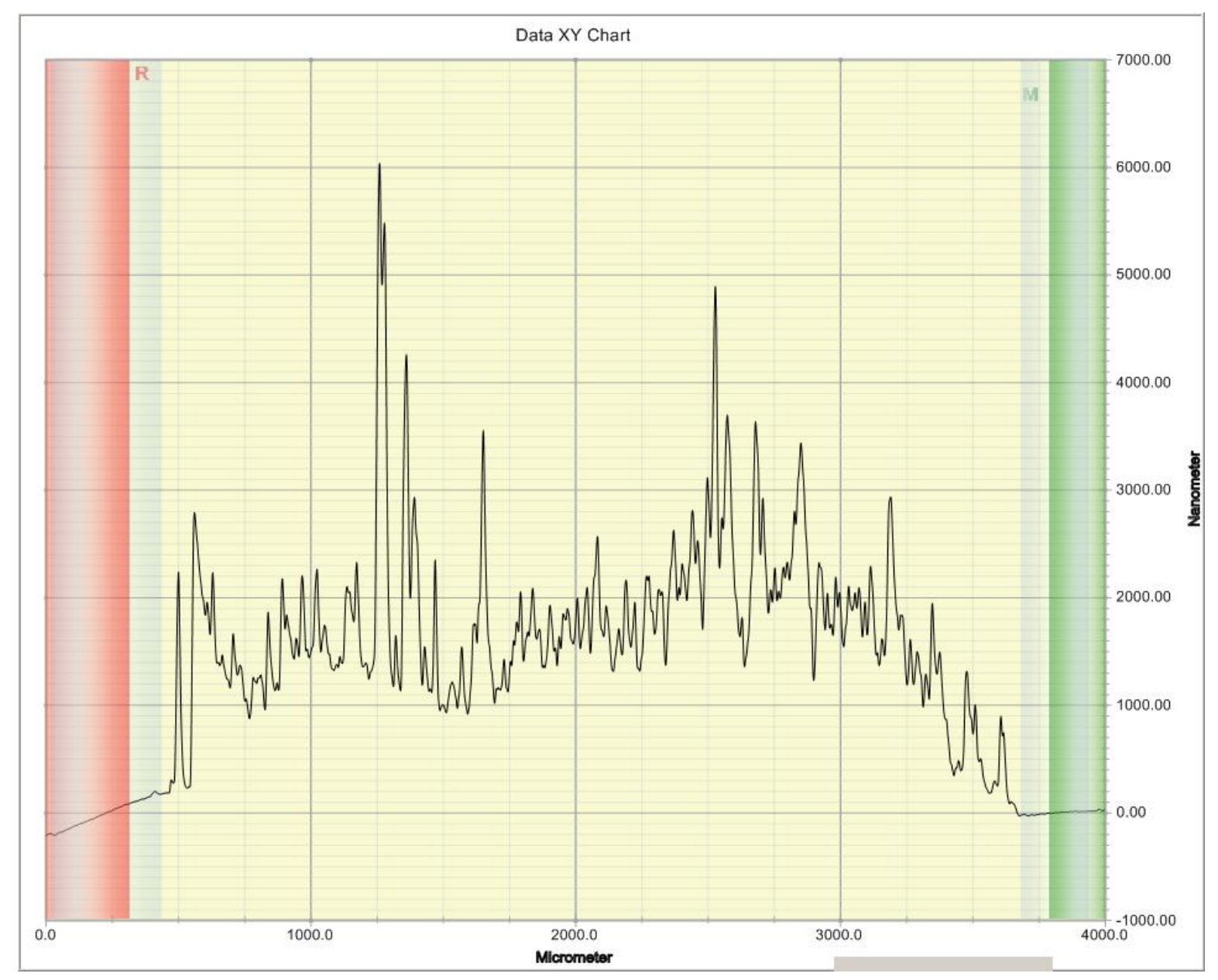

Figure 22 - Spray masked sample surface profile depicting a more uniform morphology with the location of more solids in the center of the track as desired. Evidence of decreased migration of solids during drying as was problematic with masked syringe deposition.

The lower migration of solids noticed with spray masking as compared to masked syringe deposition is contributed to the decreased time for preferential drying noticed once the ink has reached the masked pattern. This is likely resultant of premature evaporation of the ink solvent when en route to the masked substrate after exiting the spray nozzle tip. Coupled with the 20 psi pressure of the ink exiting the nozzle tip and the $12 \mathrm{~cm}$ spray height, adequate time for solvent evaporation prior arrival to the substrate surface is observed. 
Spray Masking Challenges and Benefits

Spray masking offered better track uniformity noticed when analyzing cross-sectional area with surface profilometry. This is contributed to the ability of the spray masking technique to allow premature evaporation of the xylene solvent when the deposited ink is en route to the masked pattern on the substrate. Because some of the solvent evaporates in the path from the nozzle to the substrate surface, less solid migration to the walls of the mask is noticed when drying. Thus, surface profiles are more uniform across the width of the pattern.

Challenges involved with the spray masking technique come via the reproducibility of the spray effect on each subsequent sample. Because the spraying is conducted manually, there exists some error and inconsistency when spraying the ink. The challenge comes when trying to keep a consistent speed when passing along the length of each pattern. Also, because of the operation of the air gun involving a variable air/ink release trigger, it is necessary to spray each sample with the trigger back completely so as to emit the highest concentration of ink to air ratio.

\subsubsection{Dip Pen Lithography (DPL)}

DPL operates by lowering a small tip similar to that of an AFM tip into a reservoir of liquid, or silver ink in this case. The tip is then retracted and moved above the desired printing area of the substrate. The tip is then lowered to the substrate to perform printing via the removal of the ink from the tip by adhesive forces between the ink and substrate surface (43) (37). This type of printing offers the ability to create a desired pattern such as dots, lines, connected patterns, circuitry, and 3dimensional structures. Furthermore, the advantage is the ability to deposit inks in precise substrate surface locations. Less waste is created and there is no need to employ harmful chemicals such as photoresists. 
Difficulties arise when using low viscosity inks coupled high solvent evaporation rates due to the ink reservoir being exposed to open air. This caused a significant reduction in operation time because of the quick drying of the ink in the reservoir before it can be used for deposition and patterning.

Furthermore, low viscosity inks that exhibit low adhesion with the substrate tend to have difficulties when patterning. This is especially true when attempting to form line patterns. Typically during line formation, an ink droplet is placed on the substrate surface and then pulled to extend it into a line. A lack of adhesion or low viscosity results in the droplet having a tendency to roll instead of spreading.

\subsection{Thermal Processing and Resistivity Testing}

\subsubsection{Curing of Silver Ink}

All thermal processing of the silver organic was performed using an Isotemp hot plate (Fisher Scientific) as shown in Figure 23 in an exhaust hood. This curing process was used regardless of what substrate, glass or PEN, the ink was deposited on. Similar exposure times were experienced per substrate, although longer for experiments done which required thick coatings or tracks. Also, when curing thicker tracks or patterns on PEN, curing was conducted in intervals to prevent thermal shrinkage of the polymer substrate due to lengthy exposure time at high temperature. 


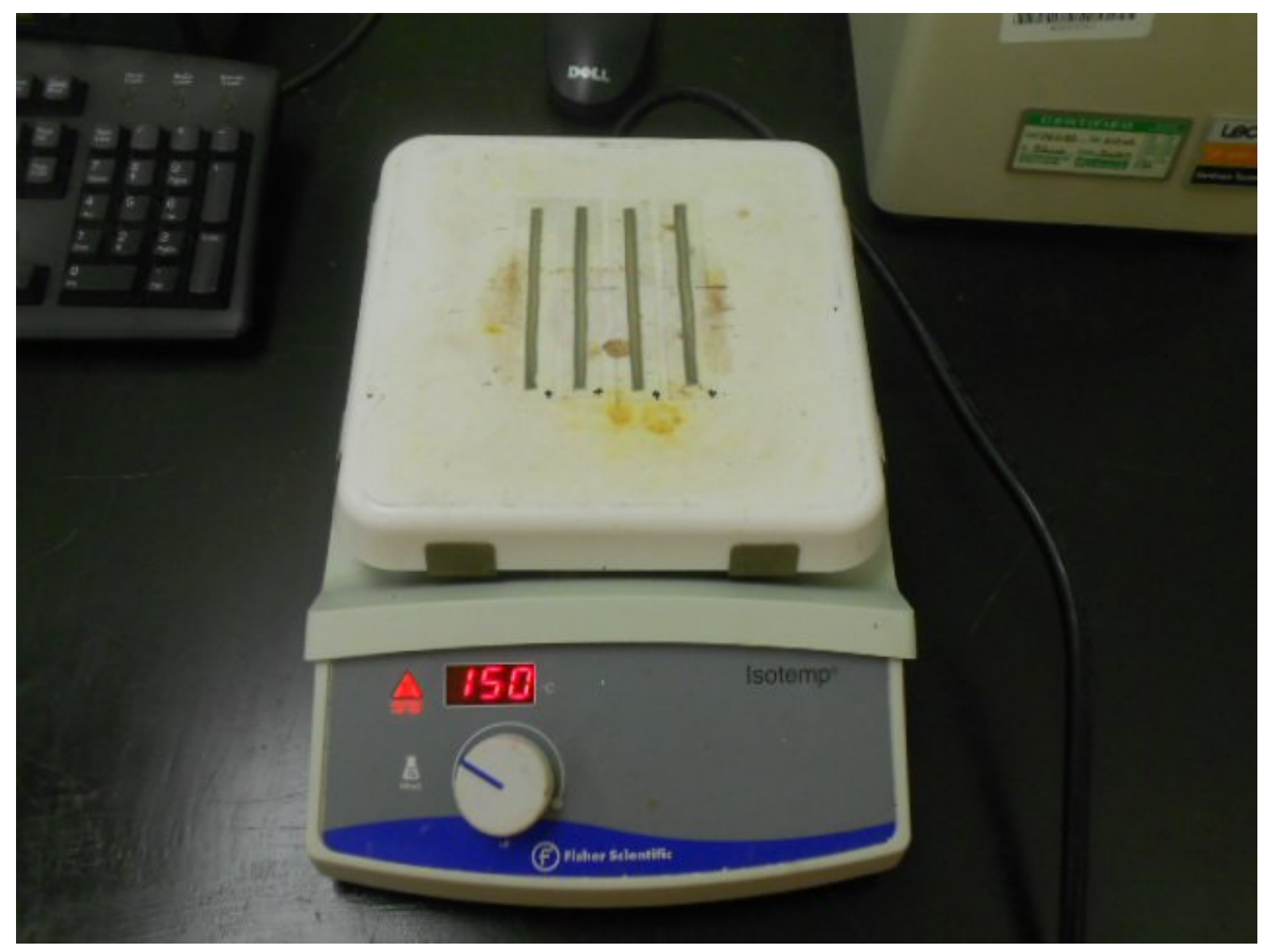

Figure 23 - A hotplate was used for all thermal processing of samples.

\subsubsection{Resistivity Testing of Cured Silver Ink}

\section{Determination of Curing Regime}

The silver octanoate ink was deposited onto glass microscope slides using the spray masking technique. The mask material was a plastic-based adhesive tape similar to that of packaging tape. The masks were cut into a uniform shape to be placed onto the glass slides leaving a rectangular shape of consistent dimensions $(2 \mathrm{~mm} \times 65 \mathrm{~mm})$. The deposited tracks were dried in a vacuum hood until the tracks turned white in color. The masks were then removed. The dried samples were then placed on a 
hotplate for curing and subsequent removal of organic material via the decomposition of organic surfactants resulting in the metallization of the silver particles of the ink. The curing study was done following the regime in Table 4.

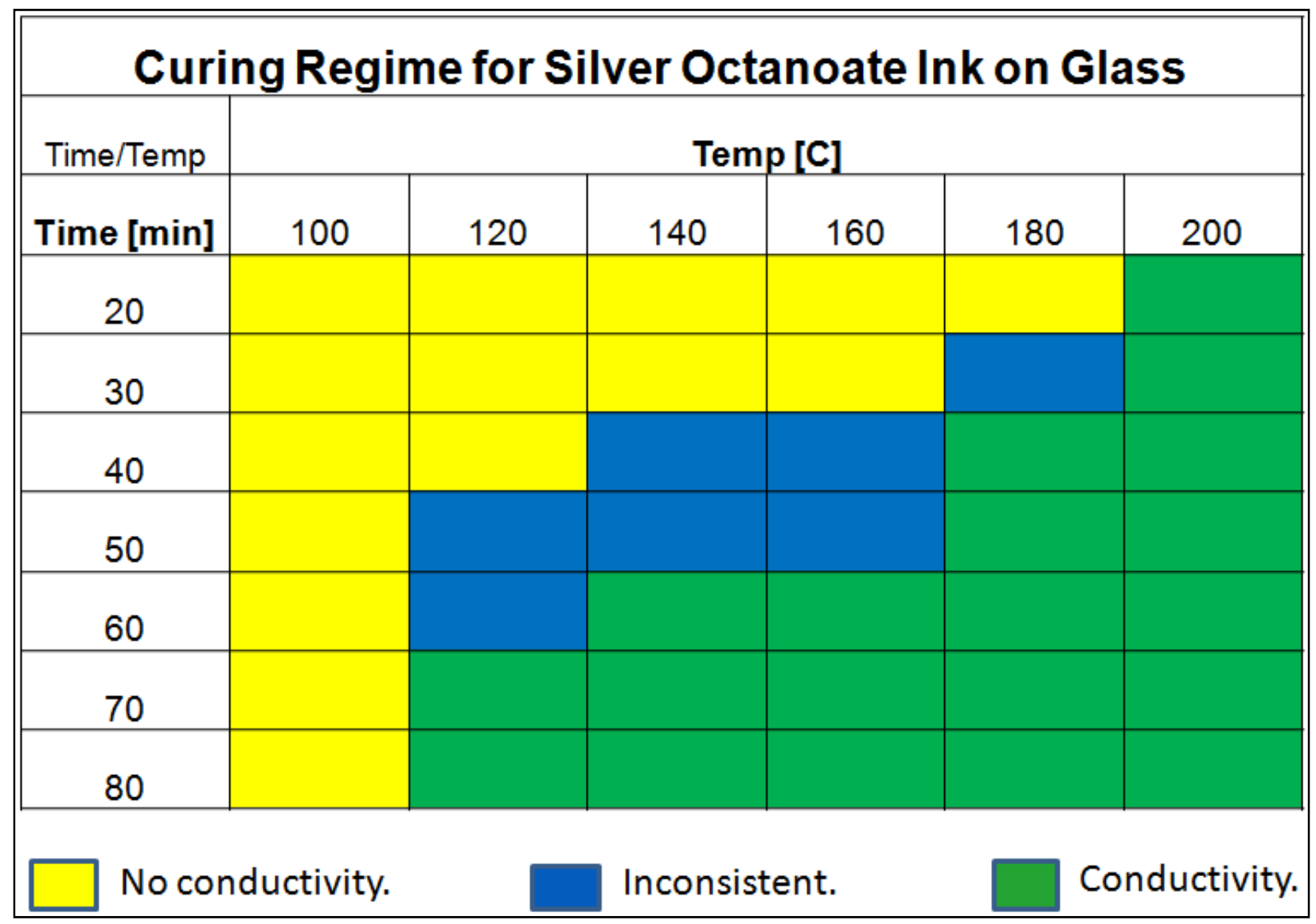

Table 4 - Temperature and time trial parameters of the curing regime used for silver octanoate ink on glass substrate.

Temperatures and exposure times resulted in various states of curing. Yellow indicates curing times and temperatures that resulted in no conductivity. Blue indicates curing with inconsistent results. Green indicates curing temperatures and times that resulted in desirable conductivity. These results are dependent on thickness of the Ag coating. The above curing regime was based on a coating thickness of approximately $2 \mu \mathrm{m}$. 
Surface Porosity Analysis of Cured Silver Ink

Surface porosity was measured using image analysis software (ImageJ) on optical microscopy images and SEM micrographs. The curing was performed at similar temperatures and exposure times as in the curing regime shown in Table 4 . Surface porosity (\%P) observed a decreasing trend with an increase in exposure time at various temperatures as shown in Figure 24.

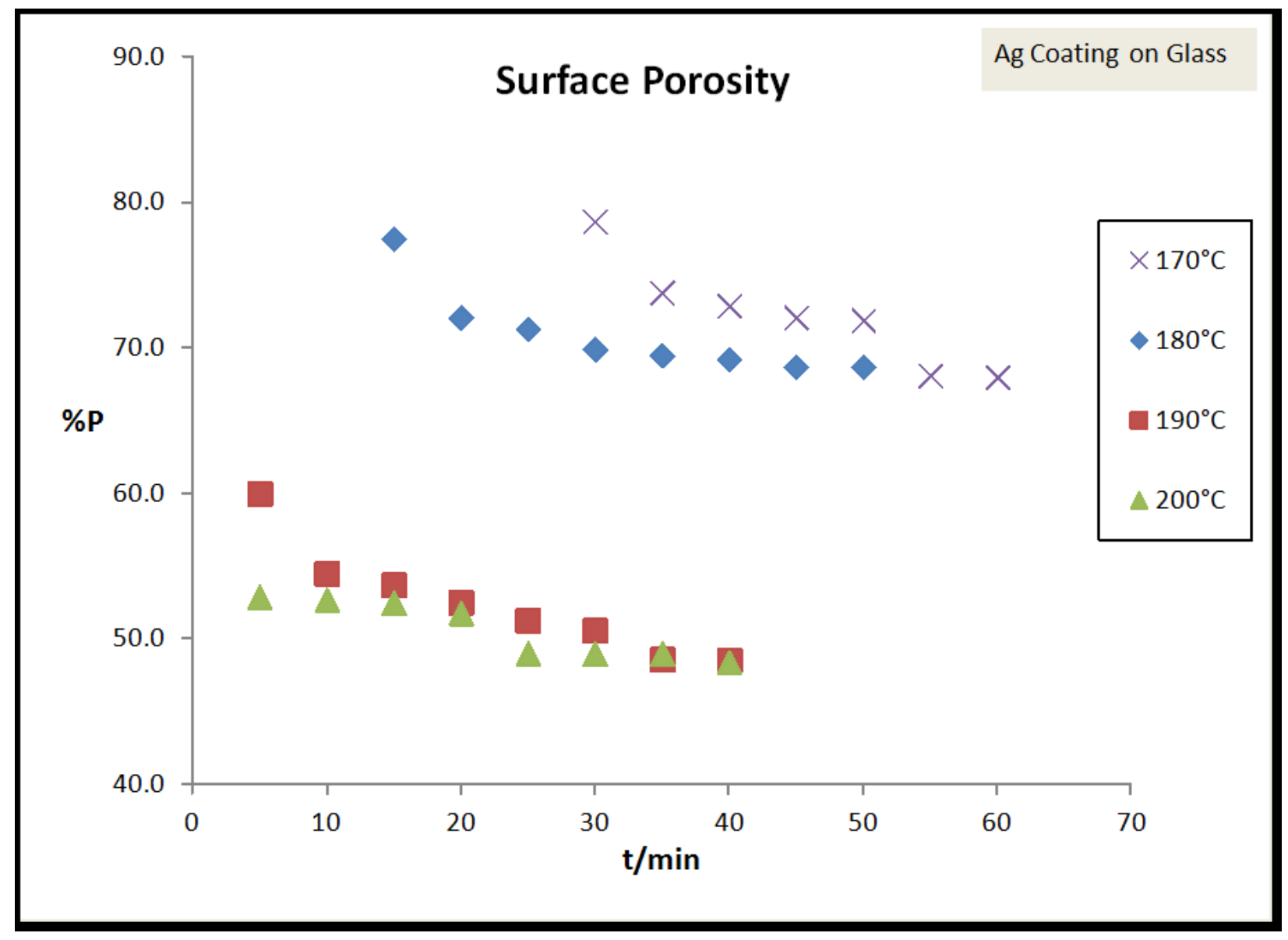

Figure 24 - Surface porosity trends approach a maximum reduction in surface porosity even with extended thermal exposure time at curing temperature.

It is noticed at respective temperatures that there is a similar 'flattening out' of the measured surface porosity trends towards longer exposure times. This suggests that even with extended exposure time 
that there is a limitation to the reduction in surface porosity. This may come as a result of the respective temperature experiencing a limitation in the removal of a certain amount of the organic surfactants of the ink through thermal decomposition.

\section{Resistivity Analysis of Cured Tracks}

Resistivity measurements of the cured tracks as done in adherence to the above curing regime was found using the well known relation $\rho=\mathrm{RAL}^{-1}$. Surface profiles were conducted using a Vecco Dektak 150 surface profiler as shown in Figure 25 to attain the profile scan of the cross-section of the tracks. The cross-sectional area was used in conjunction with the measured length of the track and the related measured resistance of each cured track across the length of the track given the temperature/time point of the aforementioned curing regime to calculate the resistivity. This was used to quantify which curing temperature/time gives the lowest resulting resistivity. This was then tried on the PEN substrate given the same curing regime without compromising the desirable mechanical characteristics of the substrate. 


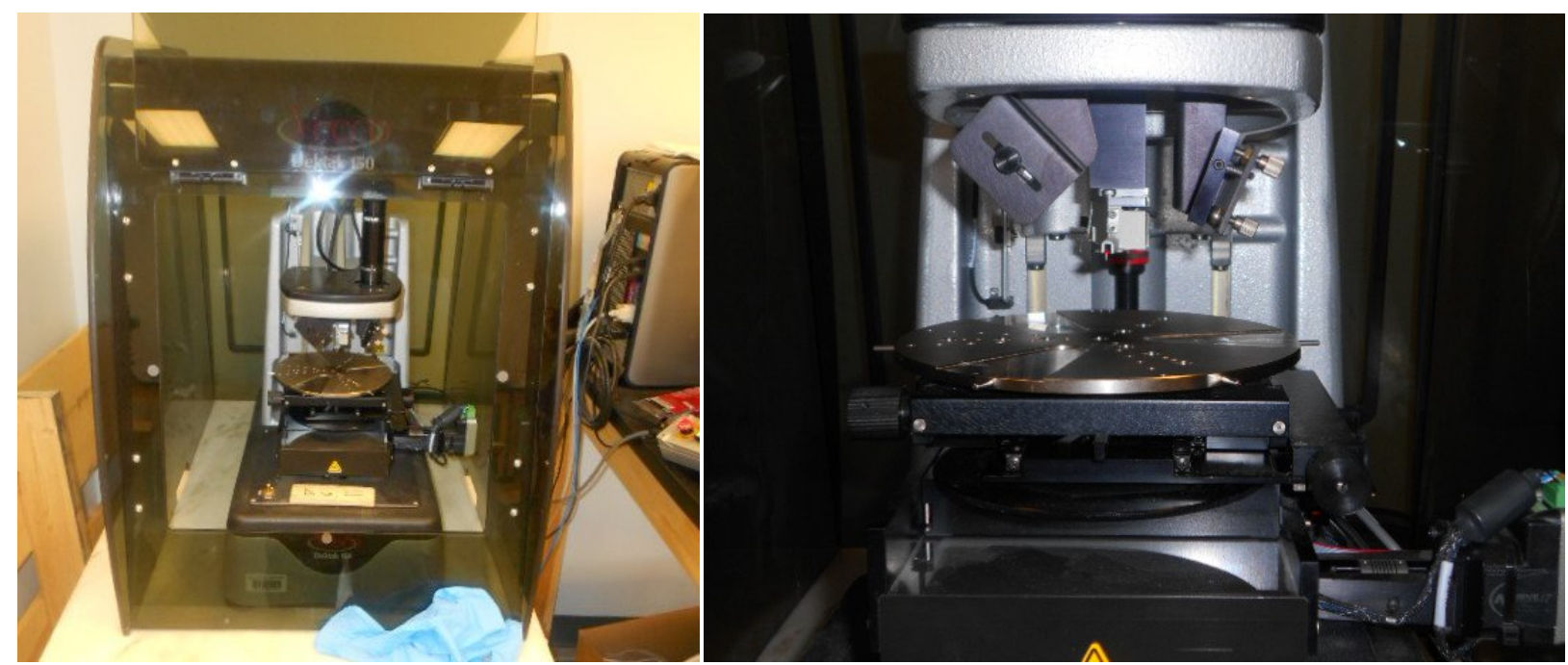

Figure 25 - Vecco Dektak 150 surface profiler used to measure cross-sectional area of track profiles. Enhanced image of profile stylus tip and leveling stage (right).

There is a previous lack of literature on the particular Ag-octanoate precipitate formula used in this work which results in an inability to compare scan data for the Ag-octanoate powder. However, XRD was used as a means of attaining a reference point for the Ag-octanoate precipitate powder prior to ink formulation, deposition, and curing. This allowed for later comparisons when determining the thermal decomposition of the organic surfactants within the ink post-thermal processing and the full removal thereof. Furthermore, this acted as a post-thermal processing check for the existence of solely Ag as shown in Figure 26. It is observed that all standard phase peaks (111), (200), (220), (311), (222) for $\mathrm{Ag}$ are evident proving the synthesis of $\mathrm{Ag}$ from the aforementioned chemical process. 


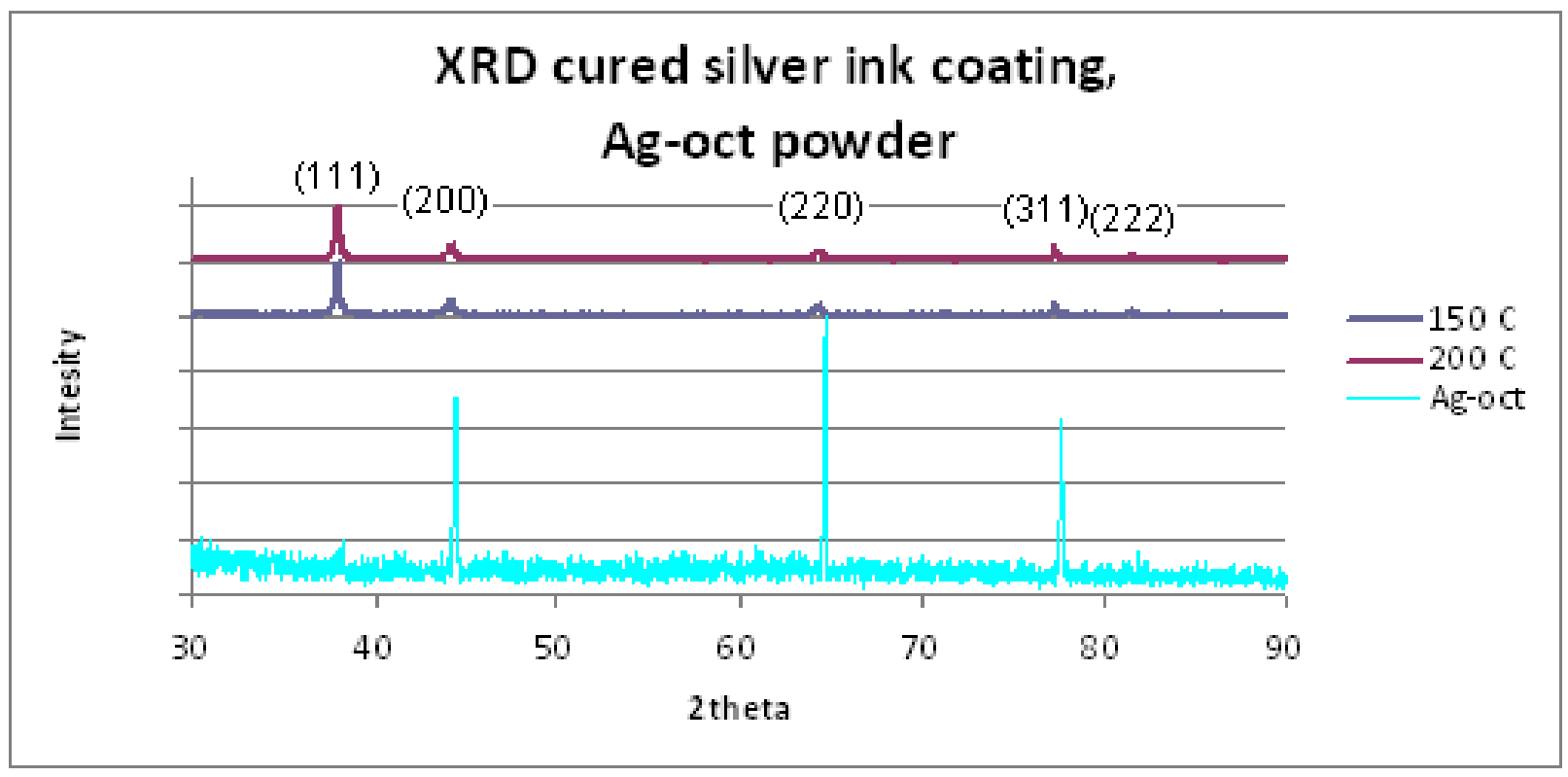

Figure 26 - X-ray diffraction analysis of Ag-octanoate precipitate powder prior to ink formulation, and scan data of the $\mathrm{Ag}$ ink cured at temperatures of 150 and $200^{\circ} \mathrm{C}$ depicting the complete removal of organic material via thermal processing resulting in the existence of solely $\mathrm{Ag}$.

XRD was done to investigate what temperatures would result in complete curing of samples within an exposure time less than 80 minutes. It was desirable, however, to achieve curing of samples at times less than 30 minutes to avoid degradation of the mechanical functionality and surface properties of the PEN substrate. XRD scans in Figure 27 were completed for extents of the curing regime, 150 and $200^{\circ} \mathrm{C}$, with the assumption that all temperatures in between would ultimately result in fully cured samples as well. Also, temperatures below that of $150^{\circ} \mathrm{C}$ resulted curing of the $\mathrm{Ag}$ ink. 


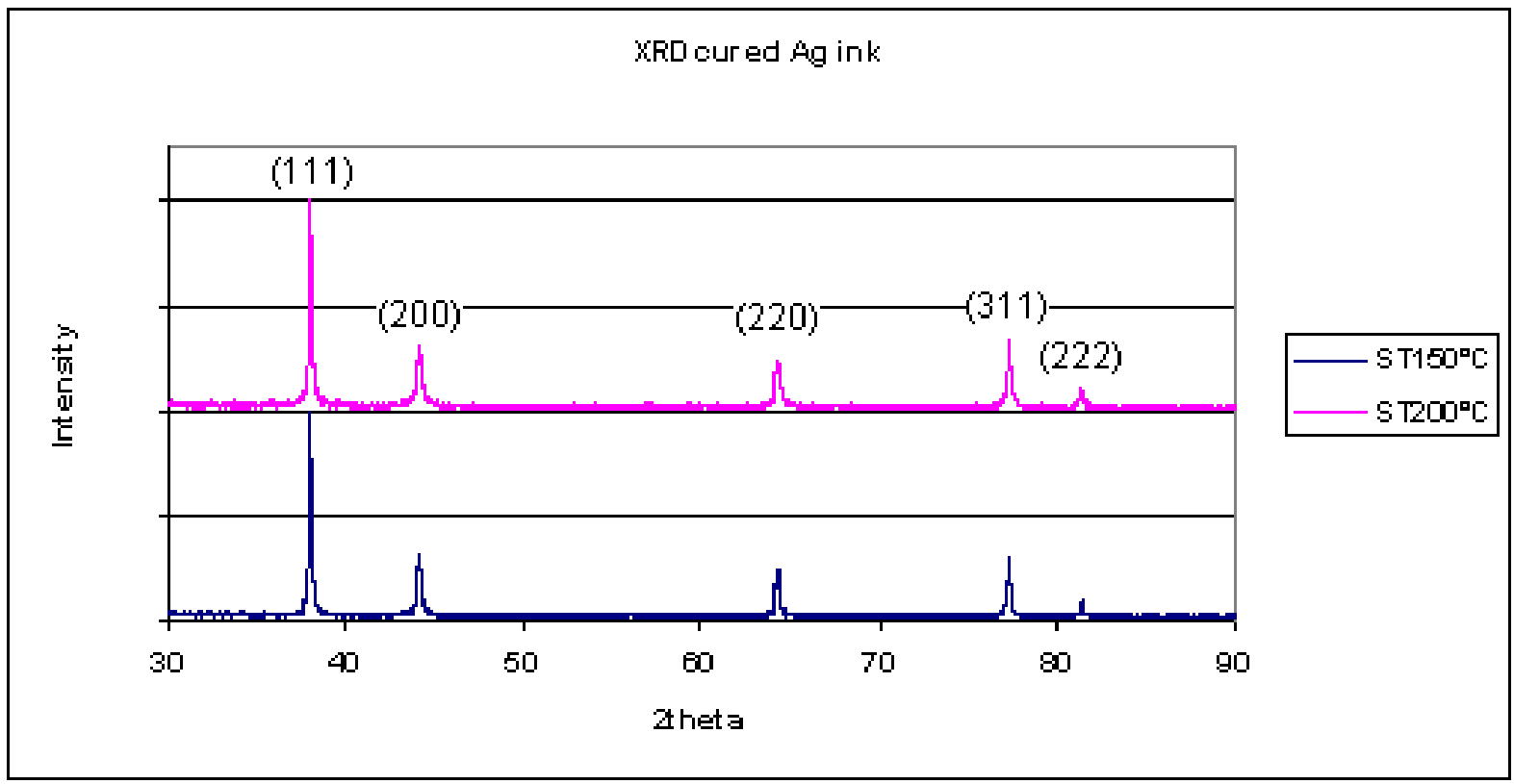

Figure 27 - XRD scan data for Ag ink coatings showing the attainability of fully cured samples at temperatures at/between 150 and $200^{\circ} \mathrm{C}$.

It can be seen in the above XRD scan results that phase peaks of Ag are evident. This proves the formation of Ag using the chemical process of this research. Furthermore, it satisfies that temperatures used in the curing regime will result in Ag if given sufficient exposure time during thermal processing.

\subsection{Electromechanical Testing}

It is necessary to perform mechanical testing on plain PEN substrate and also PEN substrate with cured silver tracks. This acts to determine the effect of the curing of the tracks on the mechanical properties of the PEN substrate. It is likely that extended exposure to heat during thermal processing of the deposited tracks will prove detrimental to the strain toleration and mechanical robustness of the PEN substrate. Furthermore, this acts as a means of further refining the curing regime to offer cured samples with best mechanical properties and lowest possible resistivity. Also, mechanical testing offers a means of testing the adhesion of the ink to the PEN substrate. More importantly, it offers insight as to 
the type of failure mechanisms noticed from straining during mechanical testing in terms of adhesion of the cured ink to the substrate.

Electromechanical testing involved tensile testing and cyclic fatigue bending testing. Tensile testing was performed to determine strain toleration and failure strain of the substrate with cured tracks. Bending testing was done cyclically using mandrels of diameter coinciding with strains at or below those seen for failure of the PEN samples during monotonic tensile testing. The mandrel chosen offered a strain of $\sim 0.6 \%$ given the thickness of the PEN substrate to be $125 \mu \mathrm{m}$. Because the PEN substrate thickness is substantially thicker than the coating thickness, the PEN substrate is dominant and thus the contribution of the coating to the total strain is considered negligible.

\subsubsection{Tensile Testing}

Tensile testing was performed using an Instron 4411 tensile testing machine shown in Figure 28 was to determine the electromechanical behavior of the cured tracks on the PEN substrate. Tensile testing was conducted at a cross-head speed of $1 \mathrm{~mm} / \mathrm{min}$ until failure. Because the PEN is heatstabilized, the unexposed samples should perform similar in comparison to later samples that have been introduced to ink deposition and curing. Knowing the failure strain of the unexposed PEN samples acts as a basis of comparison for the performance of those PEN samples exposed to thermal processing and curing. PEN samples were cut atop a thick glass base using standard razor blades into a rectangular shape of dimensions $12 \mathrm{~mm} \times 70 \mathrm{~mm}$. Due to the rectangular sample shape used for silver track application, average failure strain (50\%) of unheated PEN had a relatively large standard deviation of $\pm 16 \%$. Similarly, heated PEN samples saw an average failure strain of $40 \%$. Samples heated in timed cycles to avoid thermal shrinkage of PEN seen at $150^{\circ} \mathrm{C}$ for $30 \mathrm{~min}$. or $200^{\circ} \mathrm{C}$ for $10 \mathrm{~min}$. showed 
somewhat better strain performance. Comparatively, it can be said that PEN still exhibits mechanical functionality after thermal processing and minimal loss in failure strain. This is observed as a similarity in performance between unexposed and exposed PEN samples.

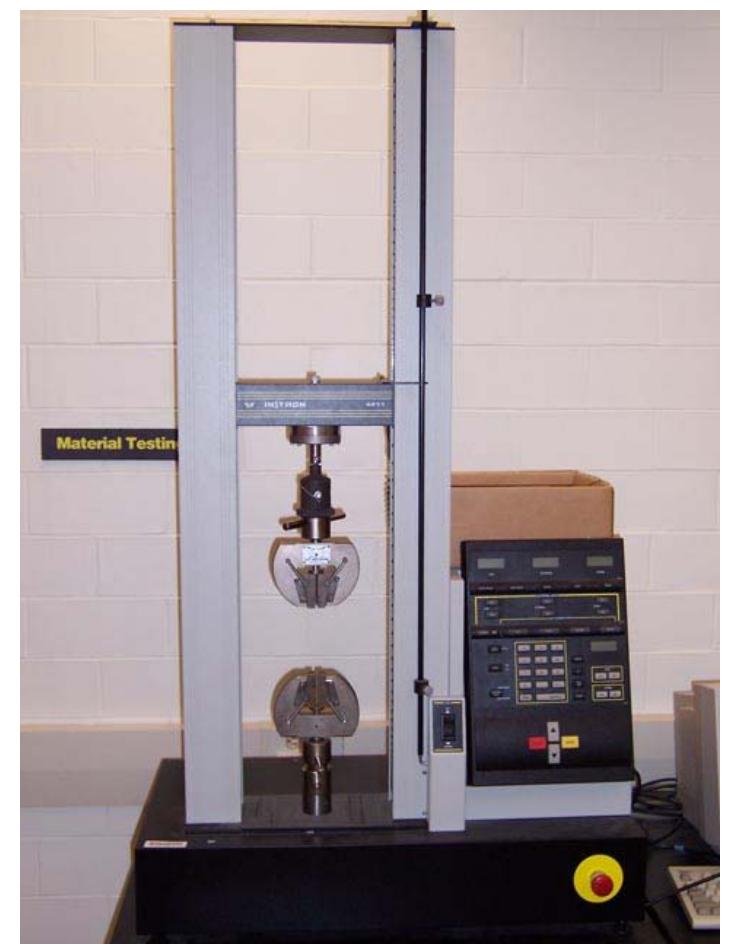

Figure 28 - Tensile testing of cured samples on PEN substrate were performed using Instron $\mathbf{4 4 1 1}$ tensile testing machine.

Electrical function of the cured track samples was measured using a Datalogger electrical resistance tracker. The change in resistance of the track was measured in relation to the change in strain of the sample. This gave useful data in terms of relating how effective the silver ink is keeping its ability to carry current when exposed to straining as would be seen in optoelectronic applications such as touch screens, liquid crystalline displays, and solar panels. This testing should show a trend with the change in resistance exhibiting a substantial increase past the point where the cured PEN sample fails. 


\subsubsection{Cyclic Fatigue Testing}

Mandrel fatigue testing was used to test the electrical response of the cured tracks on the PEN substrate to cyclic straining. The tracks were placed face down on the mandrel face to test adhesion and failure thereof via buckling or delamination. This was done with cyclic testing at a rate of 2 cycles/second using a $19.68 \mathrm{~mm}$ diameter mandrel. The mandrel was chosen to offer a strain on the cured PEN sample that is below the failure strain of the tensile tested PEN samples. The mandrel size chosen offered a strain of $0.6 \%$ which acts as a representative strain of everyday use and exposure to environments incident on optoelectronic devices. Cyclic testing offers a means of determining the lifetime of a particular track in terms of how long it will offer resistance and carrying of charge before noticing failure. This model is used as a means to determine the fatigue of a cured sample over a given number of particular strain cycles. Because the thickness of the PEN substrate is substantially thicker than the thickness of the Ag coating, the substrate is considered dominant thus and the contribution of the Ag coating thickness to the total strain is negligible.

\subsection{Mechanical Testing}

Mechanical testing was performed on the cured ink to investigate the effect of thermal processing on the electromechanical functionality of the Ag coatings. This is beneficial in helping to determine which parameters including curing temperature not only optimize the mechanical functionality of the cured coatings in relation to strain toleration, but also the electrical properties of the Ag tracks. 


\subsubsection{Nanoindentation Testing}

Nanoindentation analysis of the Ag coatings was performed using nanoindenter (CSM Instruments) with a Berkovich diamond tip. Indentations were applied with a force of $0.5 \mathrm{mN}$ with an approach speed of $3000 \mathrm{~nm} / \mathrm{min}$. Indentations were performed under the following protocol: 30 second indentation, 10 second pause, 30 second extraction. The pause phase of the indentation process is used to eliminate elastic behavior of the coating and contribution by surface porosity, and to acquire an accurate measurement. The samples used were spray masked Ag coatings of thickness $\sim 2 \mu \mathrm{m}$ on glass microscope slides. The samples were cured at temperatures of $160,170,180,190$, and $200^{\circ} \mathrm{C}$.

It was desirable to obtain indentations with a penetration depth into the coating of less than $10 \%$ the Ag coating thickness. This ensures that data does not reflect any effect of the base substrate, and solely that of the Ag coating. Higher curing temperatures resulted in more uniform surface morphologies and thus, more ease in attaining consistent indentation data.

Nanoindentation was performed to investigate the effect of curing temperature on the hardness of the Ag coatings. It was believed that there would be an increase in hardness given complete curing at higher curing temperatures. Furthermore, surface porosity was related to the respective measured mechanical properties to suggest a possible effect and relation of surface microstructure. For each temperature, multiple indentations were performed.

\subsubsection{Nanoscratch Testing}

Scratch testing was performed using a nanoscratch tester (CSM Instruments) with spheroconical or Rockwell diamond tip of $10 \mu \mathrm{m}$ radius. Samples were coated with Ag ink using the spray masking technique on glass microscope slides. Samples were fully cured at temperatures of 150, 160, 
$170,180,190$, and $200^{\circ} \mathrm{C}$. Thermal processing resulted in a final coating thickness of $\sim 2 \mu \mathrm{m}$. Scratch testing was done to measure the failure critical load ( $F C L)$ of the $A g$ coating. Additionally, scratch testing can be used to investigate the related failure mechanisms of the cured ink coating on a substrate and how curing temperature affected the subsequent adhesion. Scratching was performed using a linearly progressive loading starting with $0.3 \mathrm{mN}$ and loading rate $19.7 \mathrm{mN} / \mathrm{min}$ with a scan speed of 1.0 $\mathrm{mm} / \mathrm{min}$. This testing gave insight into how to optimize both electrical operation in relation to conductance and mechanical functionality in relation to environmental effects or manual use, as affected by curing temperature. Surface porosity was compared to the measured FCL of the Ag coating to suggest a relation of surface microstructure to the observed failure mechanisms and mechanical properties.

\subsection{Contact Angle Analysis}

Deposited ink adhesion is analyzed by measuring the contact angle formed by the ink and the substrate material. To make a comparison, contact angle analysis was performed on both glass and PEN substrates. Because the PEN has one side that is engineered for adhesion, it was desirable to compare contact angle measurements via drop analysis on both substrates using a well-known medium such as water. Contact angle analysis using the ink followed to analyze the adhesion of the ink to both substrates as well.

Drop analysis was performed using a digital microscope imaging system in coordination with ImageJ software. 3-5 drops of water or ink were dropped onto either glass or PEN substrate. The digital microscope was placed perpendicular to the substrate surface to capture the cross-section profile of the drop. Drop analysis software was used to calculate the contact angle of the respective liquid media on 
each substrate. Drop analysis was done with water and silver ink on both glass and PEN, see Figure 29 and Figure 30.

\subsubsection{Water vs. Ink}

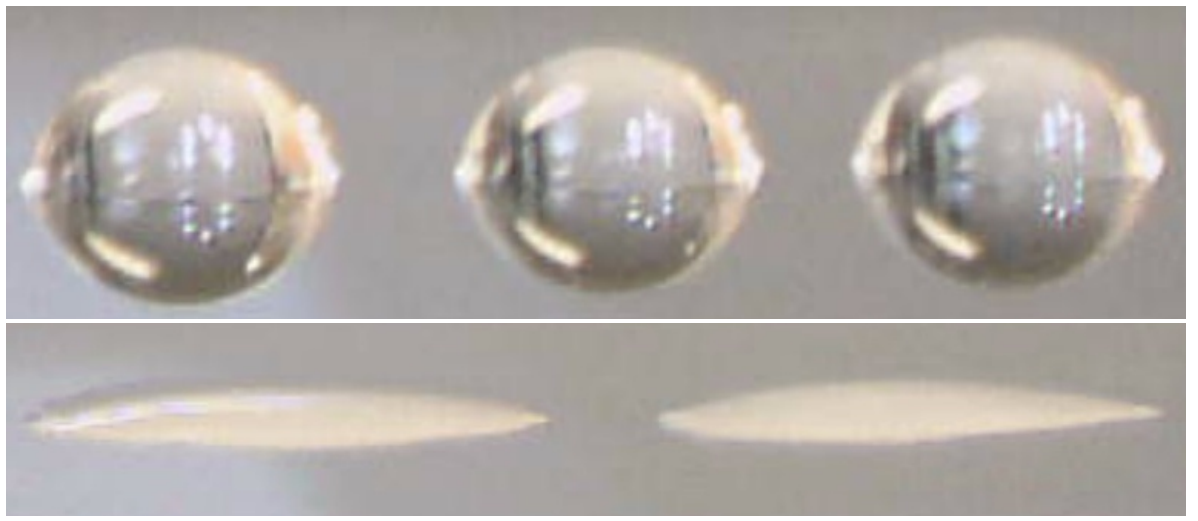

Figure 29 - Adhesion of Ag ink (bottom) to PEN substrate having contact angle of $<17^{\circ}$ is compared via drop analysis to that of deionized water (top) on PEN substrate having contact angle of $\sim 64^{\circ}$.

The wetting of the PEN substrate can be seen in Figure 29. For comparison purposes, drop analysis was performed on the PEN substrate using both deionized water and the Ag ink. In the top image, the deionized water has a noticeably higher contact angle formed between the droplet and PEN substrate surface in comparison to the contact angle formed between the ink and the same PEN substrate in the bottom image. This suggests the Ag ink has a higher adhesion to the PEN substrate characterized by a contact angle of $\sim 16^{\circ}$ as compared to the contact angle of water of $\sim 51^{\circ}$. 


\subsubsection{Glass vs. PEN}

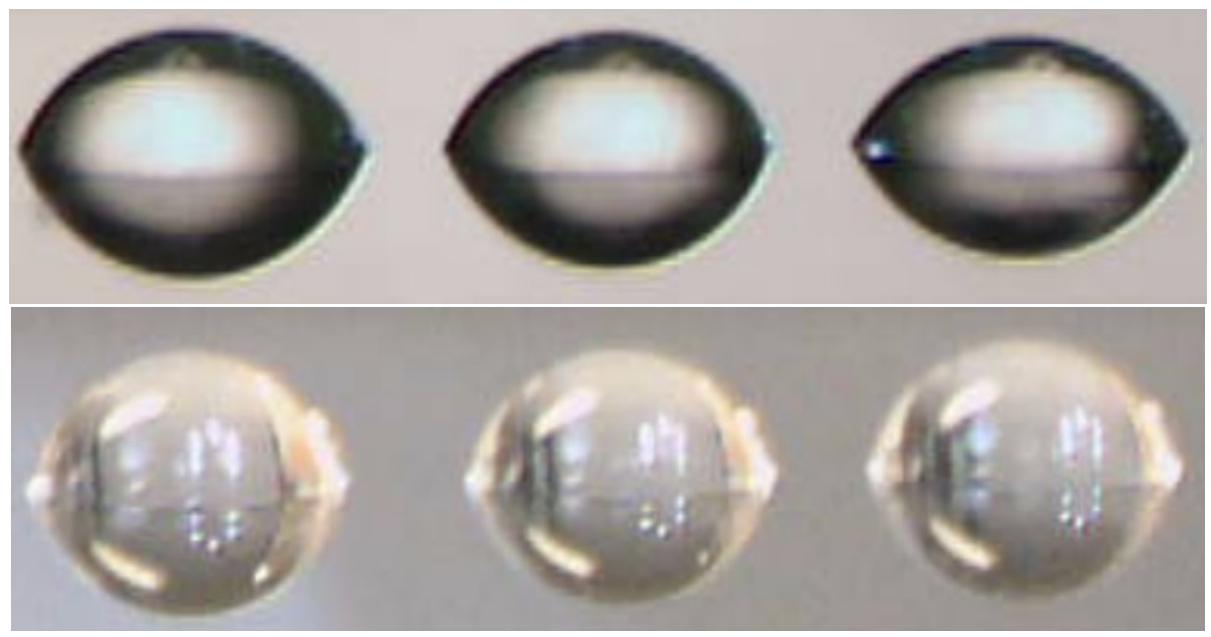

Figure 30- Drop analysis of deionized water on comparison substrates. PEN substrate (bottom image) is coated for adhesion showing lower contact angle as compared to glass substrate (top image).

As a means of characterizing the adhesion of the PEN substrate, drop analysis was performed with deionized water on both the PEN substrate and plain glass microscope slides as shown in Figure 30. In the top image, water droplets formed a contact angle of $\sim 70^{\circ}$ with the glass substrate surface. Comparatively in the bottom image, water droplets formed a contact angle of $\sim 51^{\circ}$ with the glass suggesting the PEN substrate offering better adhesion.

\subsection{Surface Porosity}

Surface porosity was investigated using image analysis software (ImageJ). Image analysis was performed on both optical microscopy images and SEM micrographs. Percent surface porosity (\%P) was related to electrical, mechanical, and electromechanical properties and performance of the silver ink and the respective hybrid flexible structures. 


\section{RESULTS AND DISCUSSION}

\subsection{Resistivity of Cured Ag Tracks}

The lowest resistivity showed a value greater than $5 \%$ that of bulk silver $\left(1.59 \times 10^{-8} \Omega \cdot \mathrm{m}\right)$.

Resistivity values ranged from $4.13 \times 10^{-6} \Omega \cdot \mathrm{m}$ down to $3.01 \times 10^{-7} \Omega \cdot \mathrm{m}$ at temperatures of 160 and $180^{\circ} \mathrm{C}$, respectively. The resistivity trends can be seen in Figure 31 and Figure 32 showing exposure times used for curing at various temperatures. As drastic drop in resistivity is observed when curing samples at temperatures above $160^{\circ} \mathrm{C}$.

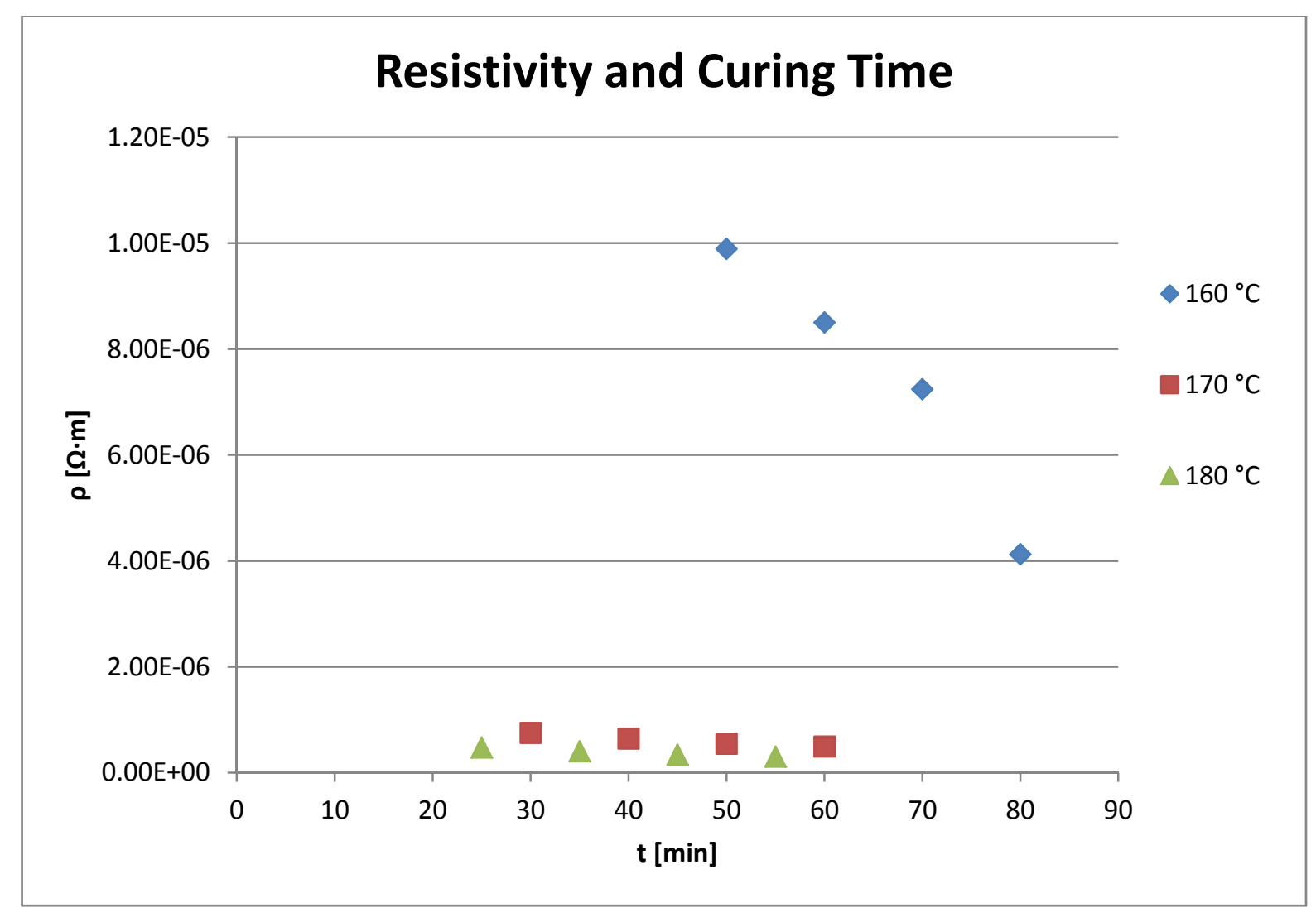

Figure 31 - Resistivity trends shown for curing of spray masked samples at temperatures of 160,170, and $180^{\circ} \mathrm{C}$. It is noticed that optimal curing for shorter exposure time occurs at temperatures above $160^{\circ} \mathrm{C}$. 


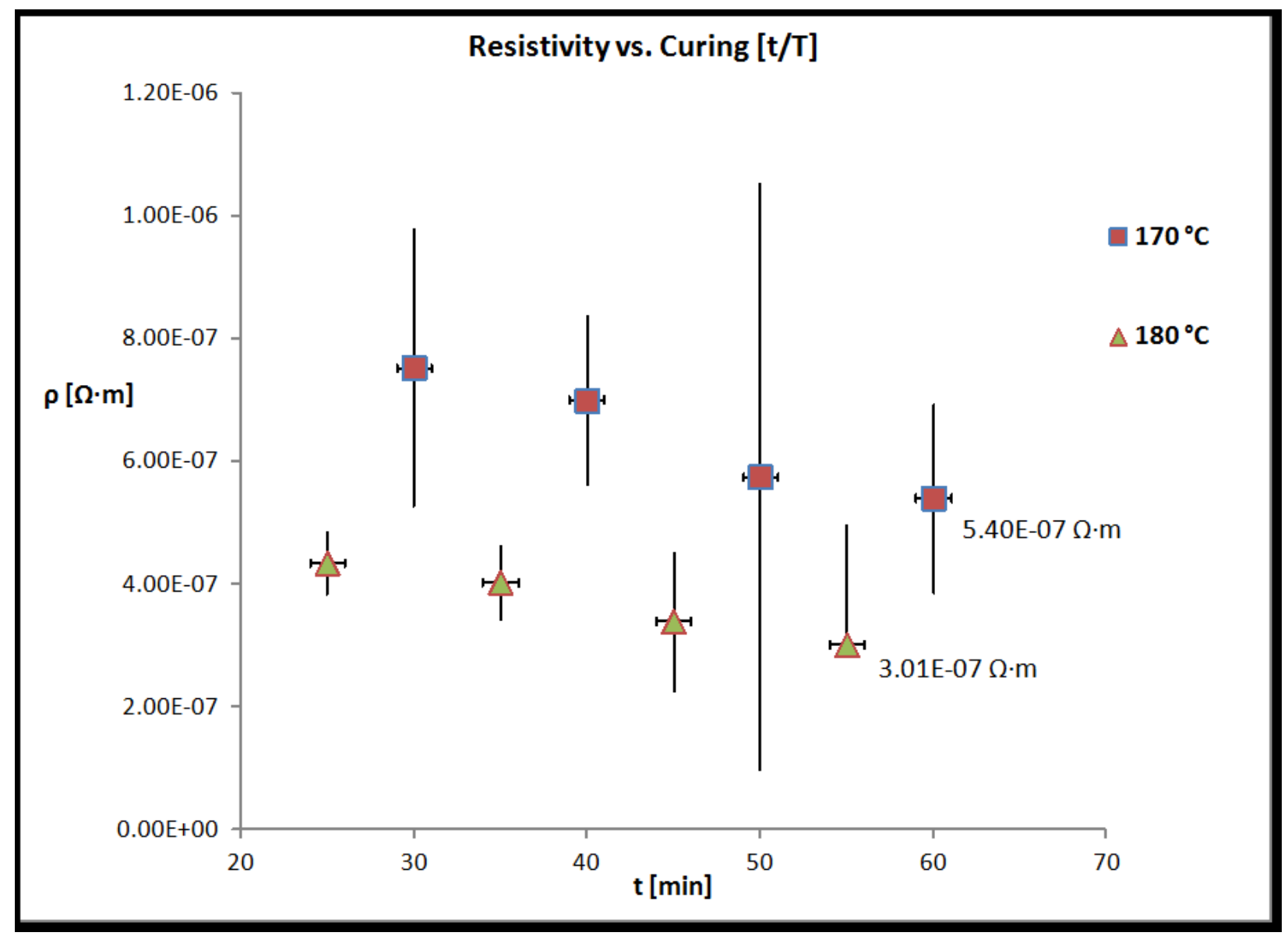

Figure 32 - Average resistivity values for curing temperatures of 170 and $180^{\circ} \mathrm{C}$ exhibited desirable resistivities around $5 \%$ that of bulk silver.

Further investigation of the resistivity trends at curing temperatures of 170 and $180^{\circ} \mathrm{C}$ shows similar behavior between the two as seen in Figure 32. Desirable resistivities were measured at $5.40 \times 10^{-7}$ and $3.01 \times 10^{-7} \Omega \cdot \mathrm{m}$ in respect to the aforementioned temperatures. The latter equates to a resistivity around $5 \%$ that of bulk silver. Considering the difference in measured resistivity between the two temperatures, it can be suggested that even lower resistivities could be achieved at higher curing temperatures such as 190 and $200^{\circ} \mathrm{C}$. 


\section{Characterization of Cured Tracks}

Optical microscopy and SEM analysis were used to investigate surface microstructure and morphology of cured tracks on both glass and PEN substrates to both determine the removal of majority of organic material from silver octanoate composition of ink and final composition of cured ink, and to analyze the curing procedure of tracks. SEM imaging and optical microscopy illustrate the $\mathrm{Ag}$ track surface after thermal processing in Figure 33 and Figure 34, respectively.

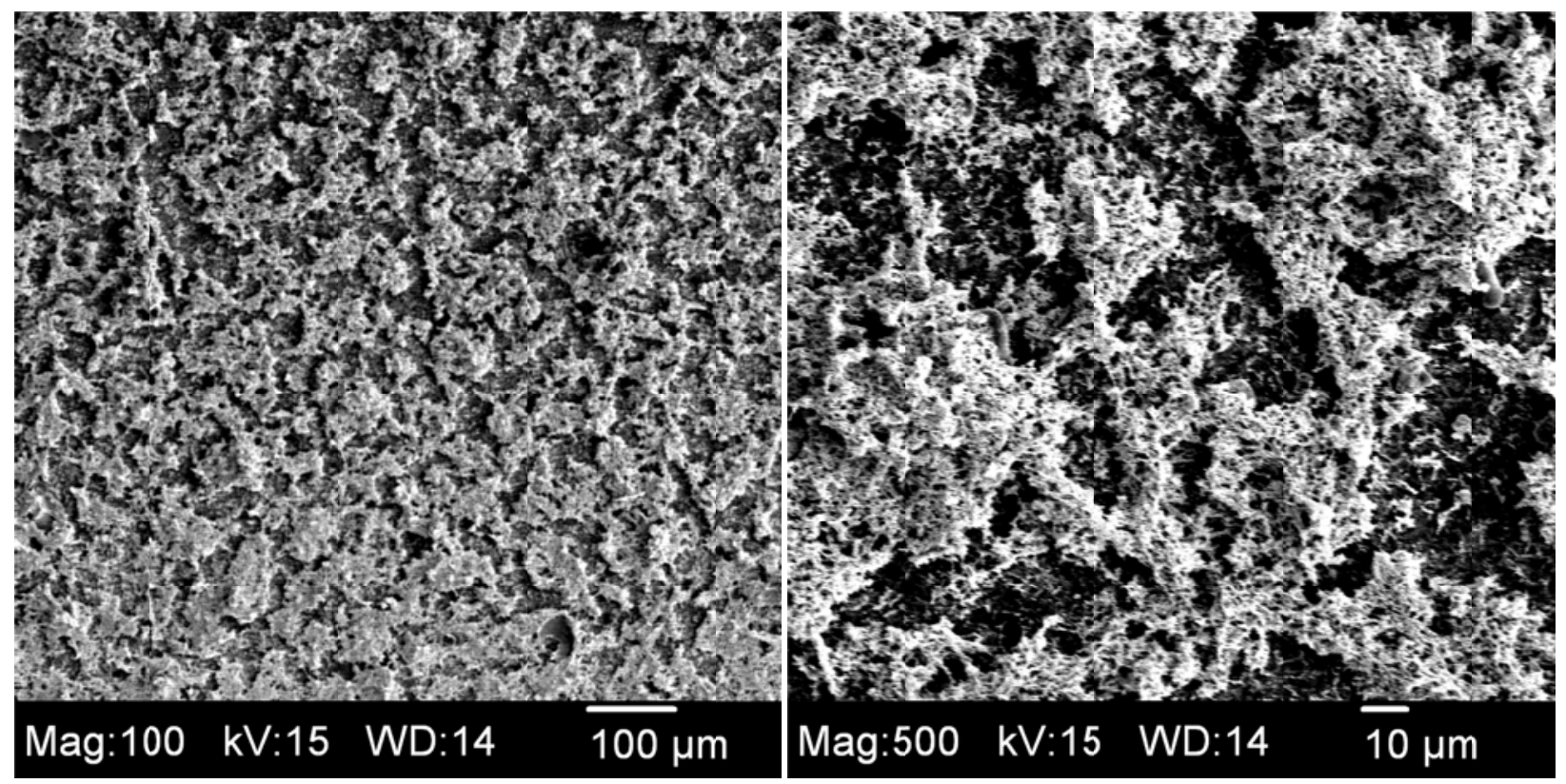

Figure 33 - SEM micrographs at different magnification showing surface microstructure with high surface porosity cured at $180^{\circ} \mathrm{C}$ for 40 min on PEN. Connected structures spanning voids likely act as percolation pathways for carrying current across silver tracks.

The SEM micrographs of different magnification shown in Figure 33 illustrate a very uniform porous surface microstructure as a result of curing. At higher magnification, it can be seen that the surface microstructure can be characterized by the existence of elevated connected structures. The connected structures likely act as percolation pathways allowing conductivity to span the length of the track. 


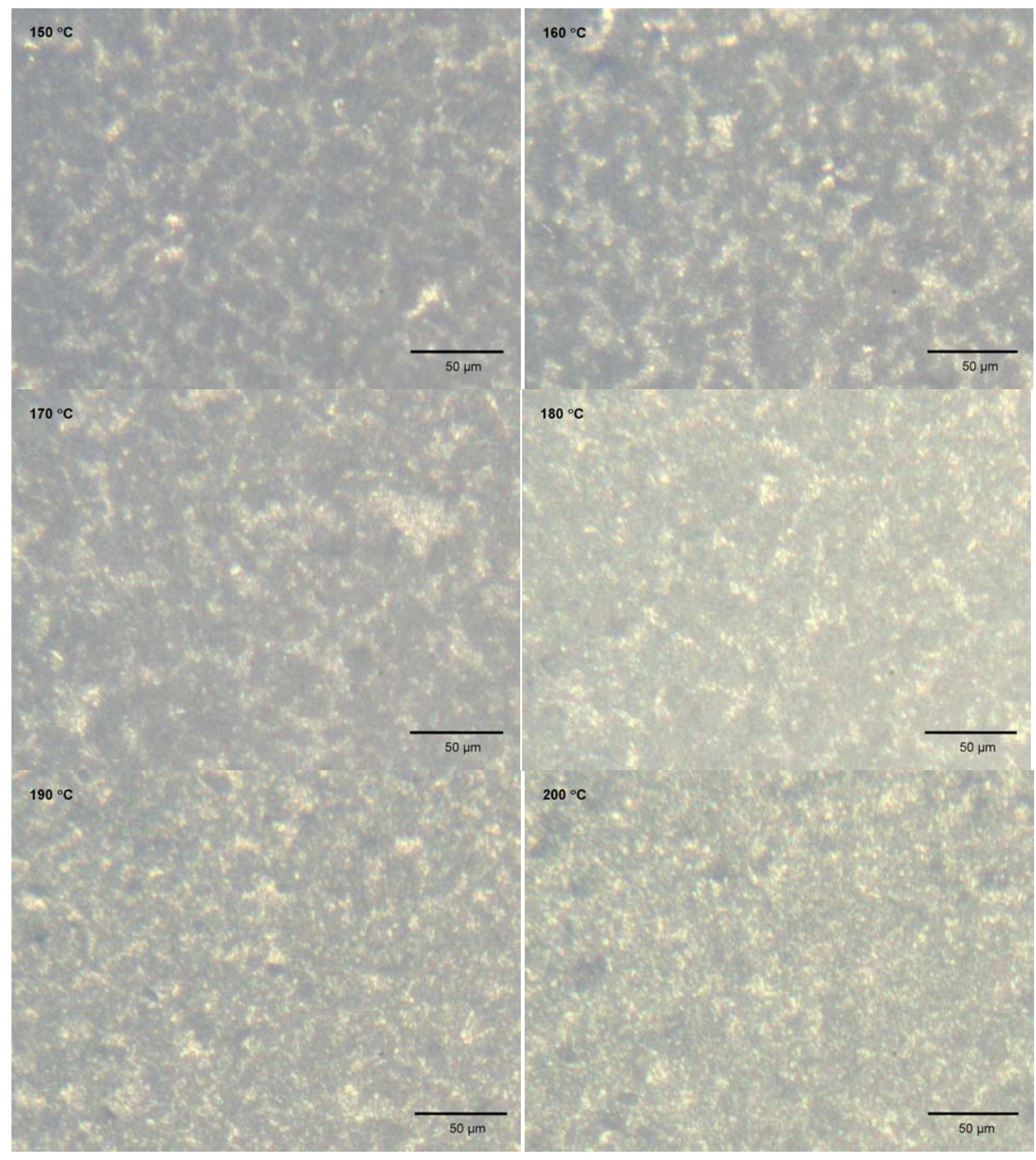

Figure 34 - Optical microscopy images of cured spray masked silver tracks on PEN showing a progressive decrease in surface dissimilarities and gained uniformity when approaching higher curing temperatures. 
In Figure 34, a similarity in surface uniformity can be seen in the optical microscopy images of samples cured with sufficient exposure times at temperatures $150-200^{\circ} \mathrm{C}$. This suggests that similar surface porosity and surface microstructure can be obtained at multiple curing temperatures, given adequate thermal exposure time. This is reflected in the relatively small decrease in percent surface porosity of $7.7 \%$ that is observed over the range of curing temperatures from 150 to $200^{\circ} \mathrm{C}$ as shown in Figure 35 . Comparatively, though, it is noticed at lower curing temperatures there exists larger, more frequent surface dissimilarities characterized by noticeably brighter localized regions or spots in comparison to the surrounding areas having a more dull and patterned appearance. This may be explained by higher curing temperatures resulting in the removal of higher amounts of residual organic components of the ink such as carbon that lower temperatures cannot. Furthermore, this suggests there might be differences in the packing density of particles after thermal processing at different temperatures. Also, the particle packing density and surface porosity could relate to the measured resistivity of the cured track given the associated curing temperature as shown in Figure 36 and Figure 37. 


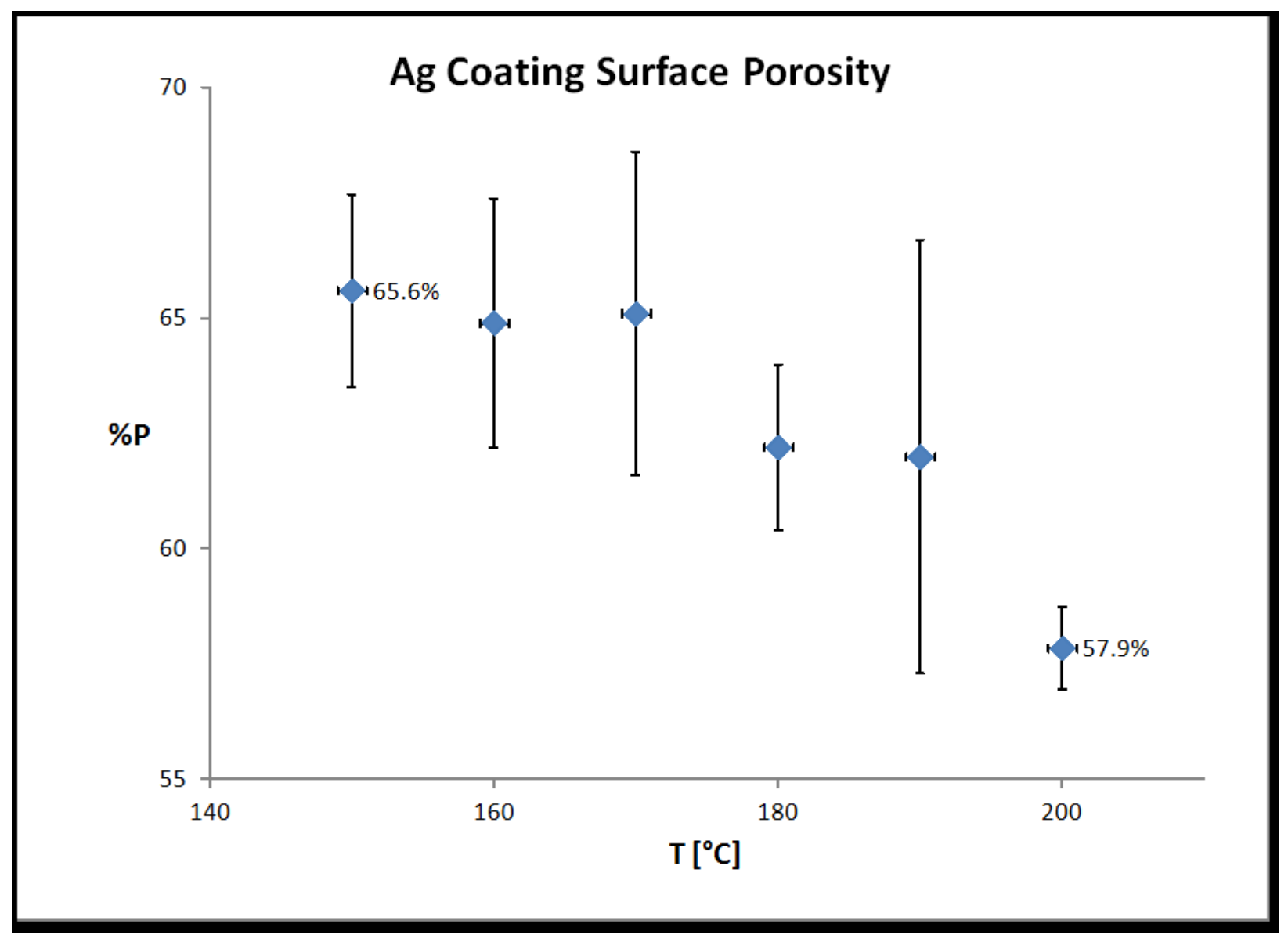

Figure 35 - A relatively small decrease $\mathbf{( 7 . 7 \% )}$ in percent surface porosity is observed for samples cured at various temperatures suggesting that similar surface porosity is obtainable if exposed for adequate time. 


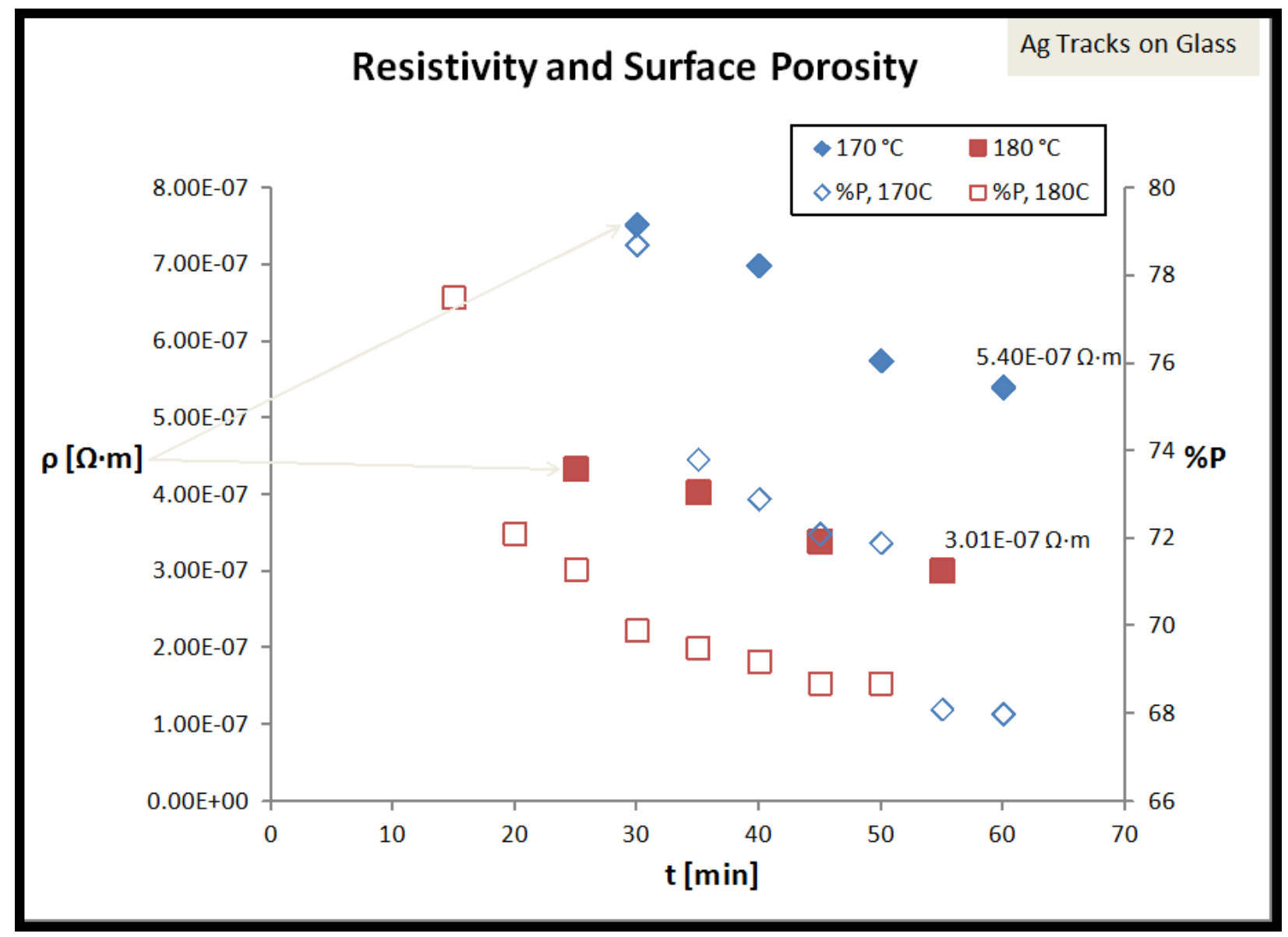

Figure 36 - Resistivity, $\rho$, and surface porosity, \%P, observe similar decreasing trends with extended exposure time at respective curing temperatures of 170 and $180^{\circ} \mathrm{C}$.

In Figure 36, resistivity and surface porosity observe similar decreasing trends with extended exposure time at respective curing temperatures. This suggests a close dependence between resistivity and surface porosity. This is to be expected as higher curing temperatures not only to promote the increased decomposition of organic surfactants in the ink, but also the further curing of the Ag particles. Additionally, the decreased surface porosity as a result of the removal of organic components allows for the formation of new percolation pathways resulting in decreased resistivity. This relation is better shown in Figure 37 with resistivity as a function of percent surface porosity at various curing temperatures showing better results at the lower range of their respective axes. 


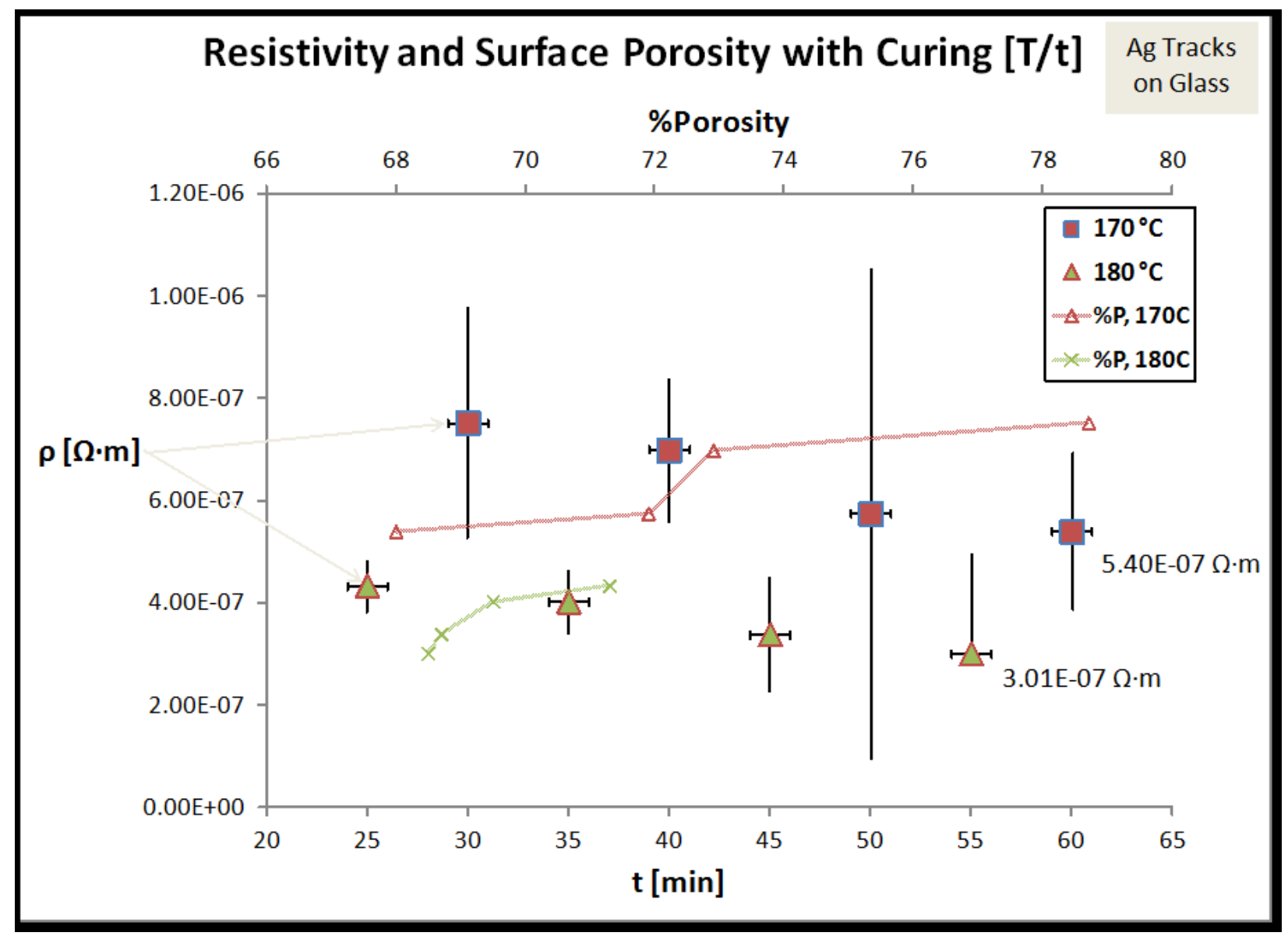

Figure 37 - Comparatively, resistivity $(\rho)$ decreases with decreasing surface porosity (\%P) as it does also with increasing thermal exposure time.

When compared with resistivity as a function of thermal exposure time at various curing temperatures, the relations are inversely proportional. Again, this reflects the close relation of resistivity and surface porosity, and their dependence on curing temperature and exposure time for better electrical performance. 


\subsection{Electromechanical Testing}

Monotonic Tensile Testing of Cured Ag Tracks on PEN

The typical change in resistance for a monotonically tensile tested sample observed the strain trend shown in Figure 38. It is noticed that there does exist some electrical behavior even at points immediately prior to failure of the substrate. Furthermore, this suggests that the cured silver ink exhibits high tolerance to strain, although the efficiency of the electrical output may be less than desired.

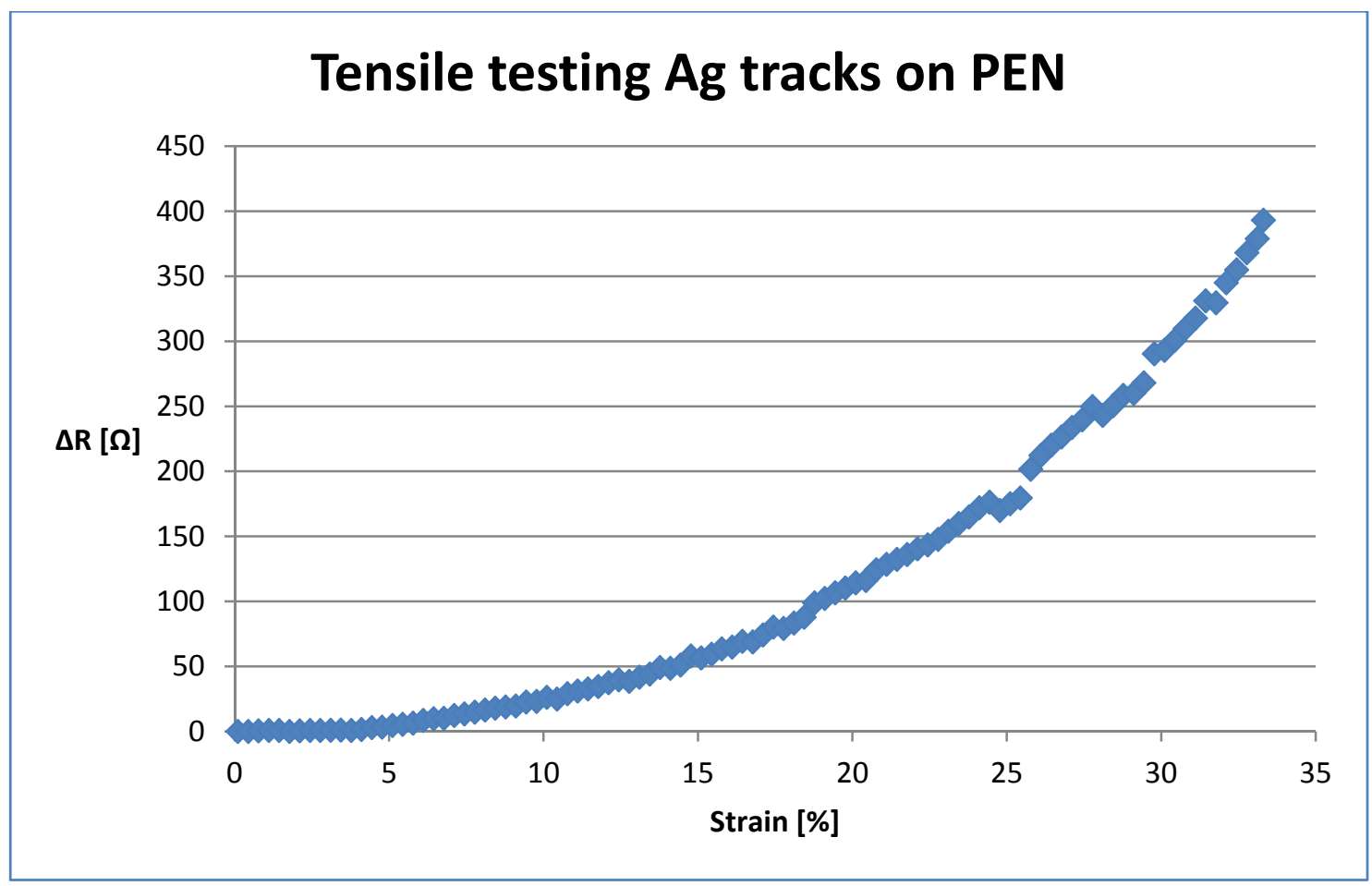

Figure 38 - Electromechanical behavior of cured silver ink tracks on PEN samples seen as a change in resistance during monotonic tensile testing. It is noticed that there exists electrical behavior up to the failure strain of the PEN sample.

Due to the rectangular shape of the PEN samples with cured Ag tracks, tensile testing resulted in inconsistencies in relation to the failure location along the strained region given the gauge length of the 
sample. This is contributed to the lack of a focused strain region as used in standard ASTM tensile

testing of thin substrates. However, in order to allow for masking during spray deposition of the ink and to ensure consistent electrical operation of the cured tracks, the rectangular PEN sample shape was necessary.

Optical microscopy and SEM were used to investigate the effect of straining on the cured track at and around the failure region of the sample. It was hypothesized that there would be a uniform straining and subsequent elongation of the cured Ag track along the gauge length of the tested sample. Also, due to the brittle nature of silver and the flexibility of the PEN substrate, delamination of the cured track is likely with straining.
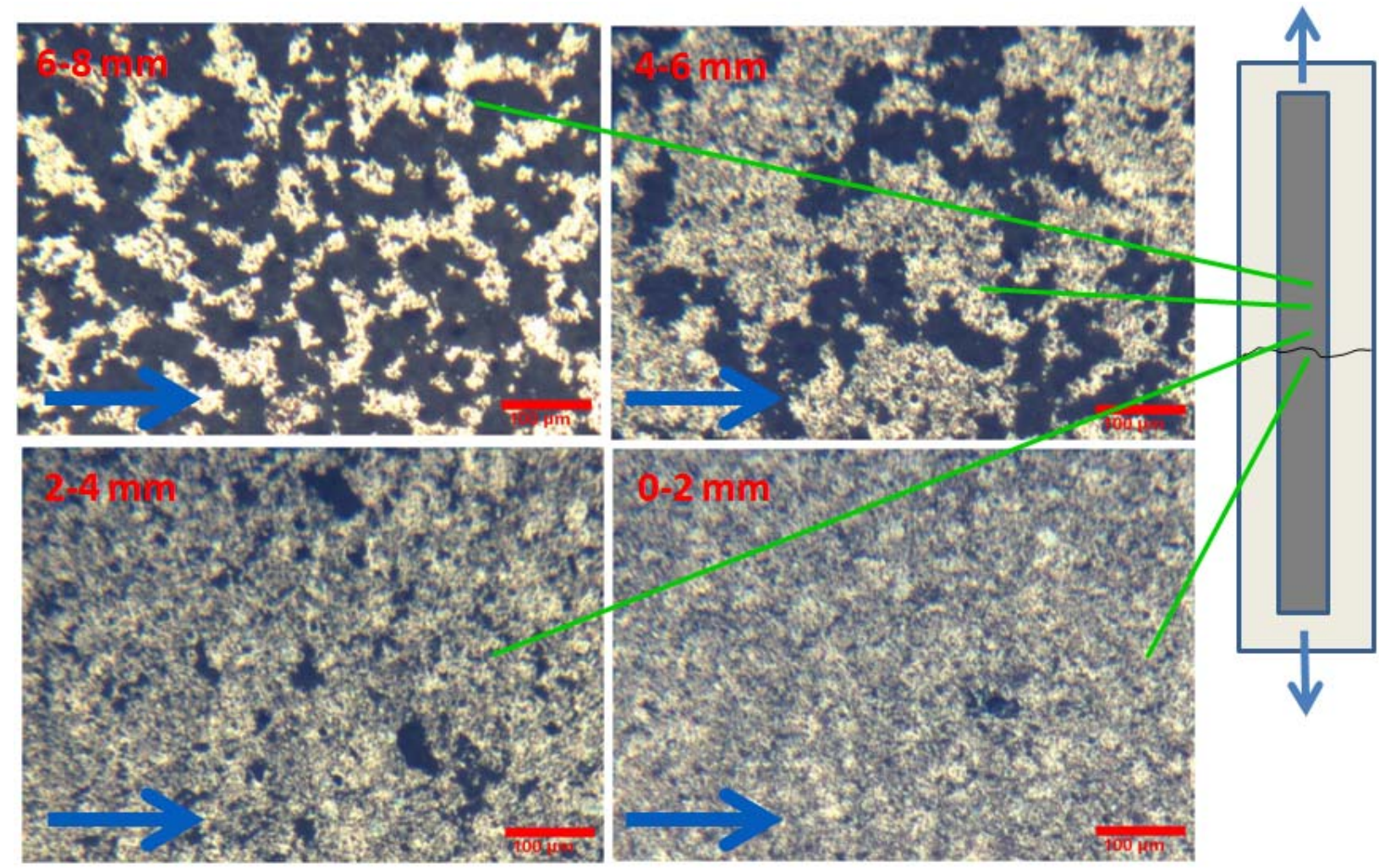

Figure 39 - Optical microscopy of spray masked cured Ag track on PEN substrate after tensile testing and failure via monotonic straining in the direction of the arrow. Depicts the migration of straining from locations between $0-8 \mathrm{~mm}$ from the failure site showing increased surface uniformity as seen with closer proximity to the failure site, as illustrated on the representative cured sample schematic on the right (not drawn to scale). 
Images were taken of the sample post-failure as seen in Figure 39. There was a migration of increased straining seen with closer proximity to the failure site. Regions further out from the failure site exhibited similar surface structures as seen with the majority of the cured sample surface. As the imaging location was moved within closer proximity of the failure site, the surface exhibited a trend of increasing uniformity. This depicts a desirable mechanical functionality of the cured $\mathrm{Ag}$ ink in relation to straining such that it can provide electrical operation up to the point of failure of the substrate.

However, the electrical operation at extremely high strain prior to failure is likely less optimal due to the creation of discontinuities and increased porosity along the percolation routes within the cured track.

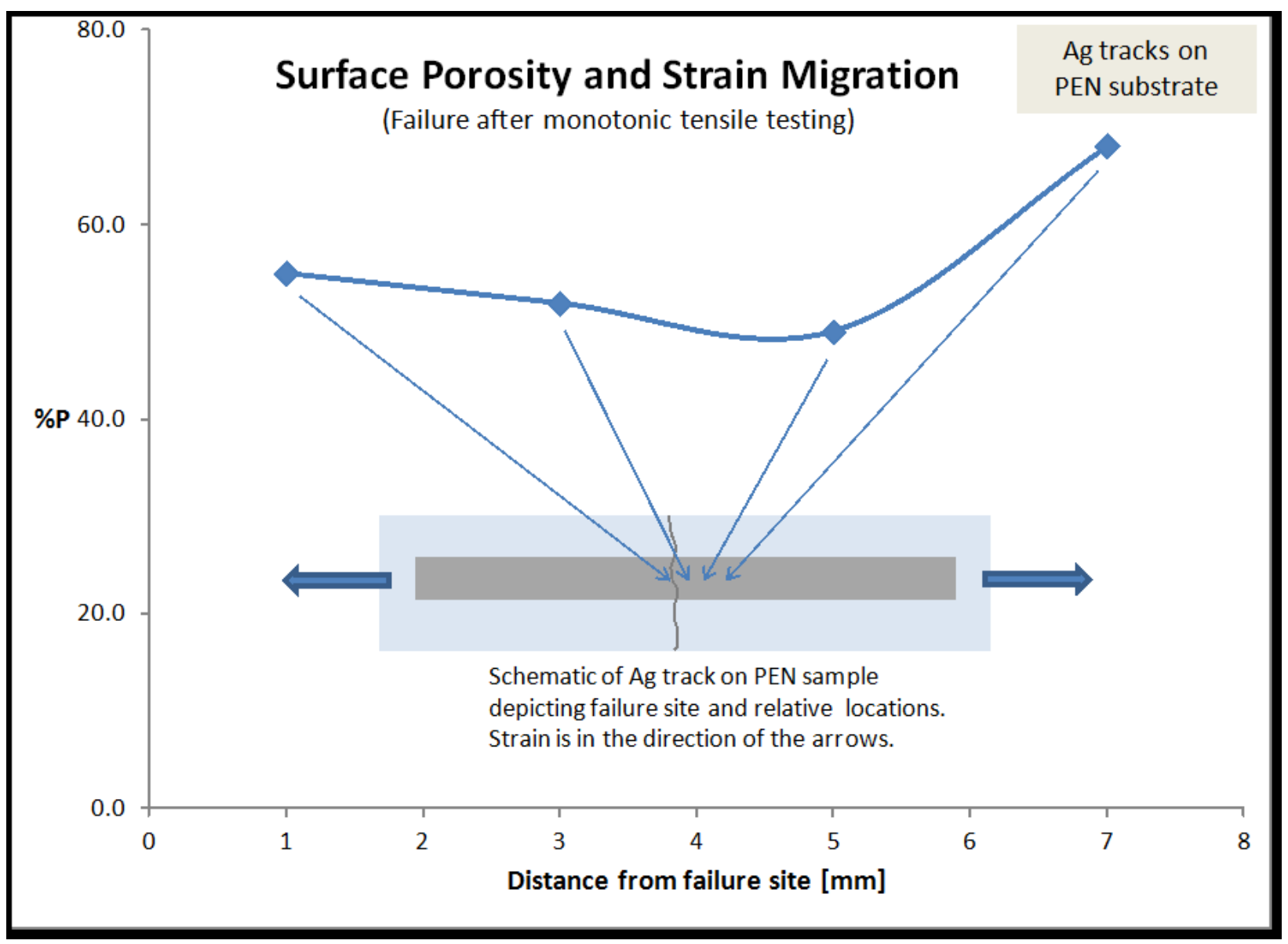

Figure 40 - Surface porosity observed an interesting trend in relation to increasing proximity to the failure site. 
Upon simple preliminary investigation, it was hypothesized that there would be a decrease in surface porosity with increased proximity to the failure site of the sample. After analyzing surface porosity of the optical images in Figure 39, a contradictory trend was revealed. In Figure 40, it is observed that there is a decrease in overall surface porosity from the outer extent of the strained region to the failure site. However, the trend is not linear as expected. At the $5.0 \mathrm{~mm}$ location, the measured surface porosity observes an initial decrease when approaching the failure site. Interestingly, though, surface porosity increases when further approaching the failure site location. Due to the small difference in the measured surface porosity at the $1.0 \mathrm{~mm}, 3.0 \mathrm{~mm}$, and $5.0 \mathrm{~mm}$ locations, it is possible that difference is contributed to imaging of a faulty section. The microscopy might have been performed on a large pore region or an area that was affected by additional damage during handling after testing.
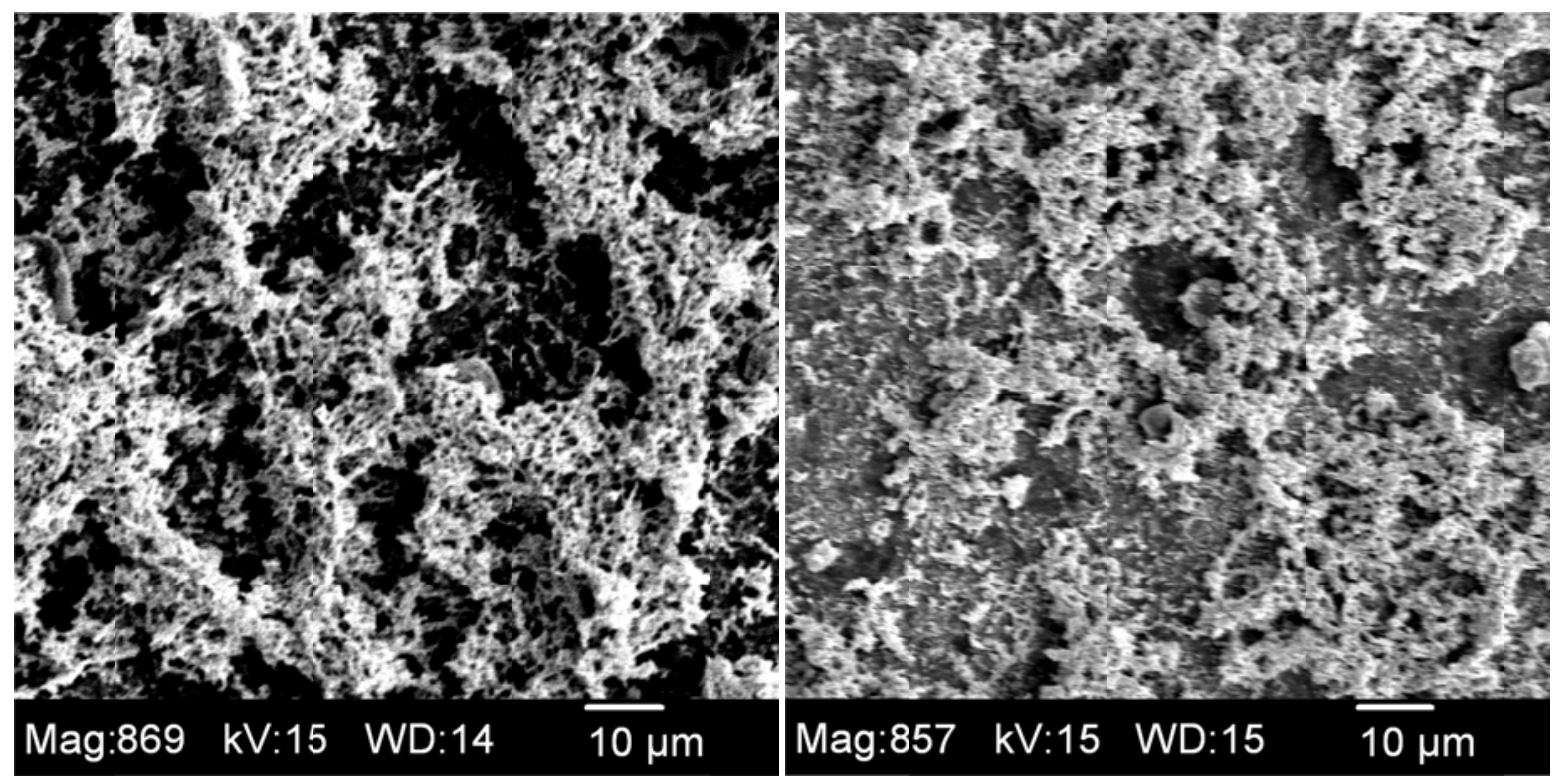

Figure 41 - SEM micrographs showing cured tracks of unstrained (left) samples having connected structures, and post-tensile testing strained (right) samples having loss of connected structures due to breakage and elongation of voids from pre-existent porosity. The direction of strain is from left to right. 
Response to straining using SEM gave further investigation to failure mechanisms involved with tensile testing of the samples. Figure 41 shows tracks before and after failure due to straining. It can be seen that the unstrained sample shows a porous surface microstructure of $57.95 \%$ surface porosity with elevated connected structures. These connected structures likely act as percolation pathways for the passing of current across the track length. Post-straining, the surface microstructure shows evidence of breakage between connected structures. This is likely the result of the elongation of pre-existent voids from the unstrained surface porosity and the subsequent loss of conductivity. The resulting strained surface has a surface porosity of $55.18 \%$ which equates to a loss of surface porosity of $2.78 \%$. A majority of the decreased surface porosity is likely due to the loss of material in the fractured connected structures.

\section{Cyclic Mandrel Fatigue Testing of Cured Ag Tracks on PEN}

The performance of a sample fatigued for $640 \mathrm{~K}$ cycles at a strain of $0.6 \%$ can be seen in Figure 42. There are three distinct regimes throughout the progression of the test. 


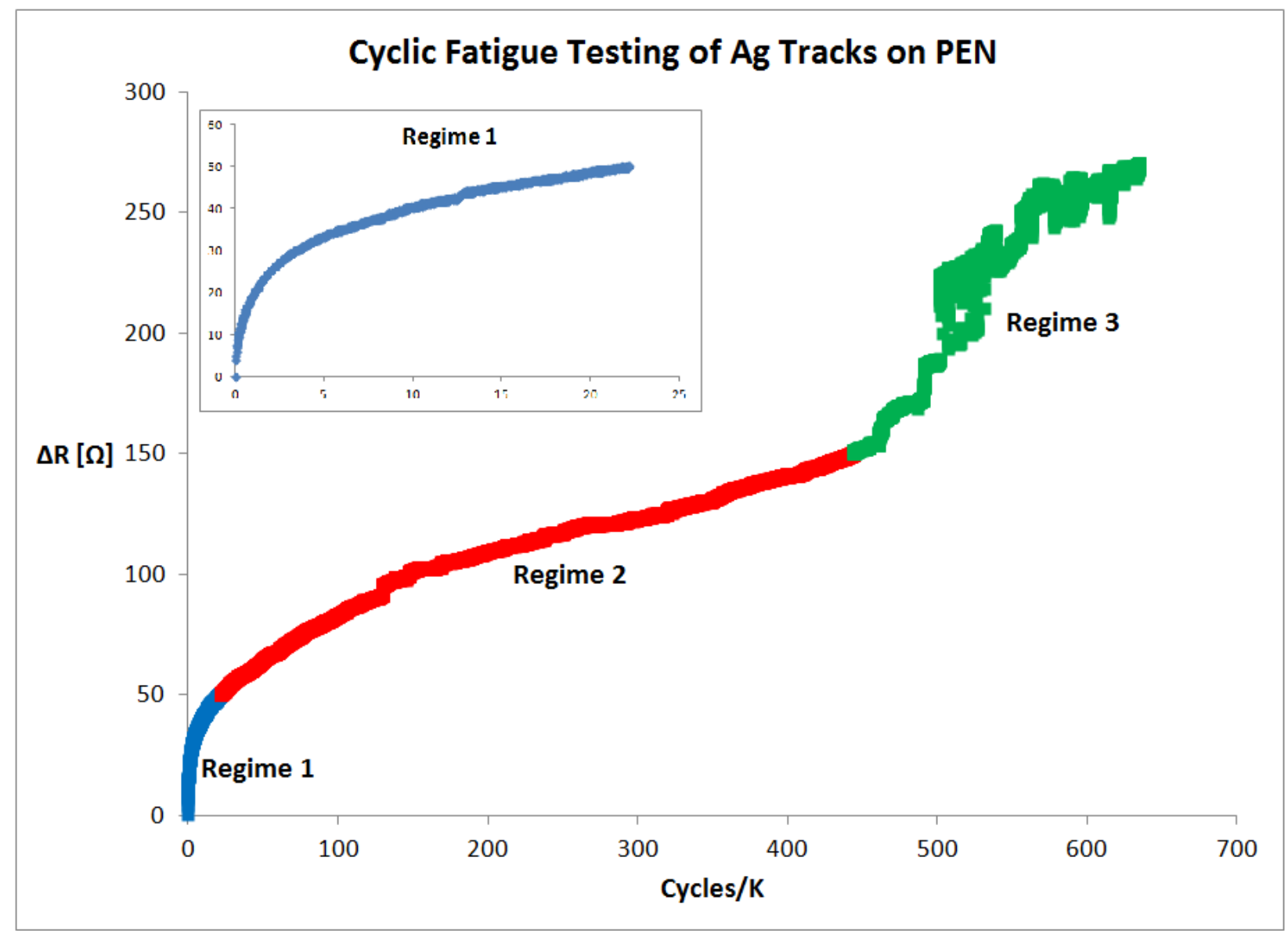

Figure 42 - Mandrel fatigue testing was performed on cured Ag track on PEN sample at $0.6 \%$ strain for $640 \mathrm{~K}$ cycles. Three distinct regimes exist. The inset graph shows Regime 1 at early cycles up to $22 \mathrm{~K}$.

. In Regime 1 , there is quick increase in measured resistance change with a $20 \%$ increase in resistance at 1,000 cycles. In Regime 2, there was a relatively linear change in resistance between $22 \mathrm{~K}$ and 500K cycles showing relatively dependable electrical performance. In Regime 3, significant degradation in electrical response is observed. Resistance change and degradation in electrical output was contributed to similar failure mechanisms as seen with monotonic tensile testing. 


\subsection{Mechanical Testing}

Nanoindentation Testing of Ag Coatings

\begin{tabular}{|c|c|c|}
\hline \multicolumn{3}{|c|}{ Nanoindentation of Ag Coatings } \\
\hline $\mathrm{H}[\mathrm{MPa}]$ & $\mathrm{E}[\mathrm{GPa}]$ & $\mathrm{T}\left[{ }^{\circ} \mathrm{C}\right]$ \\
\hline 939.39 & 60.77 & 200 \\
\hline 665.99 & 66.67 & 190 \\
\hline 450.55 & 36.39 & 180 \\
\hline 270.94 & 26.99 & 170 \\
\hline 269.91 & 12.47 & 160 \\
\hline
\end{tabular}

Table 5 - Hardness and elastic modulus data for nanoindentation testing performed on spray masked Ag coatings cured at various temperatures.

Average hardness of the Ag coating was calculated as shown in Table 5. Extremes of the trend showed a maximum hardness of $\sim 940 \mathrm{MPa}$ observed for the sample cured at $200^{\circ} \mathrm{C}$ and a minimum hardness of $\sim 270 \mathrm{MPa}$ for the sample cured at $160^{\circ} \mathrm{C}$. At temperatures of $170^{\circ} \mathrm{C}$ and above, there exists a linear trend for the hardness data in relation to curing temperature. Hardness data was compared to surface porosity of the Ag coating at respective curing temperatures as shown in Figure 35. 


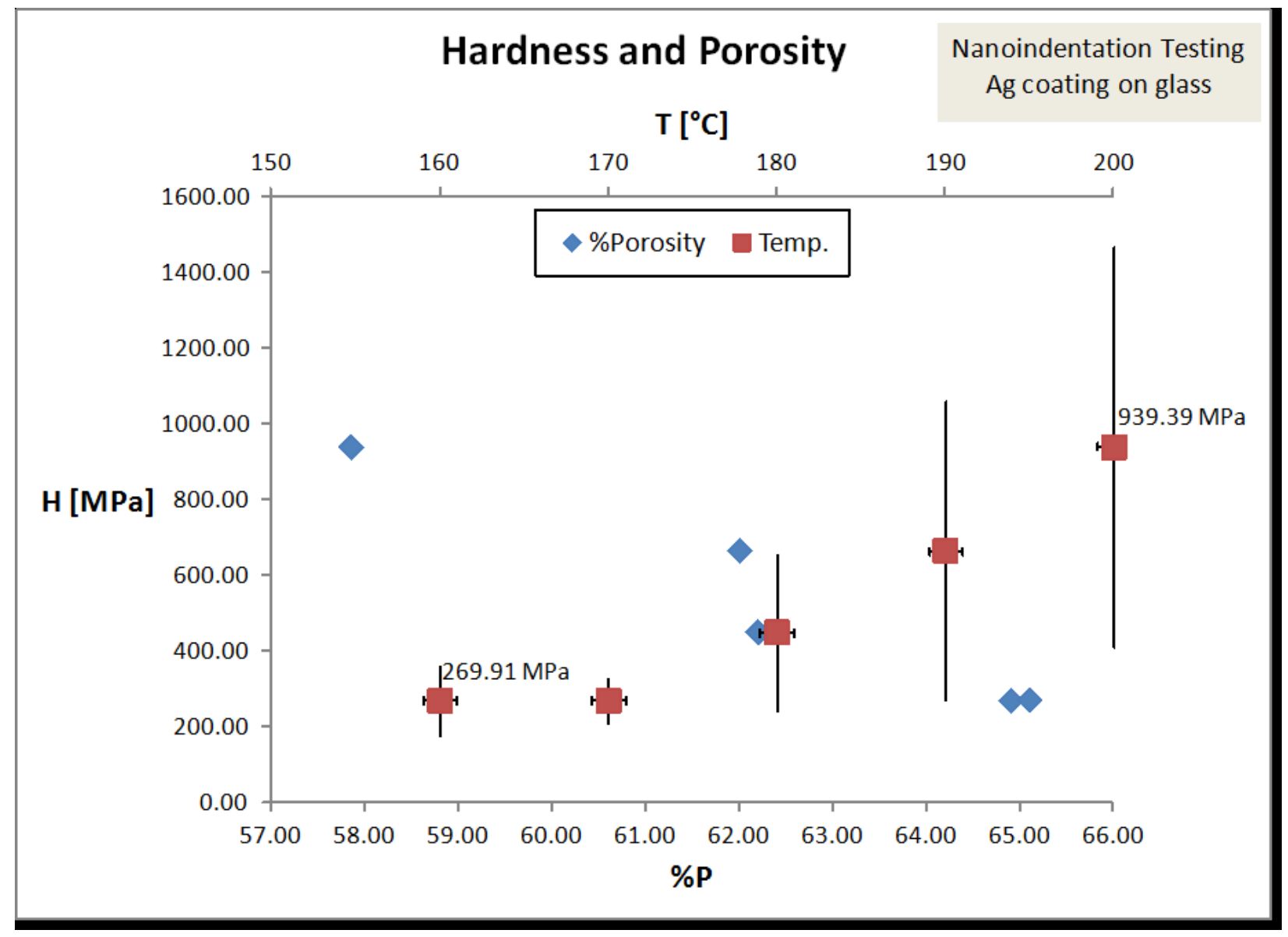

Figure 43 - Ag coating hardness exhibits a linear increase with an increase in curing temperature between 170 and $200^{\circ} \mathrm{C}$, as well as a with similar decrease in surface porosity.

Results for surface porosity were similar at 160 and $170^{\circ} \mathrm{C}$. This may explain the relatively equal hardness results for the same temperatures. Beyond $170^{\circ} \mathrm{C}$, hardness data observes a linear trend with increasing curing temperature. Similarly, a decreased surface porosity is observed with increasing curing temperature. Hardness as a function of surface porosity with increasing curing temperature observes a decreasing trend. This is expected considering hardness should increase with similar decrease in surface porosity as shown in Figure 43.

It was desirable to investigate the possibility of an increased brittleness of samples cured at higher temperatures. Although samples cured at higher temperatures exhibited better electrical 
performance, this could ultimately result in higher failure and reduced strain toleration of $\mathrm{Ag}$ coatings, tracks, and/or patterns. As with hardness, the elastic modulus should exhibit a proportional increase with increase in curing temperature. In fact, this was the case until reaching the upper extents of the exposure temperatures 190 and $200^{\circ} \mathrm{C}$.

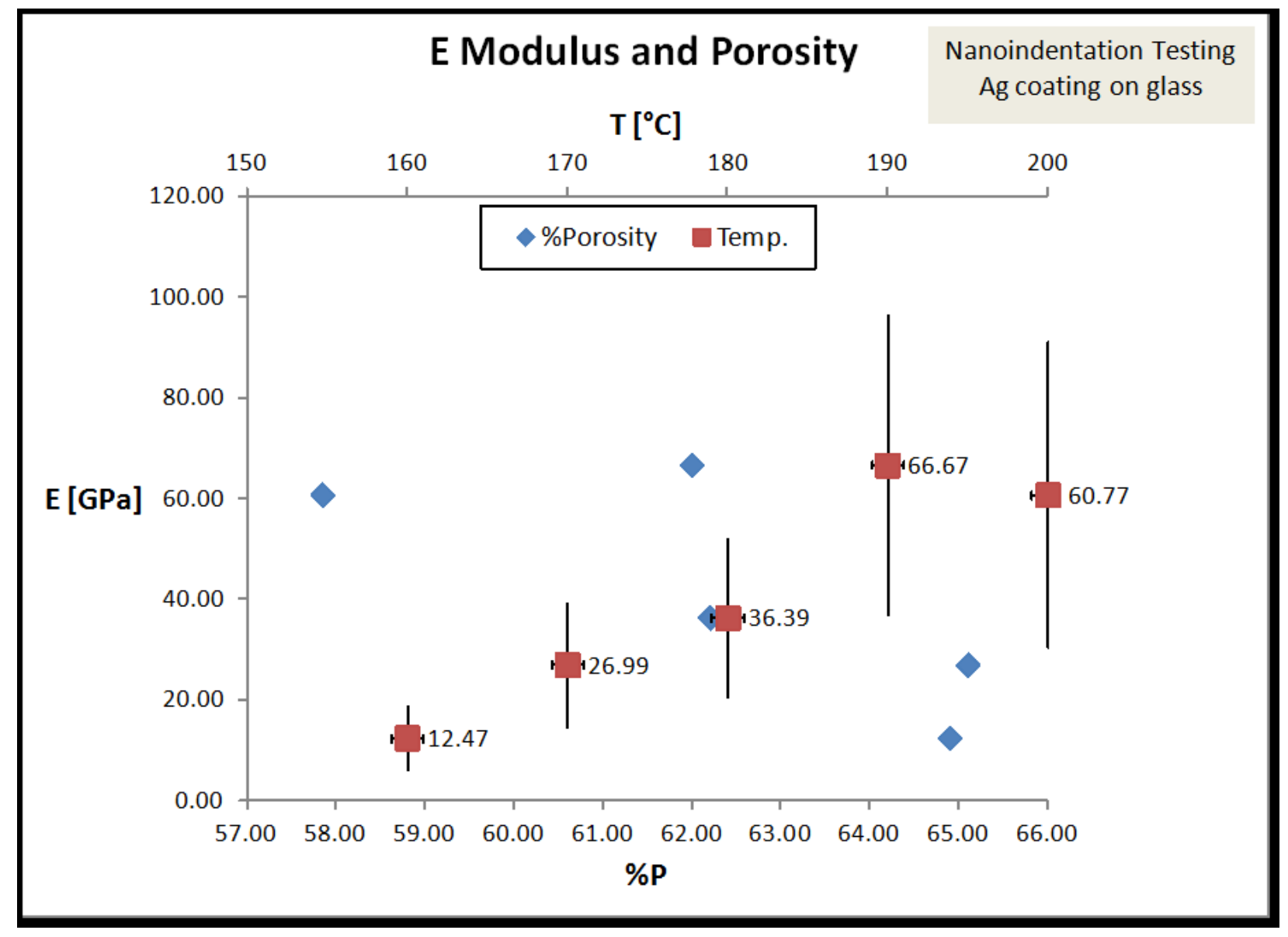

Figure 44 - Elastic modulus observes a decrease at higher curing temperature above $190^{\circ} \mathrm{C}$.

If considering a linear increase in measured elastic modulus between the extents of the trend, there is a noticeable spike at $190^{\circ} \mathrm{C}$ as shown in Figure 44 . Since the elastic modulus of a material is a measure of its stiffness, this sudden increase $190^{\circ} \mathrm{C}$ may suggest the Ag coatings evolving towards stiffer functionality. However, if considering the decrease in elastic modulus at $200^{\circ} \mathrm{C}$, this suggests the possibility of optimization of both electrical and mechanical performance of the Ag coatings without 
sacrificing possible coating brittleness. Furthermore, this suggests the possibility of metal structures on PEN at high temperatures if the complete curing is attainable within a short exposure time. However, when comparing elastic modulus as a function of curing temperature to that of elastic modulus as a function of surface porosity, results do not match similarly to that of the same relations made to hardness.

Nanoscratch Testing of Ag Coatings

Failure critical loads noticed a linear increase from 8.39 to $36.58 \mathrm{mN}$ with an increase in curing temperature of the $\mathrm{Ag}$ coating. An interesting decrease is seen in the failure critical load for the $190^{\circ} \mathrm{C}$ as shown in Figure 45. 


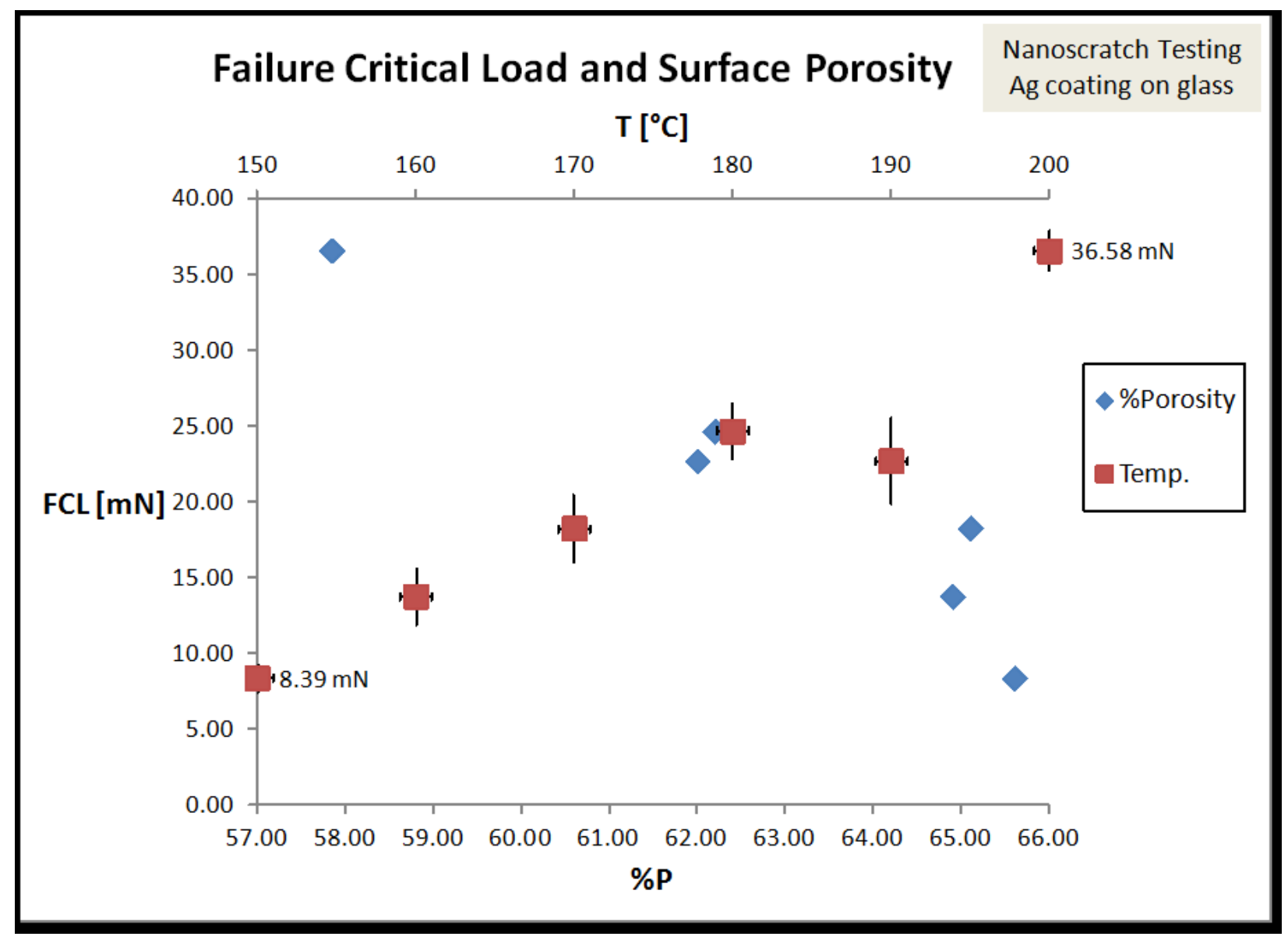

Figure 45 - Failure critical load (FCL) observes a sharp decrease at $190^{\circ} \mathrm{C}$ suggesting an increased ease in coating failure at that curing temperature.

The sharp decrease in $\mathrm{FCL}$ at $190^{\circ} \mathrm{C}$ reflects a possible state of increased brittleness as was observed in the elastic modulus data from nanoindentation testing. As shown, this would result in an increased ease in coating failure at that temperature. FCL as a function of surface porosity observes a decreasing trend with increasing temperature.

Delamination was the predominantly seen failure mechanism for the Ag coatings (44) (45) (46). The magnitude of the delamination was consistent for all curing temperatures 150, 160, 170, 180 and $200^{\circ} \mathrm{C}$. 


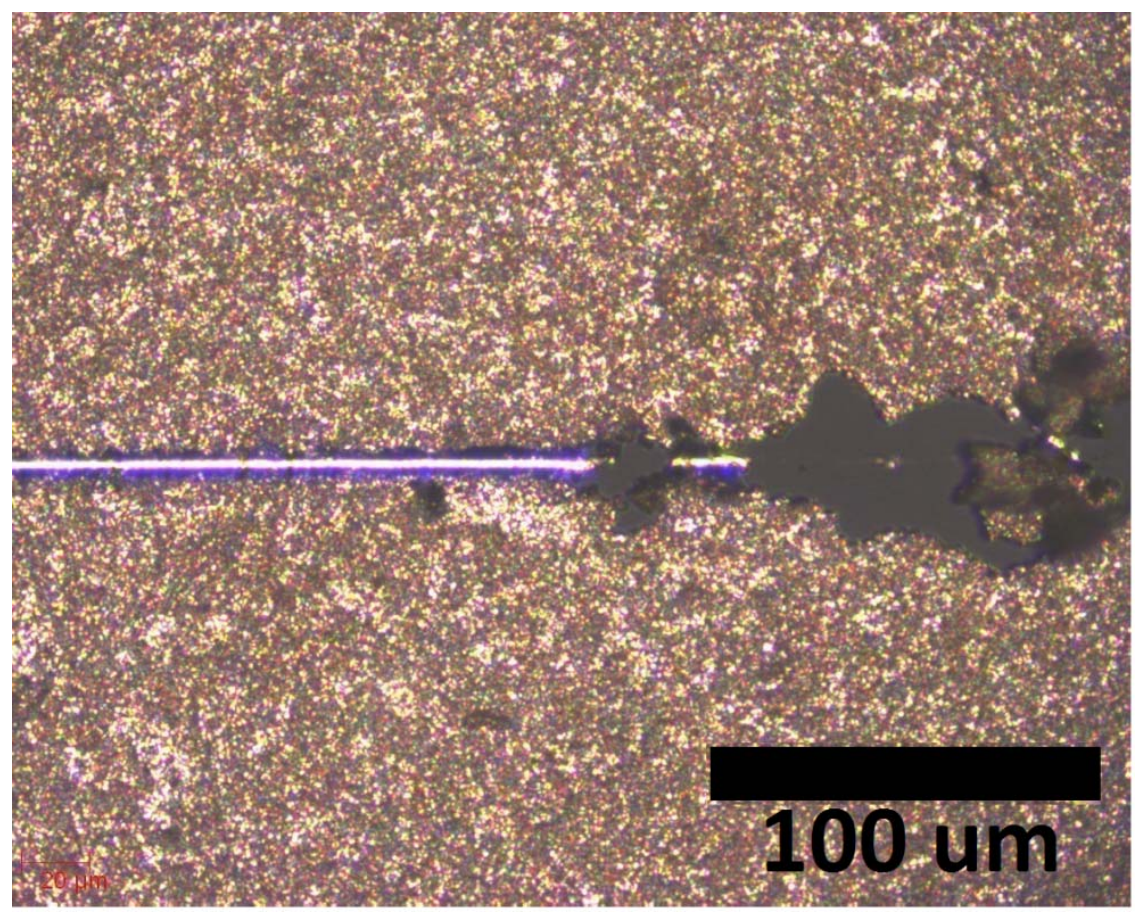

Figure 46 - The magnitude of delamination of the $\mathrm{Ag}$ coating cured at $190^{\circ} \mathrm{C}$ was greater than other curing temperatures. The scratch direction is from left to right.

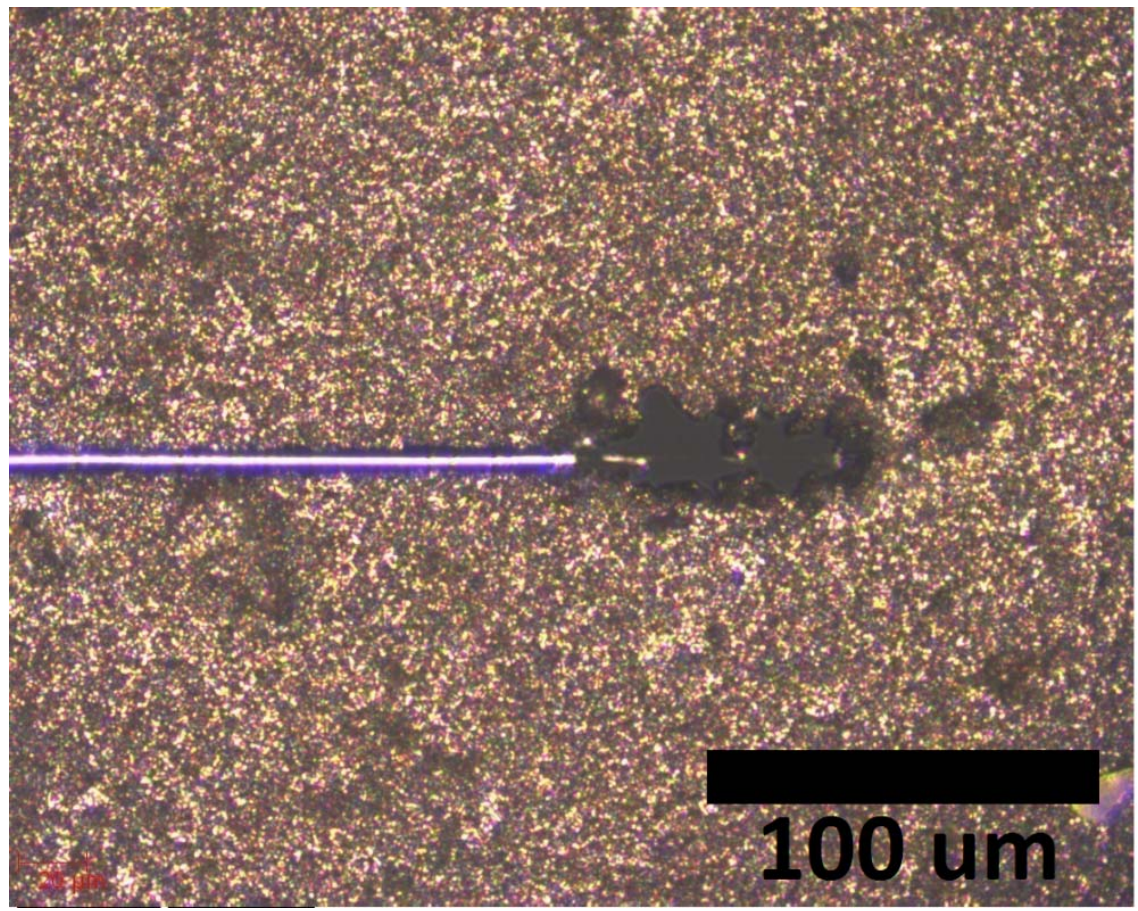

Figure 47 - The magnitude of coating delamination observed was similar with scratching performed on 150, 160, 170,180 , and $200^{\circ} \mathrm{C}$ samples. This suggests possible increased brittleness at curing temperature of $190^{\circ} \mathrm{C}$. Scratch direction is from left to right. 
In contrast, the magnitude of delamination at $190^{\circ} \mathrm{C}$ was greater as shown in Figure 46 . At temperatures of $150,160,170,180$, and $200^{\circ} \mathrm{C}$, the coating scratches noticed a similar magnitude of delamination depicting a finer scratch path with less propagation as seen in Figure 47Error! Reference source not found.. This shows an interesting similarity to previously stated nanoindentation results for the $\mathrm{Ag}$ coating exhibiting a increase in elastic modulus at temperature of $190^{\circ} \mathrm{C}$. At that point, it can be suggested that the coating began exhibiting a more brittle nature which might also be the contributing factor to the increased magnitude of delamination seen in the scratch path as performed on cured coatings of $190^{\circ} \mathrm{C}$. Since surface porosity observes a semi-linear decreasing trend with increasing curing temperature, this might suggest the possibility of sub-surface microstructure factors contributing to the measured properties.

\subsection{Dip Pen Lithography (DPL)}

\section{Preliminary Results using DPL Patterning}

Based on some preliminary results, DPL was found to be a promising technique. Figure 48 shows an Ag ink pattern on PEN consisting of successive dots of diameters 25 and $10 \mu \mathrm{m}$ with spacing of 100 and $20 \mu \mathrm{m}$, respectively. 


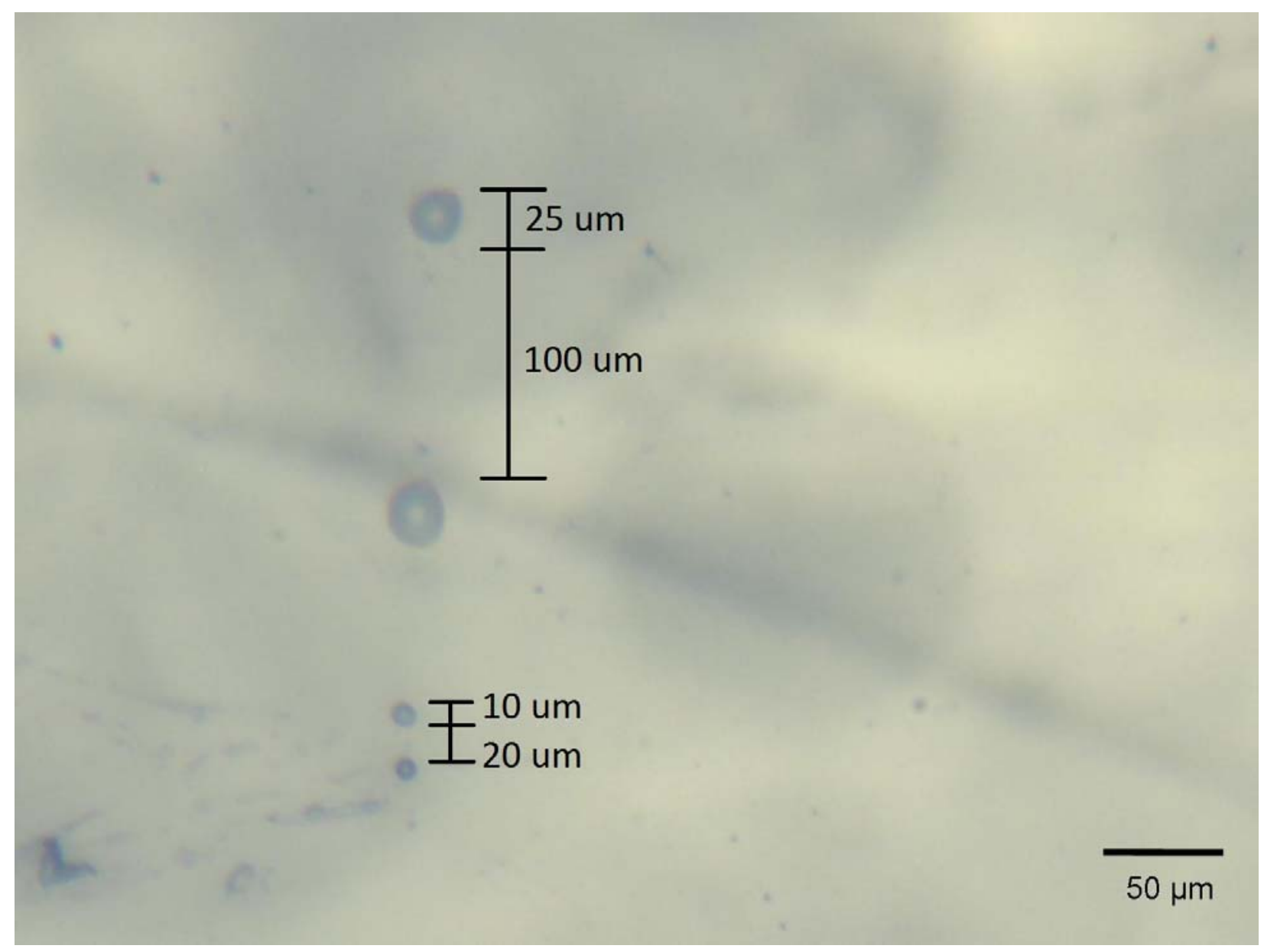

Figure 48 - Dot patterning using DPL with Ag ink on PEN depicting variability in dot size and spacing.

It was also desirable to pattern lines with the silver ink to simulate the creation of small circuitry components. There was some difficulty noticed when attempting this. Two factors contributed to the challenge in forming lined patterns. The first factor was due to the combination of the open-air reservoir in which the ink is held when operating and the quick evaporation of the xylene solvent used in the ink. This resulted in a very limited operation time to perform patterning due to the ink drying in the reservoir. The second factor came via the very low viscosity of the ink contributed again by the xylene solvent. When patterning lines using DPL the tip is lowered to the substrate so that the ink droplet makes contact with the substrate surface. The tip is then moved laterally across the surface to "drag" 
the droplet. This results in a lengthening of the droplet and pulling it into a line pattern. However, due to the low viscosity of xylene in the ink, the ink droplet tended to "roll" rather than noticing a lengthening effect and subsequent formation of a line.

The above challenge was approached by trying to increase the viscosity of the ink to change not only the short drying time of the ink but also the lack of ink/substrate adhesion limiting the formation of lines. Knowing from previous trials that the silver octanoate powder of the ink dissolves best in low viscosity solvents like xylene ( $<1 \mathrm{cP})$, similar solvents such as hexanol, butanol, and isopropanol (IPA) where chosen for experimentation because xylene would not mix with the majority of the chosen higher viscosity solvents due to its chemistry. Sonication trials showed adequate dissolution of the silver octanoate powder in each solvent similar as to seen with xylene. To keep consistency, each dissolution of powder in the respective trial solvents were done at $10 \mathrm{wt} \%$ just as with the silver ink with xylene solvent used herein. After determining the adequate dissolution of the powder in the low viscosity solvents, it was necessary to research the potential of combining higher viscosity solvents to increase the overall viscosity of the ink. The suggested viscosity range of the ink to allow for line formation using DPL was 10-30 cP. Chosen solvents were propylene glycol (PG) and terpineol. Polypropylene glycol and ethylene glycol were considered but did not offer a desirable level of mixability.

Because of the "thick" nature of the higher viscosity solvents, dissolution of the powder in each would be unsuccessful and would likely offer a non-uniform ink solution. To change this, the powder was first sonicated in the low viscosity solvents to achieve dissolution and then combined with the high viscosity solvent. For trial purposes, the low viscosity solvents were combined with the higher viscosity solvents without the presence of powder in order to conserve materials. The solvents, low and high, were combined in varying vol\% as in Table 6 and then tested for viscosity using a Brookfield LV DV-III Ultra rheometer. 


\begin{tabular}{|c|c|c|c|c|c|c|}
\hline \multicolumn{7}{|c|}{ Solvent Solutions } \\
\hline Name & density $[\mathrm{g} / \mathrm{mL}]$ & $\mathrm{M}[\mathrm{g} / \mathrm{mol}]$ & $\mathrm{vol} /$ & $\mathrm{m}[\mathrm{g}]$ & vol/ & $\mathrm{m}[\mathrm{g}]$ \\
\hline butanol & 0.810 & 74.120 & 0.9 & 0.729 & 0.1 & 0.081 \\
\hline hexanol & 0.814 & 74.120 & 0.9 & 0.732 & 0.1 & 0.081 \\
\hline terpineol & 0.994 & 154.250 & 0.9 & 0.894 & 0.1 & 0.099 \\
\hline$P G$ & 1.036 & 76.090 & 0.9 & 0.932 & 0.1 & 0.104 \\
\hline xylene & 0.864 & 106.160 & 0.9 & 0.778 & 0.1 & 0.086 \\
\hline$I P A$ & 0.786 & 60.100 & 0.9 & 0.707 & 0.1 & 0.079 \\
\hline Name & density $[\mathrm{g} / \mathrm{mL}]$ & $\mathrm{M}[\mathrm{g} / \mathrm{mol}]$ & vol/ & $\mathrm{m}[\mathrm{g}]$ & vol/ & $\mathrm{m}[\mathrm{g}]$ \\
\hline butanol & 0.810 & 74.120 & 0.8 & 0.648 & 0.2 & 0.162 \\
\hline hexanol & 0.814 & 74.120 & 0.8 & 0.651 & 0.2 & 0.163 \\
\hline terpineol & 0.994 & 154.250 & 0.8 & 0.795 & 0.2 & 0.199 \\
\hline$P G$ & 1.036 & 76.090 & 0.8 & 0.829 & 0.2 & 0.207 \\
\hline xylene & 0.864 & 106.160 & 0.8 & 0.691 & 0.2 & 0.173 \\
\hline IPA & 0.786 & 60.100 & 0.8 & 0.629 & 0.2 & 0.157 \\
\hline Name & density $[\mathrm{g} / \mathrm{mL}]$ & $\mathrm{M}[\mathrm{g} / \mathrm{mol}]$ & vol/ & $\mathrm{m}[\mathrm{g}]$ & vol/ & $\mathbf{m}[\mathrm{g}]$ \\
\hline butanol & 0.810 & 74.120 & 0.7 & 0.567 & 0.3 & 0.243 \\
\hline hexanol & 0.814 & 74.120 & 0.7 & 0.570 & 0.3 & 0.244 \\
\hline terpineol & 0.994 & 154.250 & 0.7 & 0.696 & 0.3 & 0.298 \\
\hline$P G$ & 1.036 & 76.090 & 0.7 & 0.725 & 0.3 & 0.311 \\
\hline xylene & 0.864 & 106.160 & 0.7 & 0.605 & 0.3 & 0.259 \\
\hline IPA & 0.786 & 60.100 & 0.7 & 0.550 & 0.3 & 0.236 \\
\hline Name & density $[\mathrm{g} / \mathrm{mL}]$ & $\mathrm{M}[\mathrm{g} / \mathrm{mol}]$ & vol/ & $\mathrm{m}[\mathrm{g}]$ & vol/ & $\mathrm{m}[\mathrm{g}]$ \\
\hline butanol & 0.810 & 74.120 & 0.6 & 0.486 & 0.4 & 0.324 \\
\hline hexanol & 0.814 & 74.120 & 0.6 & 0.488 & 0.4 & 0.325 \\
\hline terpineol & 0.994 & 154.250 & 0.6 & 0.596 & 0.4 & 0.398 \\
\hline$P G$ & 1.036 & 76.090 & 0.6 & 0.622 & 0.4 & 0.414 \\
\hline xylene & 0.864 & 106.160 & 0.6 & 0.518 & 0.4 & 0.346 \\
\hline IPA & 0.786 & 60.100 & 0.6 & 0.472 & 0.4 & 0.314 \\
\hline Name & density $[\mathrm{g} / \mathrm{mL}]$ & $\mathrm{M}[\mathrm{g} / \mathrm{mol}]$ & vol/ & $\mathrm{m}$ [g] & vol/ & $\mathrm{m}[\mathrm{g}]$ \\
\hline butanol & 0.810 & 74.120 & 0.5 & 0.405 & 0.5 & 0.405 \\
\hline hexanol & 0.814 & 74.120 & 0.5 & 0.407 & 0.5 & 0.407 \\
\hline terpineol & 0.994 & 154.250 & 0.5 & 0.497 & 0.5 & 0.497 \\
\hline$P G$ & 1.036 & 76.090 & 0.5 & 0.518 & 0.5 & 0.518 \\
\hline xylene & 0.864 & 106.160 & 0.5 & 0.432 & 0.5 & 0.432 \\
\hline IPA & 0.786 & 60.100 & 0.5 & 0.393 & 0.5 & 0.393 \\
\hline
\end{tabular}

Table 6 - Volume fraction (vol/) compositions of low and high viscosity solvents for rheological testing to be used in DPL patterning with silver ink. 
It was noticed that xylene readily separated when combined with PG. After heating terpineol above room temperature to reach a liquid state, xylene showed adequate dissolution. Butanol, hexanol, and IPA all noticed relatively good mixing when combined with PG. The final solvent solutions that were used for DPL exhibited a viscosity of $\sim 15 \mathrm{cP}$. This was done with the understanding that the addition of the solids of the silver octanoate powder would subtly increase the viscosity of the final ink in an attempt to keep it in the range 15-20 cP.

DPL using the higher viscosity inks showed desirable functionality and printability as well as a longer use time when in the open-air ink reservoir. However, the inks exhibited a possible short shelf time after showing an extreme color change from a milky-white to a dark reddish-brown after a few days of aging. 


\section{CONCLUSION}

Hybrid organic/inorganic flexible structures were fabricated using a low cost metallo-organic ink deposited and cured on a thin, flexible PEN substrate. The silver ink was synthesized in a modified process similar to Dearden et al (20) by the decomposition of a silver salt precursor silver nitrate $\left(\mathrm{AgNO}_{3}\right)$ which resulted in the formulation of a metallo-organic precipitate silver octanoate $\left(\mathrm{AgC}_{8} \mathrm{H}_{15} \mathrm{O}_{2}\right)$. The precipitate was washed thoroughly with excess methanol and deionized water using centrifugal separation. The cleaned precipitate was dried in a vacuum hood before being combined with the organic solvent xylene and sonicated to formulate the ink. The final ink composition was 10 wt $\%$ silver octanoate in xylene.

The ink was deposited on the PEN substrate using multiple deposition techniques. The first involved the use of a luer-lock syringe with 27-30 gauge needle tips. Deposition was performed in a free-hand writing technique in which no masking structure was applied to the surface of the substrate. Due to the coating of the PEN substrate engineered for adhesion, this deposition technique resulted in low controllability and lack of uniform surface morphology and track pattern uniformity. The second technique incorporated a masking material applied to the surface of the substrate to allow for the creation of uniform track profiles when depositing the ink. This technique offered well defined track patterns as expected but lacked well defined surface cross-section morphologies. It was noticed when incorporating the mask, that there resulted a track cross-section that showed a majority of the ink solids at the walls of the mask and very little ink solids in the center of the track. This was contributed to the migration of the ink solids towards the walls of the mask pattern during evaporation of the solvent showing preferential drying at the extents of the pattern. The third deposition technique used an air gun in combination with the masking material to obtain and spray-masking application process. Not 
only did this result in more uniform surface morphologies and track cross-sections, it also provided a means for faster sample production and sample consistency. The track cross-sections noticed a flatter profile between the extents of the masking material walls. This was contributed to the partial evaporation of the solvent when traveling from the nozzle tip of the air gun to the surface of the masked substrate. Due to the large evaporation of the solvent carrying the ink in transit to the PEN, there resulted much less migration of the ink solids and obtainment of a more uniform and consistent track profile.

The samples were thermally processed using radiation-conduction-convection heating on a hotplate. Curing temperatures ranged from $150-200^{\circ} \mathrm{C}$ in order to achieve thermal decomposition of the organic surfactants in the dried ink resulting in the formation of silver conductive patterns on the PEN substrate. Curing time and temperature were directly affected by the final dried track thickness. Resistivities of the cured Ag patterns were obtained by calculating cross-sectional area of track profiles using surface profilometry. Resistivities were found to be as low as $\sim 5.3 \%$ that of bulk silver. Surface porosity of the cured Ag samples observed a relatively linear decrease with increasing curing temperature, as well as with increasing exposure time. However, surface porosity approached a minimum value with extended exposure time for respective curing temperatures.

The cured samples were tested for electromechanical functionality using monotonic tensile testing and cyclic mandrel testing. For tensile testing it was noticed that the cured tracks offered resistivity until the point of failure of the PEN substrate. There was only a marginal yet steady change in resistance of the strained track prior to failure of the substrate. Cured samples noticed an average failure strain of $40 \%$ elongation. This suggests only marginal degradation of the mechanical properties of the PEN substrate as a result of thermal processing as compared to untreated PEN. Cyclic fatigue testing incorporated a mandrel offering about $0.6 \%$ strain on the cured track. Results showed the 
existence of three distinct regimes: $0-22 \mathrm{~K}, 22 \mathrm{~K}-450 \mathrm{~K}, 450 \mathrm{~K}-635 \mathrm{~K}$ cycles. The first regime observed a rapid increase in resistance change up to $50 \Omega$. The second regime observed linear increase in resistance change of only $100 \Omega$ over $430 \mathrm{~K}$ cycles. The third regime observed a rapid degradation in resistance change up to $270 \Omega$ over about $200 \mathrm{~K}$ cycles. Overall results showed a dependable change in resistance up to $500 \mathrm{~K}$ cycles, with complete resistance failure at $640 \mathrm{~K}$ cycles. SEM and optical microscopy were used to analyze failure and fatigue mechanisms of the mechanically tested samples. The creation of voids and formation of micro-cracks were the predominantly noticed mechanisms, although delamination of the coating was likely also contributing.

Nanoindenation and nanoscratch testing were implemented to test the mechanical properties of the cured ink. These tests were performed with cured ink coatings of $\sim 2 \mu \mathrm{m}$ thickness on glass microscope slides so that there was no contribution from the substrate to affect the results of the ink parameters. Nanoindentation was performed using a nanoindenter (CSM Instruments) to investigate the effect of curing temperature on hardness of the cured coating. Hardness values ranged semilinearly from about $270 \mathrm{MPa}$ at $160^{\circ} \mathrm{C}$ to $940 \mathrm{MPa}$ at $200^{\circ} \mathrm{C}$, as expected. Similarly, hardness and surface porosity were inversely proportional. Elastic modulus measurements also reflected a semi-linear increase from $12.5 \mathrm{GPa}$ to $66.7 \mathrm{GPa}$ at respective curing temperatures of 160 and $190^{\circ} \mathrm{C}$. Interestingly though, at a curing temperature of $190^{\circ} \mathrm{C}$, the measured elastic modulus noticed a spike in magnitude to a value of about $66.7 \mathrm{GPa}$ which reflects a increase in stiffness of the silver coating. This suggests a point in the curing regime where the Ag coating might exhibit an increased brittleness. However, beyond that temperature, the elastic modulus decreases more similar to the trend which suggests the existence of a possible point in the curing regime that not only maximizes electrical output of the coating but also exhibits a higher mechanical functionality. Furthermore, due to the higher curing temperature and subsequent shorter curing time necessary, there is less exposure to the PEN substrate to result in compromise of its mechanical properties. 
Scratch testing was performed using a nanoscratch tester (CSM Instruments) on $2 \mu \mathrm{m}$ thick Ag coatings on glass substrate. Failure critical load was analyzed as a relation of curing temperature which showed a linear increase from 8.39 to $36.58 \mathrm{mN}$ with increase in temperature from 150 to $200^{\circ} \mathrm{C}$. Delamination was the predominant failure mechanism and exhibited a similar magnitude for curing temperatures $150,160,170,180$, and $200^{\circ} \mathrm{C}$. The $190^{\circ} \mathrm{C}$ curing temperature coating exhibited a noticeable increase in the magnitude of delamination. The scratch path depicted a similar refinement and increased coating propagation which might parallel the results of nanoindentation at the same curing temperature suggesting an increased brittleness due to an increase in measured elastic modulus. However, because surface porosity demonstrates a relatively linear decrease with increasing curing temperature, the non-linear points in the elastic modulus data and FCL data suggest the possible contribution from sub-surface porosity or particle packing.

Preliminary deposition testing was performed using dip pen lithography (DPL). Patterning of dots of various size ( $25 \mu \mathrm{m}, 10 \mu \mathrm{m}$ diameter) and spacing (100 $\mu \mathrm{m}, 20 \mu \mathrm{m}$ spacing) was accomplished. At that scale, patterns would be relatively invisible to the naked eye and suggests the possibility for fabrication of transparent conductive structures. 


\section{REFERENCES}

1. Inkjet-printed Silver Tracks: Low Temperature Curing and Thermal Stability Investigation. Jolke Perelaer, Antonius W.M. de Laat, Chris E. Hendriks, Ulrich S. Schubert. s.I. : Journal of Materials Chemistry, 2008, Journal of Materials Chemistry, Vol. 18.

2. Direct Synthesis and Inkjetting of Silver Nanocrystals Toward Printed Electronics. Kwi Jong Lee, Byung Ho Jun, Tae Hoon Kim, Jaewoo Joung. s.I. : Nanotechnology, 2006, Vol. 17.

3. Room temperature preparation of silver features using spin-coating and inkjet printing. Josue J. P. Valeton, Ko Hermans, Cees W. M. Bastiaansen, Dirk J. Broer, Jolke Perelaer, Ulrich S. Schubert, Gregory P. Crawforde, Patrick J. Smith. s.I. : Journal of Materials Chemistry, 2010, Vol. 20.

4. Direct writing of silver conductive patterns: Improvement of film morphology and conductance by controlling solvent compositions. Dongjo Kim, Sunho Jeong, Bong Kyun Park, Jooho Moon. s.I. : Applied Physics Letters, 2006, Vol. 89.

5. Polymers for flexible displays: From material selection to device applications. Myeon-Cheon Choi, Youngkyoo Kim, Chang-Sik Ha. s.I. : Progress in Polymer Science, 2008, Vol. 33.

6. Goodfellow. Polyethylene Napthalate (PEN). AZo Journal of Materials Online. [Online] The A to Z of Materials. [Cited: July 11, 2011.] http://www.azom.com/article.aspx?ArticlelD=1933.

7. Greyhawk, Sam. Alternative Energy and Solar Energy - Thin Films Solar Panels. Ezine Articles. [Online] April 18, 2008. [Cited: October 9, 2010.] http://ezinearticles.com/?Alternative-Energy-And-Solar-Energy--Thin-Film-Solar-Panels\&id=1067783.

8. Polyethylene naphthalate withstands rigors of sterilization. The Free Library. [Online] 1999. http://www.thefreelibrary.com/Polyethylene+naphthalate+withstands+rigors+of+sterilization.a053691122.

9. Leo, P. Teonex PEN film for electrical insulation and flexible printed circuitry. PEN film - Teonex Polyethylene Naphthalate Film. [Online] 1998. http://www.pleo.com/dupont/xm020.htm.

10. Tekra Corporation. Polyester Films Full Line. Coated Plastic Films, Adhesive Film Distributor, Project Coating. [Online] 2008. [Cited: November 17, 2011.] http://www.tekra.com/tech_resources/general_lit/Polyester_Films_Full_Line.pdf.

11. The mechanical properties of metal oxide coated polyester films. B. M. Henry, D. Howells, H. E. Assender, C. R. M. Grovenor. s.I. : Department of Materials, University of Oxford.

12. Corey M. Dunsky, Finlay Colville. Scribing thin-film solar panels. s.I. : Industrial Laser Solutions, 2008. 
13. Mechanical properties of $\mathrm{ZnO}$ thin films deposited on polyester substrates used in flexible device applications. Konstantinos A. Sierros, Derrick A. Banerjee, Nicholas J. Morris, Darran R. Cairns, loannis Kortidis, George Kiriakidis. s.I. : Thin Solid Films, 2010, Vol. 519.

14. Electromechanical properties of transparent conducting substrates for flexible electronic displays. Darran R. Cairns, Gregory P. Crawford. s.I. : Proceedings of the IEEE, 2005, Vol. 93.

15. Scratch Behavior and Material Property Relationship in Polymers. C. Xiang, H.-J. Sue, J. Chu, B. Coleman. s.I. : Journal of Polymer Science: Part B: Polymer Physics, 2001, Vol. 39.

16. Analysis of mechanical properties of silver inkjet-printed structures. Umur Caglar, Kimmo Kaija, Pauliina Mansikkamaki. s.I. : IEEE International Nanoelectronics Conference , 2008.

17. The characterization of electrically conductive silver ink patterns on flexible substrates. S. Merilampi, T. Laine-Ma, P. Ruuskanen. s.I. : Microelectronics Reliability, 2009, Vol. 49.

18. Carbon nanotube-polymer composites: Chemistry, processing, mechanical, and electrical properties. Zdenko Spitalskya, Dimitrios Tasisb, Konstantinos Papagelisb, Costas Galiotis. s.I. : Progress in Polymer Science, 2010, Vol. 35.

19. Carbon Nanotube Thin Films: Fabrication, Properties, and Applications. Liangbing Hu, David S. Hecht, and George Gruner. s.I. : Chemical Reviews, 2010, Vol. 110.

20. A low curing temperature silver ink for use in inkjet printing and subsequent production of conductive tracks. Angela L. Dearden, Patrick J. Smith, Dong-Youn Shin, Nuno Reis, Brian Derby, Paul O'Brien. s.I. : Macromolecular Rapid Communications, 2005, Vol. 26.

21. Studies on inkjet-printed conducting lines for electronic devices. Hyun Chul Jung, Su Hwan Cho, Jae Woo Joung, Yong-Soo Oh. s.I. : Journal of Electronic Materials, 2007, Vol. 36.

22. Effect of microstructural development on mechanical and electrical properties of inkjet-printed Ag films. Inyoung Kim, Young Ah Song, Hyun Chul Jung, Jae Woo Joung, Sung-Soo Ryu, Jongryoul Kim. s.I. : Journal of Electric Materials, 2008, Vol. 37.

23. Inkjet fabrication of electronic components. M. Bidoki, D. M. Lewis, M. Clark, A. Vakorov, P. A. Millnerand, D. McGorman. s.I. : Journal of Micromechanics and Microengineering, 2007, Vol. 17.

24. Transparent Conductive Oxide (TCO) Films for Organic Light Emissive Devices (OLEDs). Sunyoung Sohn, Hwa-Min Kim. s.I. : Organic Light Emitting Diode - Material, Process and Devices.

25. Inkjet-printed 25 micron wide silver tracks on unstructured polyimide. Henning Meier, Ute Loffelmann, Dario Mager, Patrick J. Smith, Jan G. Korvink. s.I. : Phys. Status Solidi, 2009, Vol. 206.

26. Mechanical characterization of solution-derived nanoparticle silver ink thin films. Julia R. Greer, Robert A. Street. s.I. : Journal of Applied Physics, 2007, Vol. 101. 
27. Low-temperature sintered conductive silver patterns obtained by inkjet printing for plastic electronics. Antonino Scandurra, Giuseppe Francesco Indelli, Noemi Graziana Spart, Francesco Galliano, Sebastiano Ravesi, Salvatore Pignataro. s.I. : Surface and Interface Analysis, 2010, Vol. 42.

28. Nitrocellulose-stabilized silver nanoparticles as low conversion temperature precursors useful for inkjet printed electronics. Bao Toan Nguyen, Julien E. Gautrot, My T. Nguyenb and X. X. Zhu. s.I. : Journal of Materials Chemistry, 2007, Vol. 17.

29. Highly Conductive Ink Jet Printed Films of Nanosilver Particles for Printed Electronics. Dongjo Kim, Jooho Moonz. s.I. : Electrochemical and Solid-State Letters, 2005, Vol. 11.

30. Inkjet printing for materials and devices. Calvert, Paul. s.I. : Chemical Materials, 2001, Vol. 13.

31. Mitzi, David B. Solution Processing of Inorganic Materials. s.I. : John Wiley and Sons, Inc., 2009.

32. Formulation and processing of novel conductive solution inks in continuous inkjet printing of 3-D electric circuits. Junfeng Mei, Michael R. Lovell, Marlin J. Mickle. s.I. : IEEE Transactions on Electronics Packing Manufacturing, 2005, Vol. 28.

33. Inkjet printing of narrow conductive tracks on untreated polymeric substrates. Thijs $\mathbf{H}$. J. van Osch, Jolke Perelaer, Antonius W. M. de Laat, Ulrich S. Schubert. s.I. : Advanced Materials, 2008, Vol. 20.

34. One-step inkjet printing of conductive silver tracks on polymer substrates. Jolke Perelaer, Chris E. Hendriks, Antonius W. M. de Laat, Ulrich S. Schubert. s.I. : Nanotechnology, 2009, Vol. 20.

35. Engineered films for display technologies. MacDonald, William A. s.I. : Journal of Materials Chemistry, 2004, Vol. 14.

36. Printed electronics: the challenges involved in printing devices, interconnects, and contacts based on inorganic materials. Jolke Perelaer, Patrick J. Smith, Dario Mager, Daniel Soltman, Steven K. Volkman, Vivek Subramanian, Jan G. Korvink, Ulrich S. Schubert. s.I. : Journal of Materials Chemistry, 2010, Vol. 20.

37. Dip Pen Nanolithography of Conductive Silver Traces. Sheng-Chun Hung, Omkar A. Nafday, Jason R. Haaheim, Fan Ren, G. C. Chi, Stephen J. Pearton. s.I. : Journal of Physical Chemistry C, 2010, Vol. 114.

38. Inket printing and microwave sintering of conductive silver tracks. Jolke Perelaer, Berend-Jan de Gans, Ulrich S. Schubert. s.I. : Advanced Materials, 2006, Vol. 18.

39. Air stable high resolution organic transistors by selective laser sintering of inkjet printed metal nanoparticles. Seung H. Ko, Heng Pan, Costas P. Grigoropoulosa, Christine K. Luscombeb, Jean M.J. Frechet, Dimos Poulikakos. s.I. : Applied Physics Letters, 2007, Vol. 90.

40. Inkjet printing as a deposition and patterning tool for polymers and inorganic particles. Emine Tekin, Patrick J. Smith, Ulrich S. Schubert. s.I. : Soft Matter, 2008, Vol. 4. 
41. Low-temperature Wiring with Ag Nanoinks. Katsuaki Suganuma, Daisuke Wakuda, Mariko Hatamura, Masaya Nogi. s.I. : IEEE Nanotechnology Magazine, 2010.

42. Thermal cure effects on electrical performance of nanoparticle silver inks. Julia R. Greer, Robert A. Street. s.I. : Acta Materialia, 2007, Vol. 55.

43. Toward conductive traces: Dip Pen Nanolithography of silver nanoparticle-based inks. Hung-Ta Wang, Omkar A. Nafday, Jason R. Haaheim, Emma Tevaarwerk, Nabil A. Amro, Raymond G. Sanedrin, Chih-Yang Chang, Fan Ren, Stephen J. Pearton. s.l. : Applied Physics Letters, 2008, Vol. 93.

44. Finite element analysis of contact induced adhesion failure in multilayer coatings with weak interfaces. Jinju Chen, S. J. Bull. s.I. : Thin Solid Films, 2009, Vol. 517.

45. Scratch Test for Coating/Substrate System - A Literature Review. J. Li, W. Beres. s.I. : Canadian Metallurgical Quarterly, 2007, Vol. 46.

46. Chapter 7 An overview of the potential of quantitative coating adhesion measurements by scratch testing. S. J. Bull, E. G. Berasetegui. s.I. : Tribology and Interface Engineering Series, 2006, Vol. 51.

47. Silver complex inks for ink-jet printing: the synthesis and conversion to a metallic particulate ink. Jai Joon Leea, Jin Chul Parka, Min Hwan Kima, Tae Sun Changa, Sun Teak Kima, Sang Man Kooa, Young Chul Youb, Sang Jin Leeb. s.I. : Journal of Ceramic Processing Research, 2007, Vol. 8.

48. Effects of the substrate on the determination of thin film mechanical properties by nanoindentation. Ranjana Saha, William D. Nix. s.I. : Acta Materialia, 2002, Vol. 50.

49. Formulation and Processing of Novel Conductive Solution Inks in Continuous Inkjet Printing of 3-D Electric Circuits. Junfeng Mei, Michael R. Lovell, and Marlin H. Mickle. s.I. : IEEE Transactions on Electronics Packaging Manufaturing, 2005, Vol. 28.

50. Limits for Metallic Conductivity in Conducting Polymers. R. S. Kohlman, A. Zibold, D. B. Tanner, G. G. Ihas, T. Ishiguro, Y. G. Min, A. G. MacDiarmid, A. J. Epstein. s.I. : Physical Review Letters, 1997, Vol. 78.

51. Micro-scratch analysis and mechanical properties of plasma-deposited silicon-based coatings on polymer substrates. D. Ratsb, V. Hajekc, L. Martinu. s.I. : Thin Solid Films, 1999, Vol. 340.

52. Optimized curing of silver inkjet based printed traces. Z. Radivojevic, K. Andersson, K. Hashizume, M. Heino, M. Mantysalo, P. Mansikkamaki, Y. Matsuba, N. Terada. s.I. : TIMA Editions/Therminic, 2006.

53. Structural materials underpinning functional materials: teaching old dogs new tricks. MacDonald, William A. s.I. : Polymer International, 2008, Vol. 57.

54. Triggering the Sintering of Silver Nanoparticles at Room Temperature. Shlomo Magdassi, Michael Grouchko, Oleg Berezin, Alexander Kamyshny. s.I. : American Chemical Society, 2010, Vol. 4. 